\title{
How Does Professional Development Impact on Teachers' Use of an Interactive Whiteboard in New Zealand Primary Classrooms?
}

\begin{abstract}
Robyn Grover
A four paper thesis submitted in partial fulfilment of the requirements for the degree of Master of Education
\end{abstract}

Victoria University of Wellington

2010 


\begin{abstract}
My research examined how professional development impacts on teachers' use of an interactive whiteboard in New Zealand primary classrooms. The research, in the form of a survey and qualitative case study, specifically looked at the professional development experienced by teachers with an IWB and contextual factors that enhance and constrain the introduction of an IWB for teachers learning to use it in their class programme. It also explored how an IWB is used in the classroom programme. Sociocultural theory provided the theoretical framework to analyse the data.
\end{abstract}

The findings of the research showed that professional development featured as both an enhancing and constraining factor. This was determined by the content of the activity. Sustained professional development appeared to have the most impact on teachers' IWB use. The data examined how and why teachers like to use an IWB, and the impact of the unique and multi-media features of the IWB had on teacher pedagogy and students. Recommendations are made for effective professional development for IWB users and areas for further research are discussed. 


\section{Acknowledgements}

There are a number of people who have provided support in various ways throughout this study. I wish to thank:

My wonderful supervisor Mary Jane Shuker, who showed eternal patience and encouragement whilst guiding me through the process of writing this thesis. The detailed feedback you provided was hugely beneficial and you were so generous with your time.

Jill Hammond (National co-ordinator for primary ICTPD), from COREeducation who gave me permission to access their register of schools using an IWB. Without this register, my survey would not have gone to the number of schools it did.

All the principals and teachers who participated in the survey. I appreciated the time you made in your busy day to answer and return the questionnaire. You provided me with an excellent survey response.

The three teachers who agreed to participate in a case study. It was a privilege to come into your classroom and observe what you do. I would also like to thank the three principals for allowing me to come into their schools.

My friend Jenny whose active encouragement started me on the M.Ed journey. Without Jenny I would never have engaged the prospect of a thesis and her support and advice has been invaluable.

Lastly I would like to thank my family: Holly, George and Max who never questioned or complained about me working on my thesis most nights, for the last two years. To my husband Richard, whose support in so many ways, made it possible for me to complete my study. 


\section{Table of Contents}

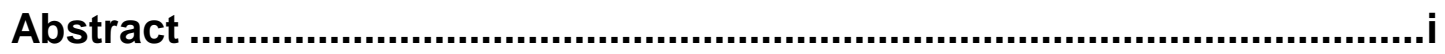

Acknowledgements .................................................................................

Table of Contents......................................................................................ii

CHAPTER 1 Introduction .......................................................................... 1

1.1 Information Communication Technology (ICT) and Interactive

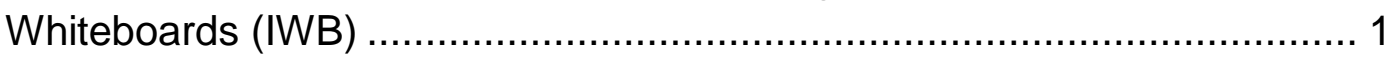

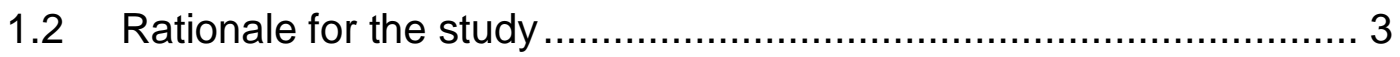

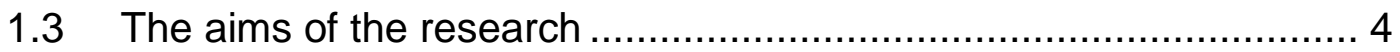

1.4 Background to the research.................................................. 4

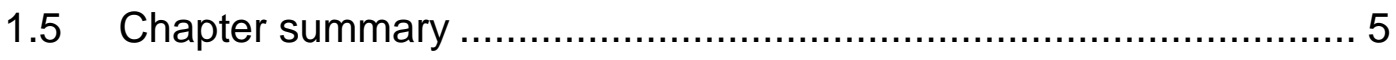

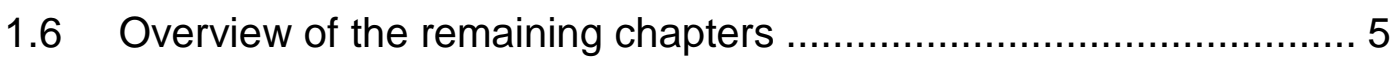

CHAPTER 2 Literature Review ............................................................8

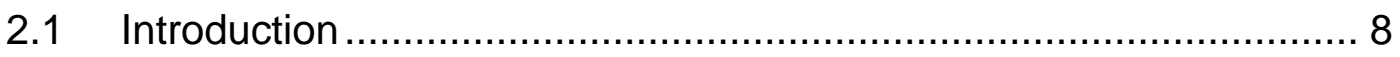

2.2 Teacher pedagogy and IWB use …....................................... 8

2.3 Professional development................................................... 15

2.4 Professional development to integrate technology in the classroom ................................................................................... 21

2.5 Socio-cultural theory .................................................. 25

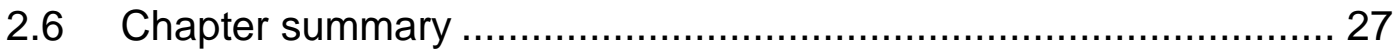

CHAPTER 3 Methodology ...............................................................29

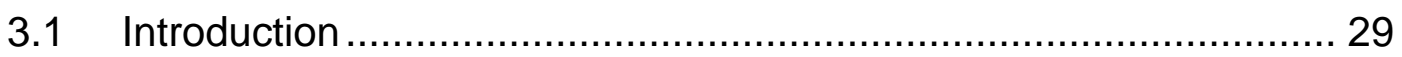

3.2 The research questions .................................................. 29

3.3 Qualitative Research.................................................... 30

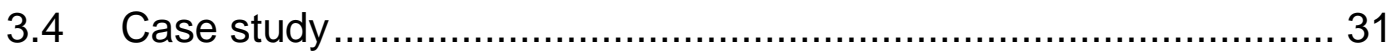

3.5 Main Sources of Data Collection.............................................. 32

3.6 Ethical Considerations ........................................................ 37

3.7 Data Analysis ............................................................. 39

3.8 Chapter Summary....................................................... 42

CHAPTER 4 Survey Results Part 1 .......................................................43

$4.1 \quad$ Introduction ..................................................................... 43

4.2 Survey responses ............................................................ 43

4.3 Professional development and training to use an IWB ................ 49 
4.4 Form of professional development activities ................................ 54

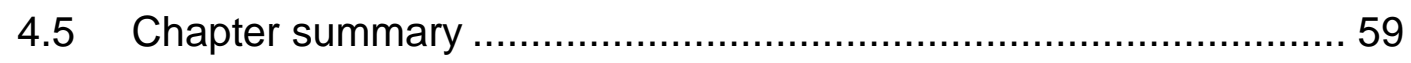

CHAPTER 5 Survey Results Part 2

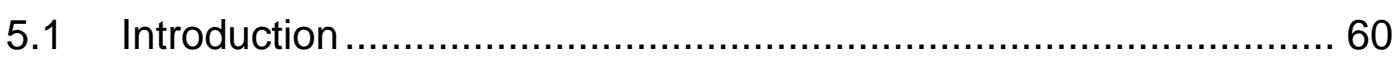

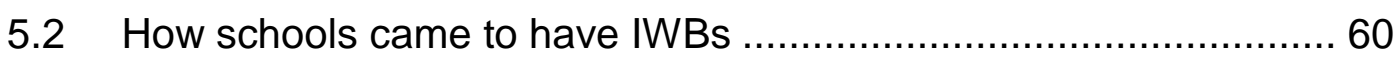

5.3 How are IWBs used in New Zealand classrooms? ......................... 62

5.4 The benefits of using an IWB in the classroom............................. 64

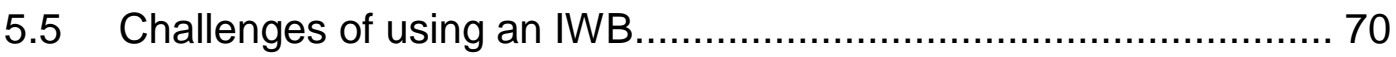

5.6 Change in teacher pedagogy by using an IWB ............................ 73

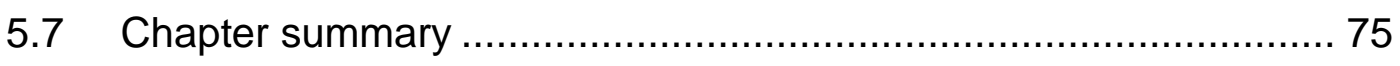

CHAPTER 6 Case study teachers' use of an IWB in their classroom programme ...................................................................................

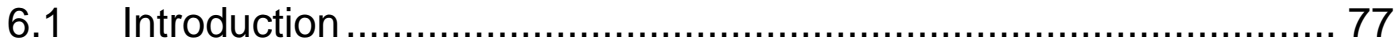

6.2 Lancewood School visit ........................................................... 77

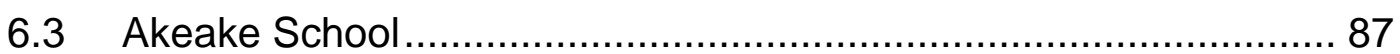

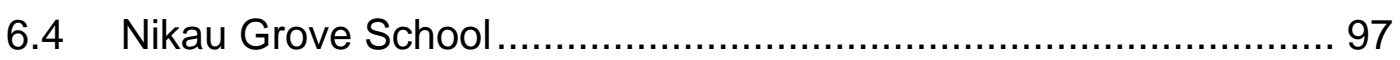

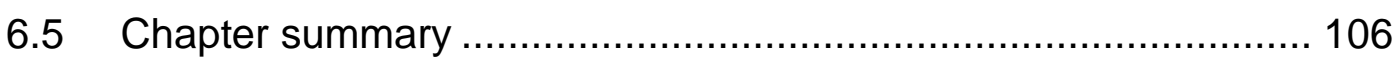

CHAPTER 7 Factors that support and hinder teachers learning to use

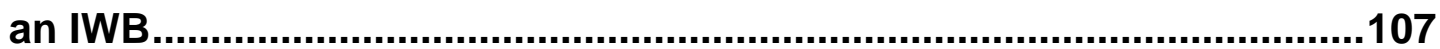

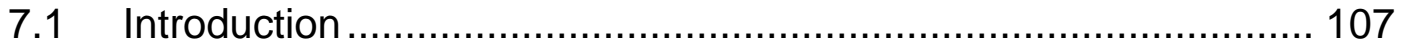

7.2 Professional development experiences ..................................... 107

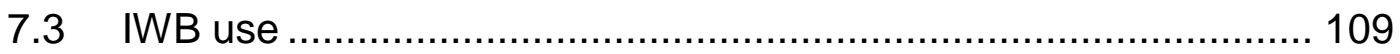

7.4 Factors that enhance the use of an IWB .................................... 113

7.5 Factors that hinder the use of an IWB ...................................... 114

7.6 The impact of professional development on the teachers'

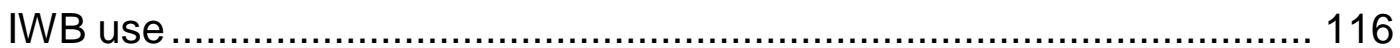

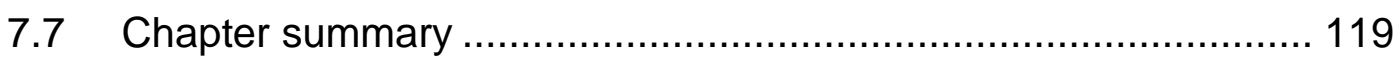

CHAPTER 8 Discussion of results and conclusion .............................120

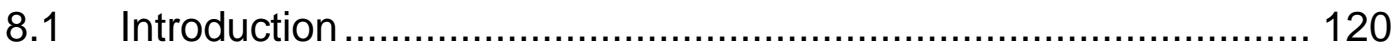

8.2 How does professional development impact on teachers' use of an interactive whiteboard (IWB) in a New Zealand Primary school? .. 121

8.3 What form of professional development did the teachers have before and after the installation of the IWB? 122 
8.4 What contextual factors enhance the introduction of an IWB for a teacher learning to use it in their class programme?

8.5 What contextual factors constrain the introduction of an

IWB for a teacher learning to use it in their class programme?

8.6 How is an IWB used in a New Zealand classroom programme?

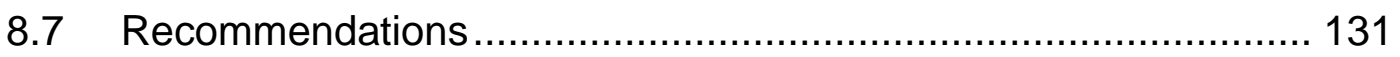

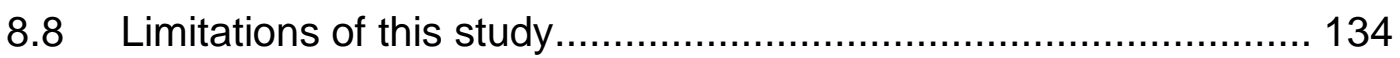

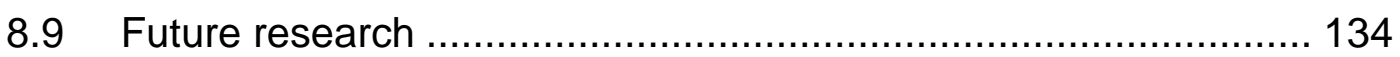

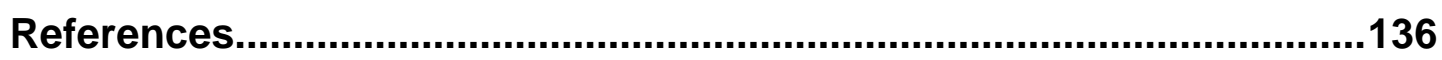

APPENDICES 


\section{List of Tables}

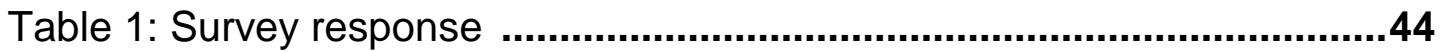

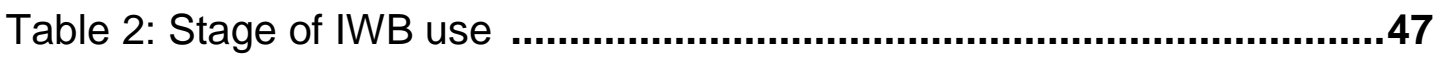

Table 3: Duration and intensity of training .................................................51

Table 4: Professional development experienced ........................................55

Table 5: Principals' rating of professional development ................................58

Table 5.1 Decile rankings of schools with IWB ..........................................62

Table 7: Kathy's classroom timetable ........................................................79

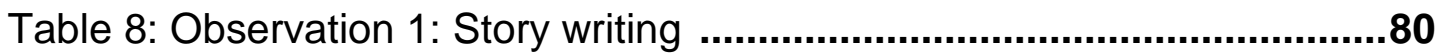

Table 9: Observation 2: Reading ................................................................81

Table 10: Observation 3: Mathematics ……...............................................83

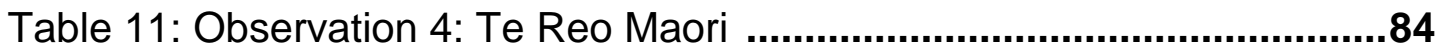

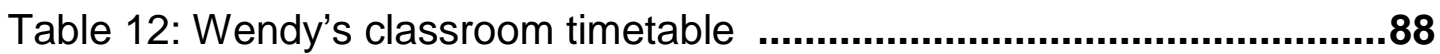

Table 13: Observation 5: Roll and handwriting ...........................................89

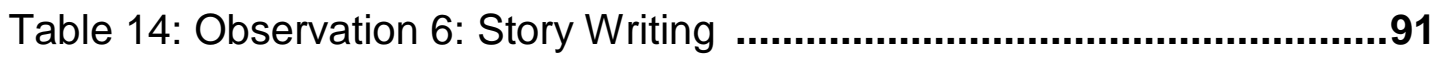

Table 15: Observation 7: Reading ............................................................92

Table 16: Observation 8: Mathematics ……….......................................94

Table 17: Liz's classroom timetable ........................................................98

Table 18: Observation 9: Roll/News board ..............................................99

Table 19: Observation 10: Mathematics ……........................................100

Table 20: Observation 11: Literacy .........................................................101

Table 21: Observation 12: Story writing ....................................................102

Table 22: Observation 13: Goal setting ……..........................................104

Table 23: Summary of the 3 teachers' professional development .............107

Table 24: summary of IWB use ...............................................................109

Table 25: Stage of IWB users with sustained professional development ...124 


\section{List of Figures}

Figure 1: Years of teaching practice .45

Figure 2: Class level of teachers with IWB .46 


\section{List of Appendices}

APPENDIX A: .143

APPENDIX B: 146

APPENDIX C: .148

APPENDIX D: 150

APPENDIX E: 156

APPENDIX F: 164

APPENDIX G: 166

APPENDIX H: 168

APPENDIX I: 170

APPENDIX J: 172

APPENDIX K: 173

APPENDIX L: 


\section{CHAPTER 1}

\section{Introduction}

\subsection{Information Communication Technology (ICT) and Interactive Whiteboards (IWB)}

Over the last decade in New Zealand schools there has been substantial growth in the use of ICT. Student learning that is supported or facilitated by ICT is defined as e-learning. Through e-learning the government wants to equip its students with 21 st century skills by "... exploiting technologies in everything we do and using ICT effectively across the curriculum to connect schools and communities and to support evidence-based decision making and practices in schools" (Ministry of Education, 2006, p. 4). A new ICT technology that is appearing in New Zealand schools is an interactive whiteboard (IWB). This study explores how professional development impacts on teachers learning to use an IWB in New Zealand classrooms and how they use it in their programme.

In New Zealand the use of IWBs in schools is a comparatively new phenomenon. An IWB is defined by The British Educational Communications and Technology Agency (BECTA), (2005) as:

...a large, touch-sensitive board which is connected to a digital projector and a computer. The projector displays the image from the computer screen on the board. The computer can then be controlled by touching the board, either directly or with a special pen (p.1).

IWBs provide a range of functions, audio and video as well as access to resources from the internet. These are:

- drag and drop (objects on the board can be moved around)

- hide and reveal (objects placed over others can be removed)

- highlighting (transparent colour can be placed over writing or other objects)

- animation (objects can be rotated, enlarged, and set to move along a specified path)

- indefinite storage and quick retrieval of material

- feedback (when a particular object is touched, a visual or aural response is generated)

(Glover et al., 2005 cited in Kennewell, 2006, p.2) 
According to Smith, Higgins, Wall and Miller (2005) and Haldane (2007) the key points of IWBs in classrooms are its unique features enabling multimedia and multi-sensory presentations, which are highly motivating and engaging for students. For teachers the benefits of using an IWB are flexibility and efficiency in lesson presentation and planning (Smith et al., 2005; Bennett \& Lockyer, 2008).

These affordances have the potential to support all the teaching approaches as suggested in the New Zealand Curriculum (NZC). "Schools should explore not only how ICT can supplement traditional ways of teaching but also how it can open up new and different ways of learning" (Ministry of Education, 2007, p. 36). Examples of how ICT might support teaching approaches are as follows:

- overcome barriers of time and distance to explore new environments

- facilitate collaborative learning by enabling students to join in or create learning communities

- open up a vast range of resources available to cater for the diverse needs of learners

- enhance student opportunities to learn by offering virtual experiences and tools. (Ministry of Education, 2007, p.36)

The unique features of an IWB, therefore, make it an obvious form of ICT for teachers. In addition, Cowie, Jones, and Harlow (2008) point out that New Zealand teachers are enthusiastic about using ICT in teaching and student learning in new ways. Exploring how teachers use an IWB in the classroom is a timely and relevant undertaking in reference to the recommendations in the NZC.

The New Zealand government does not keep a register of schools with IWBs so it is difficult to gain an accurate percentage of IWB users here. Anecdotal evidence, however, suggests that the use of IWBs is increasing. In Wellington, for example, in a particular area with ten primary schools, only 
one had an IWB in 2006. By 2010 there were five schools in that area with IWBs. Recently, ACTIVboard, a major supplier of IWBs in New Zealand, stated "that nearly 50 percent of New Zealand schools have purchased IWB systems, with classroom penetration approaching 21 percent" (Suckling, 2010, p.19). One in five classrooms in New Zealand now have an interactive whiteboard. By comparison, in the United Kingdom (UK) the IWB has, according to Kennewell (2006), been unlike other forms of ICT equipment and enthusiastically adopted. The government there has made very significant investments in the widespread installation of IWBs in schools; in 2002, 5\% of all teachers used IWBs, by 2007 the figure was 64\%. (BECTA, 2007 as cited in Betcher \& Lee, 2009). This explains why most of the research concerning IWB use in schools comes from the UK.

\subsection{Rationale for the study}

As an IWB is a very expensive investment for a school one might assume that professional development for integrating IWBs into teacher pedagogy is carefully planned, but this is not the case (Wood \& Ashfield 2008). In fact, whilst the literature on IWBs does not focus specifically on professional development with IWBs, it suggests this is an issue that needs to be addressed. Smith et al. (2005) argue that professional development around IWBs has not been sufficient to significantly change teacher pedagogy and student learning. Kennewell (2006) concurs stating that "the consistent findings concerning the limited nature of pedagogical change resulting from the introduction of IWBs suggest that a future focus on professional development would be valuable" (p.8). What defines effective professional development and how it relates to learning to use an IWB is a gap in the literature.

Somekh et al. (2007) point out that an IWB is "a technology which is still to arrive in many schools, and to which teachers are still adapting. It is still too early for there to be any settled practice to research. Few of the early articles available are from academically refereed journals or published reports" (p.154). (See also Higgins, Falzon, Hall, Moseley, Smith \& Wall, 2005; 
Schuck \& Kearney, 2007). Wood and Ashfield (2008) found that "at present, there is limited amount of research available that focuses specifically upon the IWB and associated pedagogy" (p.86). The limited availability of research into IWB use in New Zealand schools and related professional development provides a further rationale for this study.

\subsection{The aims of the research}

As already pointed out, there is limited research into the impact of professional development on teachers learning to use an IWB in their classroom both nationally and internationally. In New Zealand research has been carried out on the impact of the IWB on children's learning (see chapter 2). To date, though, no research has been carried out specifically on professional development for teachers learning to use an IWB. This study contributes to the paucity of New Zealand research about IWBs. Furthermore, the use of IWBs is increasing, thus making my research timely and relevant to schools investing large amounts of money into this expensive technology. In addition, studying how an IWB is used in New Zealand schools takes into consideration recommendations in the NZC (2007) that all schools should explore how ICT can be used to support teaching and student learning.

\subsection{Background to the research}

In 2006 I moved into a Year One classroom that had an IWB. I had not used one before so the Head of the ICT department in the school showed me how to use some basic tools of the IWB software: the pens, highlighter and stamp tools, a few days before school started. This was the extent of my training to use the IWB although the ICT colleague was generally able to come down if I had a problem using it. A colleague who had been using an IWB for a year was also helpful.

I learnt to use the tools and software of the IWB by exploring these outside of school hours. After the first few weeks of use, I discovered after 'losing work' 
on the IWB that it was not interactive with the Microsoft Publisher programme. It was a frustrating learning journey at times. During that year I became very familiar with the tools and software of the IWB and established 'set ways' of doing certain lessons on it. For example, the students used the IWB everyday to complete a news board. Here they would highlight the day of the week by changing the font and colour of it, and inserting a shape around the weather graphic for the day. They became relatively proficient in using the IWB too, and learning basic computing skills. After my initial training at the beginning of the year, the school was visited by the IWB supplier who spent two hours with those of us who had one in our classroom. I learnt to use a couple of the extra tools on the IWB. This was the extent of my professional development using an IWB that year.

In my second year I realised I was using the IWB in a routine manner and really needed to see or hear how to use it in different ways to support my students' learning across the curriculum. No professional development was offered to meet this need. Early in the year we listened to some telephone conferences from the IWB supplier on how to use the tools but by that stage we were already familiar with what was being shown. At the end of that year I left the school to go on study leave. My experience of learning to use an IWB with very little professional development prompted this study.

\subsection{Chapter summary}

The IWB is a relatively new and expensive technology within education institutions. Its unique features are highly motivating and engaging to students and in New Zealand the uptake of IWB in schools is increasing. This qualitative study explores the professional development experiences of teachers using an IWB in New Zealand schools and how they use it in their classroom programme.

\subsection{Overview of the remaining chapters}

\section{Chapter 2: A literature review}


This chapter reviews the research literature in relation to teacher pedagogy and how an IWB is used in the classroom. Studies on effective professional development are then examined with particular reference to the integration of technology in the classroom. Finally, socio-cultural theory is discussed in relation to professional development of teachers learning to use an IWB in their classroom.

\section{Chapter 3: The research methodology}

The methodology used for this study is outlined in chapter three. It describes the way in which qualitative data was collected through a national survey of teachers and principals, non-participant observations, semi-structured interviews and documentation. Ethical considerations are discussed and data analysis is explained.

\section{Chapter 4: The survey results-Part One}

The results of the two surveys that relate to professional development and the use of an IWB in a primary classroom are examined. In order to understand the context of the study, the background of the teacher survey respondents is outlined. This includes their years of teaching experience, the class level taught and time teaching with an IWB. The type, timing, intensity and content of professional development experiences of the survey respondents are presented as well as results from the principals' survey. The preferences for certain types of professional development that emerged are discussed in relation to relevant literature.

\section{Chapter 5: The survey results-Part Two}

In this chapter the survey results that relate to how an IWB is used in New Zealand classrooms is presented. The data from the principal survey explains why their schools have IWBs and how teachers are selected to have one in their classroom. The curriculum areas that an IWB is used in and the benefits and challenges of using an IWB are also discussed. Themes are analysed in relation to relevant literature. Finally, how the teachers' pedagogy changed since using an IWB is explored. 
Chapter 6: Case study teachers' use of an IWB in their classroom programme

This chapter examines the case study of three primary teachers. Data from the class observations, teacher interviews and documentation detail how they use an IWB in their classroom. The teachers also consider the challenges and benefits of using one.

\section{Chapter 7: Factors that support and hinder teachers learning to use an IWB}

The professional development experiences of the case study teachers are evaluated in this chapter as well as the factors that enhanced and hindered their learning to use an IWB.

\section{Chapter 8: Discussion of findings and conclusions}

In this chapter I examine the findings from the teacher and principal survey and the three case study teachers in relation to the key question and sub questions of this study. Recommendations are made for providing effective professional development to teachers learning to use an IWB. Suggestions are also given as to how professional development could be sustained. The limitations of this thesis and possibilities for future research are then discussed. 


\section{CHAPTER 2 \\ Literature Review}

\subsection{Introduction}

This chapter examines research involving teacher pedagogy and IWB use in the classroom as well as, professional development and its relevance to the integration of technology in the classroom. Within this section I specifically look at studies that report on the introduction of an IWB in a classroom. Lastly, I explore professional development for teachers learning to use an IWB in their classroom in relation to socio-cultural theory and practice.

\subsection{Teacher pedagogy and IWB use}

Teacher pedagogy in this study relates to the way in which teachers use an IWB in their classroom, the stages of IWB usage and the curriculum areas where an IWB is used. These are explored in the following section.

Teacher pedagogy appears to be a critical factor in the successful use of an IWB. Higgins et al. (2005) carried out a two year study on the impact of IWBs on the teaching and learning of literacy and mathematics in Year Five and Year Six classes. They found there were no major changes in teacher pedagogy and most teachers continued to use a whole class model of teaching. Further, student progress made in the first year of IWB use was not sustained in the second year. Higgins et al. (2005) state that "for the use of such technology to be justified it must be used in ways which promote more effective learning above and beyond that which is possible when teaching with other kinds of projection technology or with ordinary whiteboards" (p.66). Clearly, as with any other classroom resource, how the teacher uses the IWB as a mediating tool to interact with students is much more important than the nature of the resource itself.

In another study Bennett and Lockyer (2008) examined how four teachers in an Australian primary school integrated an IWB into their teaching practice 
over two terms. Whilst overall teacher pedagogy did not change, teachers readily used the IWBs to fit in with their existing classroom routines. Bennett and Lockyer (2008, p. 298) assert "it was clear that the lesson content and learning objectives determined the use of the IWB rather than the teachers looking for opportunities to exploit the IWBs potential".

In England there has been research done on teacher pedagogy with an IWB and whole class teaching. Wood and Ashfield (2008) undertook a case study in five primary schools to investigate how an IWB could be used support and enhance whole class teaching of numeracy and literacy. This involved ten observations of numeracy and literacy whole class lessons, interviews and focus group discussions with teachers. All the teachers involved in the study believed that the unique affordances of an IWB, such as multi-media and interactive capabilities, enhanced whole class teaching. Wood and Ashfield (2008) concluded that the most influential factor in enhancing whole class teaching is teacher pedagogy: the skill and knowledge of the teacher and how this is used to facilitate student interaction with the IWB. They recommended that when introducing IWBs the technology must be fused with pedagogy so that teachers have "a clear understanding of children's learning and how this may be facilitated within whole-class lessons." (p. 95).

\section{Stages of IWB use}

There are definite stages of teachers' IWB usage (see, for example, Glover \& Miller, 2003; Hooper \& Rieber, 1995; Knight, Pennant \& Piggot, 2004). Beauchamp (2004) carried out classroom observations and interviews of seven teachers from different levels in a primary school over two years and across the curriculum. He developed a generic progressive framework for schools introducing an IWB, which identified five stages teachers go through:

- black/whiteboard substitute

- apprentice user: the teacher is using a wider range of computer skills

- initiate user: the teacher begins to use the IWB to change and enhance his/her pedagogy 
- advanced user: the teacher involves the students in using the IWB and shows

- a high level of skill in using the software

- synergistic user: the teacher and pupils are interacting together, using the IWB to achieve learning objectives.

The teachers developed increasing skill in computer use and pedagogy as they progressed through the stages of being an IWB user. Beauchamp (2004) identified specific computer skills, including file management, importing graphics and scanned images and using the internet, as beneficial skills for teachers to have before using an IWB. This would ensure teachers only learnt new skills inherent to an IWB. Beauchamp (2004) argues that providing training in computer skills prior and subsequent to the introduction of an IWB leads to more effective use of it in the classroom. In agreement with Beauchamp (2004), Levy observed teachers who were already competent users of computers and found that they "tended to become enthusiastic 'early adopters', able to experiment and develop their own IWB use following initial training" (2002, cited in Smith et al., 2005, p. 98).

In a later study carried out in one Australian primary school, Sweeney (2008) investigated the impact of IWB on teacher pedagogy. Using the results of her study as well as research on effective pedagogy and the process of change with new technology, Sweeney (2008) developed a framework of IWB use. She adopted two of Beauchamp's (2004) stages: whiteboard replacement and synergistic, as well as the indicators. The other three stage headings were adopted from the work of Miller et al., which describe the pedagogical development of a teacher becoming more fluent using the interactivity of the IWB (2004, cited in Sweeney, 2008, p.3). Sweeney's (2008) five stages for teachers' IWB use are:

Stage 1 Whiteboard replacement

Stage 2 Supported Didactic: teacher is learning to use the IWB technology and relies on the use of flipcharts 
Stage 3 Interactive: teacher routinely uses the IWB and wants to engage students in interactive activities on the IWB

Stage 4 Enhanced Interactive: teacher shows technical expertise with the IWB and plan lessons focused on interactivity and collaboration between students and the teacher.

Stage 5 Synergistic User: both the teacher and students are expert users of the IWB and the teacher has become a facilitator of learning.

Sweeney (2008) designed the framework to focus "attention on the pedagogical transformation required by teachers and the challenges associated with moving past the third stage of development...and attempts to conceptualise the change required by teachers relinquishing control of learning to students" (p. 4). Although there was no given time limit for teachers to move through the framework, results suggested that existing traditional practice became more entrenched the longer a teacher remained at Stages one to three. In addition, Sweeney (2008) proposes that this framework could be used by teachers as a self assessment tool to analyse how they use an IWB and their professional development needs. She recommended that further research was needed "to identify the factors that supported or constrained teachers' development along this continuum" (Sweeney, 2008, p. 7).

Beauchamp (2004) and Sweeney (2008) do not point out how long an IWB takes to become embedded in teacher pedagogy. Somekh et al. (2007), however, carried out a two year evaluation of a IWB project in Britain and found it took teachers two years of IWB use for it to become embedded in their pedagogy "as a mediating artefact for their interactions with their pupils, and pupils' interactions with one another" (p. 7). Once teachers became skilled in using an IWB new patterns of teacher practice emerged. Some of these were improvements or modifications on previous pedagogy whilst others exhibited completely new ones. For instance, teachers began to use the IWB "to facilitate a co-learner style of teaching, where teacher and pupils (we) work together rather than adopting more formal roles as teacher and 
learner" (Somekh et al., 2007, p. 111). Recent research also identifies this embedding factor. Haystead and Marzano (2009) carried out a study for Promethan, Ltd, (an IWB company) on the effects of using an IWB on student achievement. Although this research was not focused on teacher pedagogy, the embedding factor of having used an IWB for two years or more emerged as one of four related conditions that might predict relatively large gains in student achievement. The other three were:

- "a teacher has 10 years or more of teaching experience

- a teacher uses the technology between 75 and 80 percent of the time in his or her classroom

- a teacher has high confidence in his or her ability to use the technology" (p. 36).

In summary, teachers go through stages of IWB use. The level of teachers' computer skills prior to using an IWB, has an impact on how they teach with it. Furthermore, there is an embedding effect of two years use, for a teacher to become skilled in using an IWB.

\section{Curriculum areas of use with an IWB}

In the United Kingdom an IWB is predominately used in the curriculum areas of numeracy and literacy in primary classrooms, and to support whole class teaching (Beauchamp, 2004; Smith et al., 2005). Wood and Ashfield (2008) suggest that the introduction of the National Literacy strategy in 1998 and the National Numeracy strategy in 1999 clearly outlined that "Literacy and Numeracy sessions were expected to consist of a substantial amount of direct, whole-class teaching" (p. 86). This expectation was the result of a Numeracy Task Force identifying whole class teaching as a key feature in the mathematic classes of the highest rated countries for mathematical attainment (Wood \& Ashfield, 2008). The use of an IWB was seen as an effective way to encourage whole class teaching as it enabled the teacher to quickly adapt activities to student responses, keeping them motivated and on task for longer, as well as moving the lesson at a faster pace. 
Outside of the United Kingdom it appears that teachers also use an IWB predominately for literacy and numeracy although for different reasons. For example, in the Australian study of Bennett and Lockyer (2008) most of the lessons using the IWB were on numeracy and literacy, because they were the focus subject areas in the school. There is little relevant research emanating from New Zealand so it is unclear whether or not this would also be the case for teachers here.

In New Zealand there have been a small number of studies on how teachers use an IWB in primary classrooms. The largest research to date has been Project ACTIVate, an action research project carried out in 2005. It involved fourteen teachers in two clusters of schools, primary and secondary, located in Southland and Auckland. The project related to questions about the effectiveness of an IWB on student learning, in a range of specific contexts and using a variety of teaching and learning approaches. McDowell and Murray (2005), for instance, compared how an IWB and a computer programme, Microsoft Publisher, facilitated a writing programme using peer tutors. Year six children were the tutors for the New Entrant children working through a writing process that culminated in a published story. Results showed that all students found working on the IWB more motivating and engaging than on a computer, and on-task behaviour was much higher using an IWB.

In another study, Bowman and Tait (2005) explored on-task behaviour when using an IWB. They compared on-task behaviour when working at three stations: an IWB, a computer shared by three students and three individually placed computers. The students, in groups of three, were using an interactive CD Rom at all stations. The IWB had the highest on-task behaviour and level of motivation and the students worked in a far more collaborative manner when using the IWB.

Kennedy and Anderson (2005), as part of the same project, trialled an IWB video conferencing programme that aimed to improve their student's oral 
language communication by interviewing and questioning each other. The two classes involved were in different schools and results showed that, despite the technical difficulties experienced in video conferencing, the project did improve the communication skills of the students.

A further study by Woods, Stevens, Mes and Reid (2005) investigated whether using an IWB increased student engagement when working on an inquiry learning project. They concluded that with highly motivated students the tool being used does not make a difference in their degree of engagement. Woods et al. (2005) noted, however, a high degree of cooperation among these students when they were using an IWB.

In summary, Project ACTIVate, carried out in 2005 did provide empirical evidence of IWB use enhancing student on task behaviour, engagement, motivation, co-operation and collaboration. The studies outlined above were examples of how an IWB was used in the classroom for a particular project so may not be indicative of continued daily use in that manner. Furthermore, none of the research projects explored the issue of professional development and its impact on the IWB use in the classroom, which is the focus of my research.

In a more recent study, Ryan and Cowie (2009) analysed the role of an IWB in a science unit, taught to year seven and eight students. Over a two week period a video of the lessons, field notes and interview with the teacher and students provided the data for the study. Ryan and Cowie's (2009) key message from their findings was that an IWB "can readily support a number of the practices recommended as effective within the NZC, such as adding relevance, building on student interests, supporting conversation and developing a sense of connection" (p.47). In conclusion, the researchers contend that it is the way the teacher uses the IWB to structure and sequence tasks that has the most impact on student learning. Overall, to date, there is little research in New Zealand on how teachers use an IWB on a daily basis in New Zealand classrooms. 


\subsection{Professional development}

Before examining how professional development can be used to integrate IWBs in the classroom, it is first necessary to outline the characteristics of effective professional development. I will then explore professional development in relation to using an IWB in the classroom.

\section{What is professional development?}

Guskey (2000) defines professional development as "those processes and activities designed to enhance the professional knowledge, skills, and attitudes of educators so that they, might in turn, improve the learning of students....It is a process that is (a) intentional, (b) ongoing, and (c) systemic" (p.16). The Educational Review Office (ERO) of the New Zealand Ministry of Education, in a national report on managing professional learning and development in primary schools in 2009, concurs that the "central purposes of professional learning and development are to improve the quality of teaching and to improve student outcomes" (p.1).

Most professional development programmes up until the 1990s consisted of one stop workshops that focused on teachers gaining mastery of prescribed skills and knowledge (Clarke \& Hollingsworth, 2002). This type of professional development to change teaching practices has been found to be ineffective. For instance, Fullan (1979) reviewed the workshop model and established that workshop topics were not selected by the participating teachers. Furthermore, follow up support and implementation was rare and the model was ineffective. In a later review of professional development programmes, Fullan (2007) points out that "almost 15 years later, Little (1993) drew the same conclusion" (p. 285).

According to Mouza (2006), research on professional development did not focus or document the critical factor of changes in teacher learning and consequent practice. Desimone (2009) concurs stating that "for decades, 
studies of professional development consisted mainly of documenting teacher satisfaction, attitude change, or commitment to innovation rather than its results or the processes by which it worked" (p. 181). Such results prompted research into the process of teacher change and professional development. The focus of professional development began to shift "from programs that change teachers to teachers as active learners shaping their professional growth through reflective participation in professional development programs and in practice" (Clarke \& Hollingsworth, 2002, p. 948). New models of professional development programmes evolved: training, observation/assessment, involvement in a development/ improvement process, study groups, inquiry/action research, individually guided activities and mentoring (Guskey, 2000). Each model has different advantages depending on the goal, content and context of the professional development plan. Guskey (2000) recommends the combination of these models to "ensure that professional development efforts remain intentional, ongoing, and systemic" (p. 29).

How professional development impacts on student learning was the subject of a seminal study carried out by Kennedy (1998). Examining a pool of 93 studies about the effectiveness of teacher education in either mathematics or science, Kennedy (1998) identified that there were only ten studies that included evidence of benefits to students. She argued this was an important finding as it showed that professional development programmes, in an attempt to move away from the much maligned 'one stop' workshop, had focused on the form and structure of programmes rather than the programme's content and its effect on student learning. Kennedy (1998) found the programmes that had the most impact on student learning were those which provided teachers with "very specific ideas about what the subject matter they will teach consists of, what students should be learning about that subject matter, and how to tell whether students are learning or not. This content makes the greatest difference in student learning" (p.25). Other features of the professional development programmes, specifically the time spent with the teacher, duration of the programme, number of class 
visits and participation as a whole school or individual were also found to have no clear benefit to student learning. Some of the programmes of brief duration or with shorter contact hours had a greater effect on student learning than those of longer duration or more contact hours, which Kennedy (1998) argued was because of the content of these programmes.

Subsequent studies have investigated in greater detail the features of effective professional development leading to a change in teachers' knowledge, skills and classroom practice. For example, in a large American study Garet, Porter, Desimone, Birman and Yoon (2001) used data from a national evaluation of the Eisenhower Professional Development programme, which funds mainly mathematics and science professional development, to find a set of 'best practices' in professional development programmes. This study is of particular significance as prior to this "empirical evidence of the relative value of specific professional development features was limited" (Penuel, Fishman, Yamaguchi \& Gallagher, 2007, p. 924).

Garet et al. (2001) identified professional development activities in terms of structural and core features. Structural features were the type, either traditional or reform, duration of the activity, and the emphasis on collective participation from the same school, level or department. Traditional type activities included workshops, courses, and conferences while reform type activities included teacher study groups, collaborative or communities and mentoring. Their findings showed both types of activities of the same duration had a similar effect on teacher learning.

The three core features of professional development identified by Garet et al. (2001) were viewed as the processes and experiences that characterises professional development. These are the focus on content and pedagogical knowledge, the opportunities for active learning by the teachers and the extent to which the activity was a coherent part of the teachers' learning. They found professional development that focuses on content and teachers being actively engaged in the learning, which is embedded in their daily 
practice, is more likely to result in their enhanced learning and change, and consequently student learning. Thus, Garet et al. (2001) concluded "it is more important to focus on the duration, collective participation, and the core features (i.e., content, active learning, and coherence) than type" (p.936).

\section{Professional development in New Zealand}

Timperley, Wilson, Barrar and Fung (2007) developed a theoretical framework that analysed the effectiveness of the professional development in 97 studies, including 24 from New Zealand. Their best evidence synthesis of professional development identified five features that contributed to effective professional development that impacted on student outcomes. These are briefly outlined below:

\section{The professional learning context}

Within a professional learning context Timperley et al. (2007) identified seven elements that contributed to effective professional development. These were:

(i) providing an extended timeframe (between six months and two years was common to the studies examined) to accommodate for changing teacher practice which was considered to be an iterative or cyclic learning process rather than linear process. (New learning involves a cycle of engagement: gaining new knowledge, integrating it into practice and assessing the outcomes of the new practice)

(ii) using external expertise to convey meaningful and manageable content to classroom teachers.

(iii) ensure the content is consistent with current research findings and policy.

(iv) engaging teachers in the learning process, whether they initially volunteered to do so or not.

(v) challenging problematic discourses such as teacher expectations about students, and teaching approaches as these changed once the impact on student learning from new teaching approaches became apparent. 
(vi) providing opportunities to interact in a professional community that was thought to support teachers in understanding and putting into practice new knowledge and teaching approaches.

(vi) active school leadership. Effective leaders need to organise opportunities for teachers to learn, have access to expertise and meet in a professional community.

\section{The content of professional learning and development}

According to Timperley et al. (2007), three key features of the professional development content are: the integration of theory and practice; a clear link between the teaching practice and student learning; and, finally, assessment used to identify student needs and then focus teaching and sustainability. In particular, the importance of content as a very influential feature of professional development continues to be reiterated in recent research. By way of illustration, Wayne, Yoon, Zhu, Cronen and Garet (2008) state that it is "generally accepted that intensive, sustained, job-embedded PD focused on the content of the subject that teachers teach is more likely to improve teacher knowledge, classroom instruction, and student achievement" (p.470). Furthermore, Desimone (2009) concluded in a review of research over the last decade that the evidence "points to the link between activities that focus on subject matter content and how students learn that content with increases in teacher knowledge and skills, improvements in practice" (p.184).

Timperley et al. (2007) found that sustainability depended on teachers being able to evaluate the impact of their teaching, identify the next step and have an in depth understanding of theory in order to decide on the most appropriate practice. In addition to this, Hawley and Valli (2007) maintain that in order to sustain new teaching practices professional development needs to be on-going with follow up and support as teachers implement new practices and discover new needs. These findings support Loucks-Horsley, Hawson, Love, and Stiles (1998) who suggested that educational practice usually takes three to five years to change with a continuous professional development programme. 


\section{The type of activities}

Timperley et al. (2007) acknowledged that the types of activities used in professional development were widely varied, from observation, reading research, discussing practices, to expert visitors. They stated that no particular activity was more effective than others. The critical factor was that a variety of activities was offered focusing on content aims and teacher understanding. Garet et al. (2001) also came to a similar conclusion.

\section{The learning processes}

Timperley et al. (2007) noted the area of learning processes and teacher responses was neglected in the studies, consequently results were a mix of theory and limited evidence. They concluded that a critical factor related to how coherent the goals of professional development are to teachers' learning goals and their goals for student learning. Timperley et al. (2007) also identified that teachers existing beliefs influences new learning and understanding by acting like a lens or filter and thereby influencing the way they come to enact new knowledge or practices.

\section{Teacher responses}

Professional development needs to address the diverse learning needs of both teachers and students, which depends on the context, physical and social, of their current practice. Penuel et al. (2007) used evidence from a study of 454 teachers, taking part in a professional development course for an inquiry science programme, to identify that the social context of a school and the social pressure within it also has a strong influence on teachers' decisions to change their practices.

Timperley et al. (2007) study is highly significant as it provides a framework of best evidence synthesis for professional developers to use to ensure the design of effective professional development programmes for all areas of the curriculum, particularly in a New Zealand context. 


\subsection{Professional development to integrate technology in the classroom}

In this section I investigate professional development and technology, and how it relates to IWBs. As Keller, Bonk and Hew (2005) and Mouza (2009) put it, there is very little research that focuses on the impact of professional development on teacher learning and practice with regard to technology.

Mouza (2006), for instance, examined two models of professional development designed to help teachers integrate technology into their classroom and the impact of this on their learning and practice. Case studies of eight teachers in one school were conducted over a year. The first model of professional development, called Technology Integration Series, aimed to improve teachers' technological skills and understanding of how to integrate technology into their class programme. The second model, entitled Curriculum Technology Theme, was designed to help teachers integrate technology within a subject area. Both models had three main components: introductory and advanced weekly workshops, school site meetings and support in the classroom. Mouza (2006) found that both models helped teachers learn how to use and integrate new technology into their classrooms. It was recommended, therefore, that the following elements be included in professional development programmes that introduced technology:

- intensive hands-on training with the new technology.

- range of curriculum activities to help teachers understand how and when they can use technology in their classroom.

- time made available for teachers to try out new strategies in their classroom and then reflect on the impact of these.

- attend to both teacher beliefs and practices as they can influence teacher participation in and of new learning.

(Mouza, 2006) 
These recommendations align with Timperley et al. (2007) findings of best practice evidence concerning professional development: provide a range of activities that will be suited to classroom practice and take into consideration teachers' present and past beliefs.

In another study, Mishra and Koehler (2006) spent five years researching teacher professional development and its impact on integrating educational technology. They created a conceptual framework using teacher knowledge to integrate technology. This was based on the work of Shulman done in 1986, and adapted his three areas of knowledge. These included:

- Technology knowledge, which is about knowing how to use technology, for example, computers and software.

- Technological content knowledge. This refers to teachers knowing their content and how it can be changed by using technology.

- Technological pedagogical knowledge. This concerns teachers knowing about the capabilities of different technology, how they are used in teaching and how teaching might be changed as a result of using these.

Mishra and Koehler (2006) believe that in order to integrate technology effectively teachers need to develop all three areas of knowledge outlined above and then combine this into Technological Pedagogical Content Knowledge (TPCK). They developed a framework around TPCK, suggesting that it could be used to restructure professional development programmes for teachers learning to use technology in their classroom. The TPCK framework:

...argues against teaching technology skills in isolation and supports integrated and design-based approaches as being appropriate techniques for teaching teachers to use technology. It argues that learning environments that allow students and teachers to explore technologies in relationship to subject matter in authentic contexts are often most useful (Mishra \& Koehler, 2006, p.1045).

These findings are similar to those of Mouza (2006). 


\section{Professional development to integrate IWB in the classroom}

To date there have been no studies, nationally or internationally, specifically focused on professional development and its impact on the use of IWB in a classroom. Some have postulated on the possible impact, for instance Smith et al. (2005) argue that the professional development around IWBs has not been sufficient to significantly change teacher pedagogy and student learning. Kennewell (2006) concurs with this stating that "the consistent findings concerning the limited nature of pedagogical change resulting from the introduction of IWBs suggest that a future focus on professional development would be valuable" (p. 8). More recently, Bennett and Lockyer (2008) point out that research results about the impact of IWBs on teacher practices and student learning takes a 'snapshot' perspective; "Iongitudinal studies that might explain how teachers' practices change as they start to use IWBs are harder to find" (p. 290).

Other studies have identified specific features of professional development that impact on IWBs in the classroom. Schuck and Kearney (2007), for example, explored pedagogy with IWBs in four primary and two secondary schools in New South Wales. In their literature review they examined current research on the contextual factors that contribute to the success or failure of IWB use in schools. They found that the research emphasised "the crucial nature of professional development, highlighting how the teacher uses the IWB as being far more important than the nature of the technology" (author's italics. p.11). Schuck and Kearney (2007) assert that one of the key common factors that promoted use of IWBs in schools was a supportive and enthusiastic principal and a collegial atmosphere where teachers share ideas and resources allowing collaboration to occur.

Miller and Glover (2007) also provided evidence of the importance of collaboration in professional development in the induction of an IWB. They examined the professional development undertaken in a mathematics department of seven secondary schools when IWBs were introduced. The main aim of their study was to see how the teachers felt about the 
professional development they had participated in and what impact the induction experience had on classroom practice. Miller and Glover (2007) results did not identify any clear relationship between professional development and subsequent classroom practice. The varying experiences, however, of the seven schools led them to suggest that "the introduction of the technology without sufficient training in technology and teaching and learning may inhabit the realisation of the full value of the equipment" ( $p$. 329). The factors of the professional development that were found to be most successful were regular collaboration with colleagues in the development of teaching materials and approaches, and time provided for this. In addition, the availability of a mentor (internal or external) from a very early stage for pedagogical development and a technical expert available when needed was also effective.

To briefly summarise, it appears that research identifying the features of effective professional development that leads to a change in teacher practice and improvement in student learning has recently come to a consensus. Firstly, the focus of all professional development activity needs to be on the content rather than the type of activity. The content needs to be readily integrated in a classroom programme and include active learning by the participants. Furthermore, professional development needs to be on-going or sustained and involve collective participation. These features were also identified for effective professional development to integrate technology in the classroom. The only additional feature identified was providing intensive hand-on training to use the new technology. Timperley et al. (2007) provided a best evidence synthesis of professional development with a framework to use when designing a programme for effective professional development. In addition, this literature review has identified that there are very few studies that examined the impact of professional development on teacher learning and practice in relation to IWB use in schools and to date none in the New Zealand context. The intention of my research, therefore, is to investigate this issue. 


\title{
2.5 Socio-cultural theory
}

This final section examines socio-cultural theory and explains why it is appropriate to relate it to professional development for teachers. Sociocultural theory is associated with Vygotsky and the following definition outlines his main ideas that are important to this study. According to Tharp and Gallimore (1988), socio-cultural theory has:

\begin{abstract}
... profound implications for teaching, schooling and education ... A key feature of this emergent view of human development is that higher order functions develop out of social interaction. Vygotsky argues that a child's development cannot be understood by a study of the individual. We must also examine the external social world in which that individual life has developed...Through participation in activities that require cognitive and communicative functions, children are drawn into the use of these functions in ways that nurture and 'scaffold' them (p. 6-7).
\end{abstract}

There are three principles of Vygotsky's work that are most salient for professional development programme. These are thought and language are inherently connected and central to learning and development; the impact of the social, cultural and political context on learning; and the Zone of Proximal Development (ZPD) (Wink \& Putney, 2002).

Vygotsky (1978) believes speaking is a cognitive tool for internalising our social interactions and a mediating tool for communicating with others. However, this process of internalising social interaction does not occur automatically. "The transformation of social interaction from the intermental to the intramental (i.e., the process of internalization) is a complicated and prolonged process that requires engagement of two or more people in a practical activity" (Eun, 2009, p.138, author's italics). The process of learning, then, is a significant consideration to take into account when designing the type and intensity of a professional development programme. In addition, the social and cultural environment of learners also influences the social interactions that will take place with others. The third key principle of Vygotsky's theory is the Zone of Proximal Development (ZPD). Vygotsky (1978) defined the ZPD for student learning as: 
...the distance between the actual developmental level as determined by independent problem solving and the level of potential development as determined through problem solving under adult guidance or in collaboration with more capable peers (p.86).

Using this concept of ZPD, Wood, Bruner and Ross developed the term scaffolding which is "permitting the child to do as much as he can by himself, while what he cannot do is filled in by the mother's (or other tutor's) activities" (1976, as cited in Smith, 1998, p. 4). The ZPD is a useful concept to examine in the context of all learners not just children. Essential to this learning process are mediating tools through which the transformation of social interaction becomes internalised. Such tools may be printed materials, another person such as a peer, mentor, teacher or parent, computers, an IWB or anything that supports learners to complete an activity or task independently. When learners have reached this stage the scaffolding can be withdrawn. The concept of ZPD is one that is used in many models of professional development.

Socio-cultural theory provides an appropriate framework for exploring the experiences of teachers introducing and integrating an IWB in their class programme as it "emphasizes the importance of context, the nature of human interactions and the reciprocal relationships formed between tools and their users" (Schuck \& Kearney, 2007, p.73). One could not study teachers without examining their interactions within the social and professional context in which they work and the tools they use, in this case the IWB. The IWB is mediating tool of interaction between teachers and students and teacher and colleagues.

Eun (2008) examined each of Guskey's (2000) seven models of professional development: training, observation/assessment, involvement in a development/improvement process, study groups, inquiry/action research, individually guided activities and mentoring within Vygotsky's socio-cultural theory on the basis that each one has an emphasis on the concept of development and more importantly, "both consider social interaction to be the 
main source underlying human development" (p. 141). Each one of Guskey's (2000) models involves some form of social interaction with an expert, a colleague, mentor, group or community. Furthermore, the concept of ZPD where a learner is 'scaffolded' by a more expert learner is clearly seen in the professional development models of training and mentoring. Timperley et al. (2007) also identified the socio-cultural context of professional development as having a very strong influence on what and how individual teachers learn and practice, and they argued that this influence should be acknowledged and planned for when designing effective professional development. Lastly, by framing professional development programmes dominated by social interaction within Vygotsky's socio-cultural theory, one can understand why "follow-up support systems are crucial in sustaining the effectiveness of teacher training" (Eun, 2009, p.153). In relation to IWB use, a follow-up system would be an expert or mentor one could contact when problems, either technical or pedagogical, occurred.

\subsection{Chapter summary}

There are stages of IWB use that teachers move through (Beauchamp, 2004, Sweeney, 2008), when integrating an IWB in their classroom. Very early stages of teachers' use focuses on learning to use the technology while their teaching pedagogy remaining unchanged. The final stage involves teachers changing their pedagogy to becoming a facilitator of student learning. The students are also technical experts at using an IWB and are collaborating with each other to achieve their learning goals. IWBs, in particular are being used with whole class groups and for Numeracy and Literacy (Higgins et al., 2005)

The key features of effective professional development are the content, type and duration of activities, the learning processes and the teacher responses (Timperley et al., 2007; Desimone 2009). There is, however, limited research on professional development to integrate technology, especially in reference to the integration of IWBs in a classroom. 
Vygotsky's (1978) socio-cultural theory was also discussed to show why it is an appropriate framework for professional development. According to Vygotsky (1978), social interaction is the basis for learning. As most models of professional learning include some form of social interaction, socio-cultural theory is appropriate when designing effective professional development. In addition, the IWB can be seen to be a mediating tool in interactions between the teacher and students and teachers and colleagues.

The following chapter describes the methodology used in my research. 


\section{CHAPTER 3}

\section{Methodology}

\subsection{Introduction}

Chapter three outlines the methodology used in this qualitative case study, which examined the context, interactions and individual perspectives of primary classroom teachers using an (IWB). Sociocultural theory provided the theoretical framework to analyse the data. This was also used to explain teachers' professional development and their learning processes of how to use an IWB with their class. I collected data through: a national survey of primary teachers who had an IWB in their classroom and ten of these teachers' principals, non-participant observations and semi-structured interviews with three case study teachers; and their documentation.

\subsection{The research questions}

My key research question was:

- How does professional development impact on teachers' use of an interactive whiteboard (IWB) into a New Zealand Primary classroom?

The following sub-questions were also used to further inform my study:

(i) What form of professional development did the teachers have before and after the installation of the IWB?

(ii) What contextual factors enhance the introduction of an IWB for a teacher learning to use it in their class programme?

(iii) What contextual factors constrain the introduction of an IWB for a teacher learning to use it in their class programme?

(iv) How is an IWB used in the classroom programme? 


\subsection{Qualitative Research}

Qualitative research methods were used extensively in this research. Denzin and Lincoln (2008, p. 4) define qualitative research as:

a situated activity that locates the observer in the world. It consists of a set of interpretive, material practices that make the world visible...it involves an interpretive, naturalistic approach to the world. This means that qualitative researchers study things in their natural settings, attempting to make sense of, or interpret, phenomena in terms of the meanings people bring to them.

The advantages of qualitative research are the multiple methods used to collect data, such as interviewing teachers, observation of teachers, artefacts and documents, all of which contribute to a holistic perspective and an understanding of the IWB phenomena being studied (Denzin \& Lincoln, 2008). Furthermore, these techniques provide the means to study a phenomena or behaviour in a natural and authentic setting. Using a qualitative approach enabled me to share the experiences and perspectives of teachers learning to use an IWB in their classroom. It provided a rich description of the contextual features that enhanced and constrained the introduction of an IWB in a New Zealand primary classroom. As stated by Denzin and Lincoln (2008), "qualitative researchers are more likely to confront and come up against the constraints of the everyday social world. They see this world in action and embed their findings in it" (p.16). The identification of these features also ensured a balanced perspective in my study of teachers' use of an IWB in the classroom.

My key research question required investigation into how professional development impacts on teachers' use of an IWB. According to Yin (2003), how a researcher defines the problem and its questions determine a study's design. He states that research asking '...'how' and 'why' questions are likely to favour the use of case studies, experiments, or histories" (p.6). Yin (2003) suggests these as being appropriate research methods because these questions can help the researcher to explain what is being studied. 'How' and 'why' questions are the focus of this study, using a case study approach. 


\subsection{Case study}

A case study was appropriate for this small scale research investigation. Merriam (1998) defines a case study as "an intensive, holistic description and analysis of a single entity, phenomenon, or social unit", with the defining feature being the "case as a single entity, a unit around which there are boundaries" (p. 27). A case study involves the systematic collection of qualitative and quantitative data about what or who is being studied, using multiple sources of evidence and methods of data collection. There are three special features of case study that made it particularly suitable for my study. Firstly, it is particularistic as it focuses on one particular aspect of the situation or phenomenon, which for my case study was the way the IWB was used in the classroom by the teacher. Next it is descriptive: my observations and interviews allowed me to gather a rich and thick description of how an IWB was being used in a classroom. Finally, it is heuristic: the case study provided me with a further understanding of the technological phenomenon of the IWB and the impact of professional development on its use. When deciding whether to use the case study method Yin (2003) points out that "in general, case studies are the preferred strategy...when the focus is on a contemporary phenomenon within some real-life context" (p. 1). This fitted my research as IWBs are a contemporary phenomenon and part of my study was carried out in the real-life context of a classroom.

A characteristic of case study methodology is the use of various methods to collect data. Yin (2003) states that there are six major sources of evidence used in a case study: documentation, direct observation, participant observation, interview, archival records and physical artifacts. These sources are "highly complimentary and a good case study will therefore want to use as many sources as possible" (Yin, 2003, p. 85). In this investigation, therefore, I used the following sources of evidence: survey, direct observations, interviews, documentation and archival log, which are discussed below. 


\subsection{Main Sources of Data Collection}

\section{Survey}

A survey, in the form of a national postal questionnaire, was sent to schools with IWBs and their principal. According to Denscombe (2007), the advantages of a survey are the empirical data it produces from real life observations, its wide breath of coverage, which means it is more likely to be representative, and generalisations made about the population sampled. In addition, the cost of a survey can be relatively low compared to other strategies, such as experiments. More significantly, a survey can be organised for a quick return of the data.

The questionnaire used in my study was a combination of open and closed questions. Open questions allowed the respondents to express their own views and feelings about using an IWB in rich variety of detail. Closed questions were designed to provide information such as demographic data about the participants and the curriculum areas the IWB was used in.

One of the reasons for using a survey was to find out what form of professional development teachers were given when IWBs were introduced into their classroom and how they were being used throughout New Zealand. Principals were surveyed to provide another source of data on why and how IWBs were being installed in New Zealand primary schools. Before sending out the survey I carried out a pilot study with three former colleagues. They did not participate in the final survey.

As IWBs are relatively new to New Zealand schools it was necessary to first locate the schools using them to ensure that a survey could be carried out for this research. The New Zealand Ministry of Education does not keep a national database of schools with IWBs. On the recommendation of my university lecturer whose area of expertise is ICT, I contacted COREeducation in Christchurch where the national facilitators for primary ICT professional development are based. The national facilitator for primary 
Information and Communication Technology Professional Development (ICTPD) gave me permission and a password to access the ICT cluster homepages listing schools using an IWB, twenty-nine in total. She also gave me the contact person for another region, who provided me with the names of six more schools with an IWB. My local ICT advisor also gave me a list of fifteen schools in my region that use an IWB.

I sent e-mails to four ICT advisors in two large urban centres asking if they knew which schools in their area had an IWB. One advisor replied with the names of two schools with an IWB. I was advised by one ICT advisor to contact IWB suppliers for the names of schools with an IWB. One supplier, for example, offered me the opportunity to advertise in their monthly online newsletters for schools to participate in this research, requiring ethics permission. The time involved in gaining such permission would have held up my research, without any guarantee of procuring schools to participate, so I decided not to pursue this option. At the end of my investigation I had the names of fifty-two schools throughout the country that had IWBs. Once ethical permission was granted e-mails were sent to the principals of schools asking for their permission to send a postal survey to teachers with an IWB in their class. Principals were also asked to forward the e-mail to any other schools they knew of with IWBs. Attached to this e-mail were the following:

- Information Sheets for the principal and teachers, which provided background information about the study and its purpose. (see Appendices A, B)

- an Information Sheet (see Appendix C) about the case study so that possible participants would know what was involved and what would be required from them as a participant. Teachers were given the option of participating in the case study, which would involve a day's observation in his/her classroom, an interview, keeping a log of IWB use and providing copies of school documents such as class timetable and school policies.

- a questionnaire for principals (see Appendix D).

- a questionnaire for teachers (see Appendix E). 
Teacher and principal questionnaires were sent out to those who requested a hard copy of these, along with a self addressed envelope for the return of the questionnaire to the researcher. Questionnaire respondents were asked to return the questionnaire in two weeks time. A week later the same e-mail, with attachments, was re-sent. After a two week period I telephoned the schools who had not replied to the e-mails. In total sixty-nine teacher questionnaires were sent out and fifty-three were returned. Twenty principals indicated that they would print out the teacher questionnaires and twelve of these were returned. Overall, sixty-five teacher questionnaires were returned with twenty-one teachers indicating that they were willing to participate in my study.

\section{Selection of teachers}

Three teachers were selected to be involved in my case study using the following criteria:

- Proximity to researcher's city.

- The amount of time they have had an IWB in their classroom.

- The need to be from three different schools and clusters.

- Teaching at a Year One or two levels (provided there were a high enough number of volunteers at this level).

This criterion for selection of participants was to provide, as much as possible within the scope of this research, a cross section of teacher experiences in terms of professional development and use of an IWB in a classroom.

I chose the Year One or Two levels because that was my level of teaching experience with an IWB. I believed this would be advantageous for understanding the purpose of activities observed and the range of skill level of the children that I would be observing using an IWB. 
Twenty-one teachers volunteered to participate in my study, of which twelve were teaching at the Year One or Two levels. Using the set criteria I selected two volunteers in my area in the North Island and one from the South Island.

Once I selected the teachers, I contacted them by e-mail to confirm their participation and sent out a Consent Form for the principal and teacher to sign (see Appendices F, G). I then arranged by e-mail, a suitable time with each teacher to visit for a day's observation. When a date had been confirmed by the teacher, I sent them an Information Sheet for parents and students, a parent Consent Form and a student Consent Form (see Appendices $\mathrm{H}, \mathrm{I}, \mathrm{J})$. The teachers agreed to hand out and be responsible for collecting these, prior to my visit.

\section{Observations}

Observations were a main source of data collection. They were an ideal way to examine how things happen first hand, allowing the researcher to "better able to understand and capture the context within which people interact. Understanding context is essential to a holistic perspective" (Patton, $2002 \mathrm{p}$. 262). This meant that I did not have to rely on someone else's interpretation of an event or setting and perhaps noting 'routine' things that would not otherwise be picked up or mentioned as relevant. The type of observation I used for my study was non-participation. As a non-participant observer my focus was on observing the teacher and the children using the IWB. Being a participant observer and participating in the lesson would have detracted from the focus of the observation as I would have been interacting with pupils and the teacher (Patton, 2002).

I observed each teacher over one day. Observation of a 'normal' day in a class, following its usual daily programme, gave me the opportunity to observe an IWB being used in a real-life context, rather than one off demonstrations of an IWB use. The day's observation showed how each teacher used an IWB in the classroom programme and to what extent they utilised its interactive functions. I also identified the areas of the curriculum 
where the IWB was being used. The data collected from these observations informed the research questions about how the IWB was used in the classroom and in what ways training and professional development had impacted on each teacher's use of an IWB. These observations objectively confirmed and verified answers given in the survey by the case study teachers.

When carrying out any observations there is an issue of perception. It is possible that personal factors may influence the researcher's perceptions of a situation, which may make the data collection unreliable (Patton, 2002). To ensure that any misperceptions were corrected an interview with each of the teachers at the end of the observations was also carried out to confirm and validate my observations. The observations of the three case study teachers were carried out over a two week period.

\section{Interviews}

At the end of the classroom observation each teacher was interviewed to gain some insights into her thoughts and attitudes about what was observed, how and why the IWB was used in the classroom and the professional development she had received to use one. The interviews I carried out were semi-structured (see Appendix $L$ for the interview schedule). In such an interview, "a framework is established by selecting topics on which the interview is guided...certain questions are asked, but respondents are given freedom to talk about the topic and give their views in their own time" (Bell, 2005 , p. 161). The interview was also used to clarify or extend on the teachers' responses in the survey. The value of these interviews was the depth of information given specifically about lessons observed using the IWB, the benefits and constraints of using this technology and the professional development experienced. The teachers were able to explain their feelings and identify what they believed to be critical factors in the integration of an IWB in the classroom (Denscombe, 2007). All interviews were audio recorded and transcribed. The transcription was then returned to each teacher for checking to ensure that they were happy with what was written 
and provide them with the opportunity to make any changes or clarifications. One teacher made clarifications regarding the spelling of labels.

\section{Documents}

Documentation is another source of data collection that was used in this research. Yin (2003) points out that "the most important use of documentation is to corroborate and augment evidence from other sources" (p.87). School documentation including copies of class timetables and the school ICT policy were used to provide a further source of information for the triangulation of data. Only three principals provided a copy of their school's ICT policy. All ten principals said they did not have a professional development policy.

The teachers in the case study were also asked to keep a log listing which curriculum areas they use the IWB in (see Appendix K). This information was corroborated by the direct observations that I undertook.

\subsection{Ethical Considerations}

This study followed the guidelines of Victoria University of Wellington Human Ethics Policy (2003). Ethical protocol was followed to ensure that the identity and interests of the research participants were protected at all times.

\section{Informed Consent}

The premise of informed consent, according to Denscombe (2007), is that people's "participation must always be voluntary, and they should have sufficient information about the research to arrive at a reasoned judgement about whether or not they want to participate" (p.145) To gain informed consent all participants received an Information Sheet explaining the background and purpose of the study and what was required of them. Consent Forms for the principals and teachers answering the questionnaires were not required as the completion and return of the questionnaire was taken as implied consent (Berg, 2004). The principals, teachers, parents and students in the case study received an Information Sheet, and a Consent 
Form. As students are legally considered minors, parental consent was needed from their parents. The student Consent Form was necessary because if they were using the IWB they may have been displaying their work. As I was collecting data on how the IWB was being used there was a possibility that students' work could become part of the data.

\section{The Participants' Rights}

All participants were given the right to accept or decline participation in this research. They were informed that they would be able to ask question about the study at any time and also withdraw from it at any stage. This information was also given to the parents of the children involved in the case study.

\section{Confidentiality and Anonymity}

All information gathered, including the names of all schools, their principal and teachers was kept confidential. The participants were assured that their names and that of their school would not be used anywhere in the research: pseudonyms were given. In relation to the questionnaire, it was generally the principal of the school who requested a certain number of teacher questionnaires to be sent to the school which he/she would then pass on to the teachers. To ensure the confidentiality of the teachers' responses, all questionnaires sent out had a self addressed and stamped envelope for the questionnaire to be returned to me. Furthermore, all participants were informed that access to all research data was restricted to my supervisor and myself as investigator.

\section{Conflict of Roles}

There were two possible conflicts of interest that I needed to be aware of. The first related to the fact that I have had an IWB in my primary classroom for the last two years and this information was on a letter of introduction for all participating teachers. As a researcher I had to resist the temptation, during classroom observations, to comment on how the IWB was being used or suggest using the IWB in an alternative manner. During the interviews I 
needed to remain neutral by not making any responses that may show approval or disapproval in relation to how the teachers were using the IWB in their classrooms. Patton (2002) refers to this researcher stance as 'empathic neutrality', which means the researcher "communicates understanding, interest and caring" (p. 53) towards the research participant whilst retaining a neutral or non judgemental stance at the same time. Each of the case study teachers shared a different perspective in terms of teaching experience, IWB use and professional development, so it was important I portrayed a neutral stance.

The second possible conflict related to the issue of researcher effect (Denscombe, 2007). As the teachers knew well in advance when I was coming to observe them in their classroom, they may have planned to use their IWB in a way different from usual classroom practice. How each teacher used their IWB was triangulated by the questions asked in the teacher survey, a log of IWB use they kept the week before the observation and my observations.

\subsection{Data Analysis}

The five stage process of qualitative data analysis (Denscombe, 2007) was utilised in this study as follows.

\section{Preparation of the raw data}

In order for the raw data to be amenable to analysis it was necessary to collate and organise the data in a systematic manner. The survey responses were the first raw data received in my study and as each survey was returned I gave it a reference number and letter on a register. This also provided a daily update of how many surveys had been returned and from which schools. Using a word document I created a table for each question of the survey and I wrote the respondents' answers to each question with their reference number beside each one. Having the answers on separate pages 
made it very easy to begin coding the data as well as finding significant data when needed later on.

The next form of raw data was field notes taken during the teacher observations. These notes were filed and referenced. The interviews with each teacher were recorded and I transcribed and made backup copies of these in case of loss or damage to the originals.

\section{Familiarity with the data}

By collating the comments from the survey responses on a daily basis I became familiar with the data as I was constantly re-reading each page of responses. By the time I had received the final survey responses I felt very familiar with the content of the survey results and had started to cross reference the answers to notes from my teacher observations and interviews in preparation for interpreting the data.

\section{Interpreting the data}

Qualitative data from the survey, observations, interviews and documents were analysed by a process of category construction. The data from the survey was initially sorted according to the question responses. From this data, common themes were sorted into a category and deeper analysis revealed sub categories, which were coded and labelled. For example, one of the categories was benefits of using an IWB and a further level of analysis provided sub categories of lesson planning, student engagement and motivation, distinct features of IWB technology, efficiency in lesson planning and preparation and the nature of interactions. The next step was to compare these categories and identify any key concepts, patterns or theme among these categories as well as relationships among the categories. Analysing how the categories are linked together sought to develop themes about professional development and its impact on the use of an IWB in the classroom (Merriam, 1998). This was also used to answer the other sub questions of this research. 


\section{Verifying the data}

Due to the qualitative nature of this case study it was imperative that multiple sources of evidence were collected to ensure triangulation occurs, as this facilitates the validation of the data. As Stake (2005) points out, "triangulation has generally been considered a process of using multiple perceptions to clarify meaning, verifying the repeatability of an observation or interpretation" (p. 454). For each of my research questions there were three different sources of evidence being collected so that triangulation would occur and ensured the data would be verified (see Appendix M). Survey, observation, interview strategies and documentation were used in this study to gather data and ensure triangulation. Although the data was mainly qualitative there were aspects of quantitative data from the survey, IWB use $\log$ and the direct observations. This related to teaching experience, teaching level, years of IWB use, and the areas of the curriculum in which an IWB was used.

The validation of data in a study is also connected to the question of external validity or generalisation of the findings. As qualitative case study research is often based on a small intensive study, it raises the question of how the researcher can generalise findings on the basis of such a small number of cases. Lincoln and Guba suggest an approach that looks at the 'transferability' of the findings: using the information in the study the reader asks the question "to what extent could the findings be transferred to other instances?" (1985, cited in Denscombe, 2007, p. 299). Using this approach I provided sufficient detail for the reader to be able to transfer the findings to other instances and the significant factors that enhance or constrain the introduction and integration of an IWB have been identified. Rich description of the factors and the context of each case are detailed. This will provide readers with the information needed to compare or apply the findings to their own situation or other similar situations if they choose to do so. In this manner the issue of generalisation was addressed. 


\section{Representing the data}

Denscombe (2007) argues that because qualitative data is largely based on words or images, and has a complicated process of data analysis, it provides a challenge for the researcher to present it in a concise and convincing manner. Researchers need to take on an editor's role. This thesis has undergone several drafts in an effort to present the most significant findings and themes that emerged from the data.

\subsection{Chapter Summary}

This chapter has provided the methodology for this study outlining the approaches and methods used in order to answer the research questions. Ethical considerations were discussed and the procedure for analysis of qualitative data was identified. The following two chapters present the findings from the survey which was carried out as part of my study. 


\section{CHAPTER 4 \\ Survey Results Part 1}

\subsection{Introduction}

Chapter four examines the results of the two surveys that were carried out for this study relating to professional development and teachers using an IWB. The purpose of the principals' survey was to provide another prospective on the provision of an IWB in a classroom, the professional development provided to teachers in their school, learning to use an IWB and the benefits they perceive having one in a classroom. Nine principals consented to completing a survey and returned the questionnaires for a $100 \%$ response rate. When relevant the results from the principals' survey will be included in the same section as the teachers' survey.

In order to understand the context of my study, the background of the teacher respondents are outlined, including years of teaching experience, class level taught, experience teaching with an IWB and their professional development experiences. The questionnaire results are then explored.

\subsection{Survey responses}

As described in chapter three, forty-nine schools were contacted throughout New Zealand, from Southland to Auckland. Questionnaires were then sent out after gaining permission from the school principal to twenty-four schools. Some schools chose to print out the questionnaires rather than have them sent out and these were recorded as teacher or principal 'self printed'. According to Burton (2000) and Ruane (2005), a common response rate for postal questionnaires is twenty to thirty percent. Of the eighty nine questionnaires sent out in this study a total of sixty-five teacher questionnaires were returned, a very good $73 \%$ response rate. Interestingly, teachers electing to print out the questionnaire had the lowest return response. A summary of the survey responses from the teachers and principals is presented below (see Table 1). 
Table 1: Survey response

\begin{tabular}{|c|c|c|c|c|c|c|}
\hline \multirow[b]{2}{*}{ Area } & \multirow[b]{2}{*}{$\begin{array}{c}\text { Schools } \\
\text { contacte } \\
\text { d }\end{array}$} & \multirow[b]{2}{*}{$\begin{array}{l}\text { Schools } \\
\text { respond } \\
\text { yes }\end{array}$} & \multicolumn{2}{|c|}{$\begin{array}{l}\text { Posted } \\
\text { questionnaires } \\
\text { returned }\end{array}$} & \multicolumn{2}{|c|}{$\begin{array}{l}\text { E-mailed and self } \\
\text { printed } \\
\text { questionnaires } \\
\text { returned }\end{array}$} \\
\hline & & & Teacher & Principal & $\begin{array}{l}\text { Teacher } \\
\text { printed }\end{array}$ & $\begin{array}{l}\text { Principal } \\
\text { printed }\end{array}$ \\
\hline Southland & 6 & 4 & $11 / 14$ & $2 / 2$ & $0 / 4$ & 0 \\
\hline Otago & 3 & 2 & $2 / 2$ & $1 / 1$ & $3 / 3$ & 0 \\
\hline Christchurch & 2 & 0 & $0 / 0$ & $0 / 0$ & $0 / 0$ & 0 \\
\hline Upper Hutt & 4 & 2 & $1 / 1$ & $1 / 1$ & $3 / 7$ & $1 / 1$ \\
\hline Kapiti/Otaki & 6 & 2 & $2 / 4$ & $1 / 1$ & $0 / 0$ & 0 \\
\hline Wellington & 2 & 2 & $4 / 4$ & $0 / 0$ & $2 / 2$ & 0 \\
\hline Taranaki & 2 & 1 & $1 / 1$ & $1 / 1$ & $0 / 0$ & 0 \\
\hline Hawkes Bay & 4 & 4 & $18 / 23$ & $1 / 1$ & $0 / 0$ & 0 \\
\hline Gisborne & 1 & 1 & $10 / 13$ & $0 / 0$ & $0 / 0$ & 0 \\
\hline Rotorua & 5 & 4 & $3 / 7$ & $1 / 1$ & $0 / 0$ & 0 \\
\hline Hamilton & 3 & 1 & $1 / 1$ & $0 / 0$ & $0 / 0$ & 0 \\
\hline $\begin{array}{l}\text { Thames/ } \\
\text { Coromandel }\end{array}$ & 6 & 0 & $0 / 0$ & $0 / 0$ & $0 / 0$ & 0 \\
\hline Auckland & 5 & 1 & 0 & $0 / 0$ & $4 / 4$ & $1 / 1$ \\
\hline Totals & 49 & 24 & $53 / 69$ & $8 / 8$ & $12 / 20$ & $2 / 2$ \\
\hline
\end{tabular}

Although Auckland is our largest city, only a very low number of schools were contacted. The two ICT advisors contacted there unfortunately did not respond to my request for information as to which schools in their area had an IWB.

\section{Background of respondents in teacher survey}

Respondents provided information on their years of teaching experience, the class level they taught and the length of time teaching with an IWB. These are discussed below. 


\section{Years of teaching experience}

Teaching experience varied among the respondents, as illustrated in the table below.

The two largest groups taught between 1 to 5 years (24\%) and 6 to 10 years (26\%).

Teaching experience and the use of new technology are examined later in this chapter in relation to the stages of IWB use.

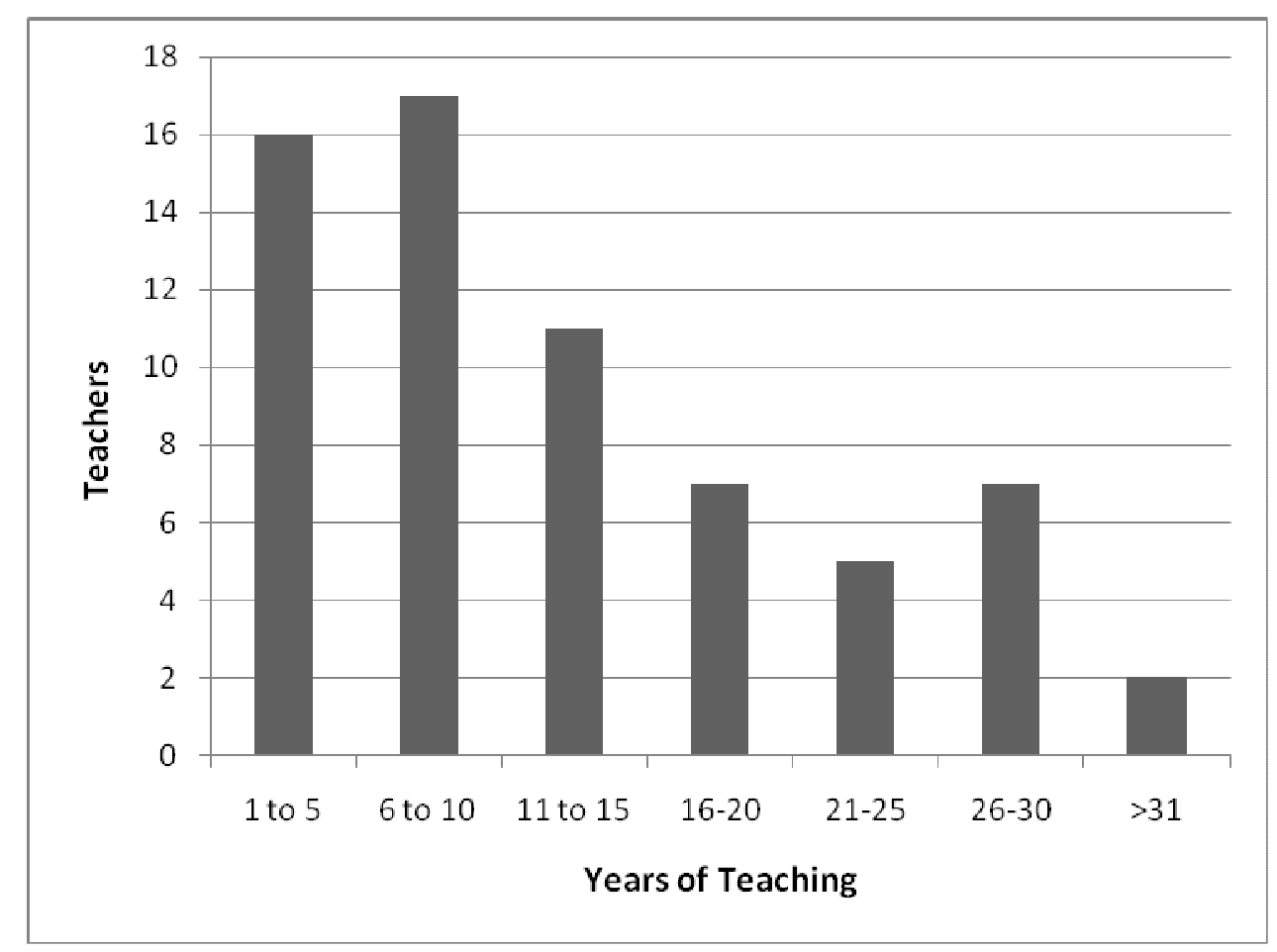

Figure 1: Years of teaching practice

\section{Class level taught}

The data revealed that $41 \%$ of the respondents taught at $\mathrm{Y} 0 / 1 / 2$ (see Figure 2). This was surprising as most of the literature reviewed involved studies of older children in their fourth year or above of primary schooling rather than the first two years of schooling. (See, for example, Higgins et al, 2005; Gillen, Staarman, Littleton, Mercer \& Twiner, 2007; Wood \& Ashfield, 2008.) 


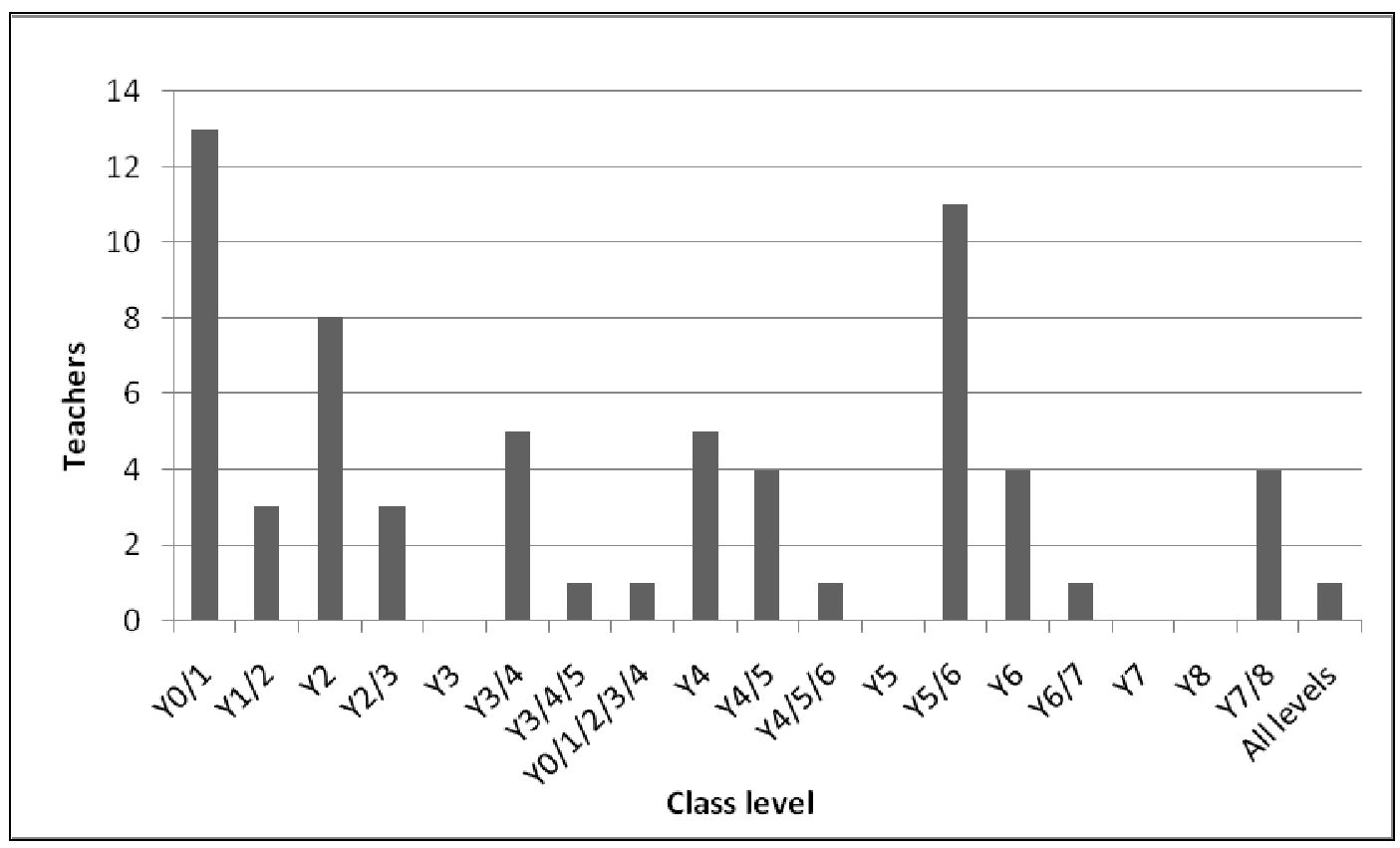

Figure 2: Class level of teachers with IWB

\section{IWB teaching experience}

Respondents were asked to state how long they had been teaching with an IWB and to rate their skill level, using the stages identified by Beauchamp (2004) (see chapter 2). The results indicated a wide variance among respondents, summarised in Table 2. 
Table 2: Stage of IWB use

\begin{tabular}{|c|c|c|c|}
\hline $\begin{array}{c}\text { Time } \\
\text { teaching with } \\
\text { an IWB }\end{array}$ & Respondents & Stage of IWB use & $\begin{array}{c}\text { Number at that } \\
\text { stage }\end{array}$ \\
\hline $0-6 m t h$ & $\begin{array}{l}n=10 \\
(16 \%)\end{array}$ & $\begin{array}{l}\text { Black/white board subs } \\
\text { Apprentice } \\
\text { Initiate } \\
\text { Advanced } \\
\text { Synergistic }\end{array}$ & $\begin{array}{l}1 \\
4 \\
3 \\
1 \\
1\end{array}$ \\
\hline $7-12 \mathrm{mths}$ & $\begin{array}{l}n=6 \\
(9 \%)\end{array}$ & $\begin{array}{l}\text { Black/white board subs } \\
\text { Apprentice } \\
\text { Initiate } \\
\text { Advanced } \\
\text { Synergistic }\end{array}$ & $\begin{array}{l}0 \\
0 \\
3 \\
1 \\
2\end{array}$ \\
\hline 13-18mth & $\begin{array}{c}n=21 \\
(32 \%)\end{array}$ & $\begin{array}{l}\text { Black/white board subs } \\
\text { Apprentice } \\
\text { Initiate } \\
\text { Advanced } \\
\text { Synergistic }\end{array}$ & $\begin{array}{l}0 \\
4 \\
7 \\
9 \\
0\end{array}$ \\
\hline 19-24mths & $\begin{array}{c}n=6 \\
(9 \%)\end{array}$ & $\begin{array}{l}\text { Black/white board subs } \\
\text { Apprentice } \\
\text { Initiate } \\
\text { Advanced } \\
\text { Synergistic }\end{array}$ & $\begin{array}{l}0 \\
0 \\
3 \\
2 \\
1\end{array}$ \\
\hline$>2$ yrs & $\begin{array}{c}n=22 \\
(34 \%)\end{array}$ & $\begin{array}{l}\text { Black/white board subs } \\
\text { Apprentice } \\
\text { Initiate } \\
\text { Advanced } \\
\text { Synergistic }\end{array}$ & $\begin{array}{c}1 \\
1 \\
3 \\
12 \\
5\end{array}$ \\
\hline
\end{tabular}

According to Somekh et al (2007), it takes two years of classroom use of an IWB for it to become embedded in teacher pedagogy. This appears to be reflected in the self ratings of those twenty-two teachers with two or more years of IWB use. Of these teachers, $55 \%$ rated themselves at the advanced level of use (the teacher involves the students in using the IWB and shows a high level of skill in using the software) and $23 \%$ at the synergistic level of use (the teacher and students are interacting together using the IWB to achieve learning objectives).

Interestingly, there was a variation in stages of use of an IWB by teachers at the same school, even though they both had one for 7-12 months, they rated themselves differently using it. One respondent (R43) self rated her level of 
use at initiate, while the other respondent (R42) placed herself two stages ahead at synergetic, the highest level in stages of IWB use. In order to explain possible reasons for this difference I looked at the training and professional development they had received and compared their responses to the related questions. When both respondents moved into their classrooms there was no IWB. Only the synergistic user (R42) was given the choice to have one or not and there was only one place the IWB could be positioned. The initiate user (R43), however, was not consulted on where she would like the IWB to be.

Both the initiate (R43) and synergistic (R42) respondents had training before the IWB was installed, from the IWB supplier, colleagues and the school ICT co-ordinator. Their training is on-going. The synergistic user (R42) had been released during the school day for training but the initiate user (R43) had not. Both respondents mentioned ICT conferences specifically for IWB users as being the most helpful form of training received. The initiate user (R43) also identified discussions with colleagues and useful ideas from them as being helpful too.

Next I examined the two respondents' responses to the questions related to teacher pedagogy. Sweeney (2008) believes that whilst there is no time limit for teachers to move through each stage of IWB use, in order to move beyond the first three stages, there needs to be a change in their pedagogy that increases learner autonomy. The synergistic user (R42), for instance, related what she liked most about using an IWB and its benefits:

...Students creating ownership of their learning, interactivity and
kinaesthetic attributes...interactive practice, ownership of learning,
focused learning/engagement, inventiveness, energy and
excitement (R42).

Her response seem to indicate she has moved on, changed her pedagogy and is focused on her students taking an active role in deciding how they will use the IWB to achieve their learning objectives. This is one of the pedagogical indicators of the synergistic stage of IWB use (Sweeney, 2008). The initiate user (R43), on the other hand, stated the benefits as being 
additional resources, an added visual tool to use as a resource within the classroom. She did not mention learner autonomy in any form. In agreement with Sweeney (2008), this could explain why she has not progressed past the initiate stage of IWB use.

Another important factor identified from the data collected was motivation. One respondent, who had an IWB for six months in the classroom, stated this was a factor in learning to use an IWB. I am in need of $P D$ to get to the next step. PD may not happen as soon as possible. Hopefully momentum and enthusiasm aren't lost. (R27) When the IWB was installed in her classroom she had had twenty minutes of training from a colleague. Neither Beauchamp (2004) nor Sweeney (2008) consider motivation as a factor in their research.

\section{Time teaching with an IWB related to years of teaching experience}

I also examined whether the teachers' years of teaching experience and the stage of IWB use mattered. Mouza (2006) found this relationship was a critical variable in teachers changing their practice with the use of new technology because beginning teachers "experienced more challenges in their efforts to use technology because they still felt overwhelmed with the daily demands of teaching and lacked a clear familiarity with the curriculum and other aspects of schooling" (p.436). Thirty-nine respondents rated themselves as advanced users and, of these, $80 \%$ had six or more years of teaching experience. Fourteen percent of respondents were at the highest stage of IWB use: synergistic. Of these, $78 \%$ had six years or more teaching experience. These results indicate that years of teaching experience may be a critical factor in using an IWB, an important consideration when deciding who should have one in their classroom.

\subsection{Professional development and training to use an IWB}

According to Mouza (2006), professional development in the form of training is often used when introducing a new technology. Guskey (2000) cites training as one of seven models of professional development and states that 
it "typically involves a presenter or a team of presenters that shares its ideas through a variety of group based activities" (p. 22). Further research has shown that the timing, duration and intensity of professional development impacts on its outcome and may also influence how quickly teachers move through the stages of IWB use (Beauchamp, 2004; Sweeney, 2008). Respondents, therefore, were asked to comment on their IWB training in relation to timing, duration and intensity of these experiences, which are discussed below.

\section{Timing of training}

Seventy-two percent of respondents received some form of training before or as soon as an IWB was installed in their classroom. Eight percent received some form of training a week to a month after it had been installed, while $14 \%$ received some form of training a month or more afterwards. A small number, $6 \%$, received no training at all, with one commenting if the technician installing the IWB hadn't still been in my room when I got back, I would not have known how to switch on the IWB and I wasn't having a training session until next term (R17).

The training for most of the respondents was done predominately in their own time. Forty percent were released from their classroom to undergo training while $60 \%$ were not. Of those who were not released, $82 \%$ had training during their lunch hour or after school, $17 \%$ attended training in the school holidays and $1 \%$ attended training at a Teachers' Only Day. One respondent emphasised that: it would be great to receive CRT release for $P D$ in Active boards rather than after school. Time is a huge factor (R63).

\section{Duration of training}

Receiving some form of training before having an IWB installed in your classroom would appear to be sound practice. However, in reality the duration and intensity of the training experienced by the respondents presented a different picture: 
Table 3: Duration and intensity of training

\begin{tabular}{|c|c|c|c|}
\hline Number of sessions & Duration & Respondents & \\
\hline 1 & $\begin{array}{l}20 \text { mins } \\
1 \text { shared hour } \\
2 \text { hrs } \\
1 \text { day } \\
\text { not stated }\end{array}$ & $\begin{array}{l}1 \\
1 \\
1 \\
1 \\
2\end{array}$ & $(n=6)$ \\
\hline 2 & $\begin{array}{l}1 \text { - } 2 \text { hr } \\
3 \text { hrs } \\
1 \text { day }\end{array}$ & $\begin{array}{l}7 \\
1 \\
1\end{array}$ & $(n=9)$ \\
\hline 3 & $\begin{array}{l}1 \mathrm{hr} \\
2 \mathrm{hr} \\
3 \mathrm{hr}\end{array}$ & $\begin{array}{l}1 \\
3 \\
1\end{array}$ & $(n=5)$ \\
\hline 4 & $\begin{array}{l}30 \mathrm{mins}-1 \mathrm{hr} \\
3 \mathrm{hrs} \\
1 \text { day }\end{array}$ & $\begin{array}{l}2 \\
5 \\
1\end{array}$ & $(n=8)$ \\
\hline is on-going & stated in 2 replies & 37 & $(n=37)$ \\
\hline not answered & & 2 & $(n=2)$ \\
\hline
\end{tabular}

Table 3 shows that the duration and intensity of training varied widely from one session of twenty minutes to the most intensive of four one day sessions. The most common type of training was two sessions of one to three hours. On-going training, for instance, was described by two respondents as with colleagues (R9) and continuous questions of our school ICT co-ordinator. He also gives training for 30 mins about once a month at staff meetings (R13).

\section{Intensity of training}

It would seem that training sessions to use an IWB for survey respondents were at low level of intensity. This means training sessions were predominately spent as a part of a group watching a trainer use the IWB as described by one respondent who said help from IWB supplier was good but was in a group and lots of information was given out (R9). This type of group ICT training aims to give as much information as possible to a large number of participants and is known as 'just in case' training. Hixon and Buckenmeyer (2009) define this as a one-size-fits-all model of technology training and suggest it is not sufficient for the integration of new technology 
into a classroom programme. They contend that 'just in time' technology training relevant to individual needs should be provided. Guskey (2000) also argues that "the major shortcoming of training is that it offers few opportunities for choice or individualisation. Hence it may not be appropriate for the varied levels of educators' skills and expertise" (p23).

A possible explanation for the low intensity of training was provided by one of the case study teachers, who explained in her interview that the purchase of an IWB included four sessions of three hours, spread over four terms from the IWB supplier.

\section{Most useful form of training}

The questionnaire listed different forms of training to cater for all the possible training experiences of the respondents. Ninety-two percent of the respondents had training from their IWB supplier; for some this was as a group while for others this involved one to one training. Other training on how to use the IWB came from colleagues (n31), School ICT co-ordinator (n27), On-line training (n2), and conference/audio call (n2). (Respondents were able to select more than one form of training.)

Sixty-three out of sixty-five respondents identified colleagues as being the most useful form of training stating that:

- help from colleagues is invaluable as you learn immediately (R9)

- Working 1-1 with school ICT co-ordinator and observing colleagues when they're using the IWB. (R13)

- I learnt a little from the training sessions but usually forgot what to do when I wanted to apply it, so was able to ask an 'expert' teacher on the staff." (R61)

The next most useful form of training was considered to be one to one training (16\%) and then 'hands on' (11\%) practice of using the IWB outside of the class timetable to become familiar with its tools and software. Mouza (2006) recommends that professional development on the use of new 
technology should "provide intensive hands-on training to increase technological competence. Novice users will not experiment with technology in their classroom unless they feel comfortable with the equipment" (p.437). The comments of some respondents certainly reflected this need for hands on training:

- Hands on-actually using it (R10)

- Consultation with colleagues as and when needed after the initial training sessions. Time is needed to use and practise different techniques before moving on. Too much, too soon is confusing.(R1)

- Release time for demonstrations and follow up release time to try out new things we learnt.(R21)

Observing teachers using an IWB in their classroom or hearing ideas on how to use the IWB (13\%) was also considered to be useful training. Others mentioned conference sessions, ICT PD cluster activities and using the internet to share ideas and access resources.

\section{Principals' response to the training}

Eight of the nine principals said their school had a training programme provided by the IWB supplier for teachers to learn how to use an IWB. This was included in the purchase price of the IWB. The one school that did not have any training said that was because they could not afford the cost of it.

When asked to evaluate the training programme, four of the nine principals said if they were to introduce an IWB into their school again they would change the training programme. This was illustrated by the following comments:

- Explored the tools of other IWB companies. This issue is quite big and schools that are new to the game are at the mercy of the company and their agents. Our company had huge UK resources which I found unsuitable for NZ classes (P4).

- More time and more 1-1 (P5).

- Allow initial training then ask the trainers to meet the needs of the teachers on a regular basis rather than one-off group 
training assuming that everyone is at the same stage in their training (P6).

These reflect the preference for more intensive training and 'just in time' technology training to meet teachers' individual needs rather than 'just in case' training for groups.

The most useful forms of training, then, for teachers' learning to use an IWB appears to be a mixture: training from colleagues, one-to-one intensive training, hands on and observing others. Respondents' comments are in agreement with Guskey (2000) who asserts, "training sessions also must be extended, appropriately spaced, or supplemented with additional follow-up activities to provide the feedback and coaching necessary for the successful implementation of new ideas" (p.23). In addition, it appears that both the teacher and principal respondents would like 'just in time' technology training rather than 'just in case' technology training.

Both intensive and 'just in time' training is supported by research as contributing to effective training (Mouza, 2006; Hixon \& Buckenmeyer, 2009).

\subsection{Form of professional development activities}

Teacher respondents were also asked what form of professional development they had to help them learn how to use the IWB in their classroom. This was to establish what types of activities were provided for professional development as well as the content. Kennedy (1998), Timperley et al. (2007), Mishra and Koehler (2006) and Wayne et al. (2008) all assert that it is the actual content of the professional development that is critical not the activity. Mouza (2006) specified exactly what this content should be: knowing how to use the technology and its software, pedagogical knowledge which is knowing how to integrate the technology into the classroom programmes and pedagogical content knowledge that combines both the technical knowledge and specific subject knowledge. 
The respondents were asked to rank the forms of professional development they had experienced from 1-6, with 1 being the most valuable. The results are as follows:

Table 4: Professional development experienced

\begin{tabular}{|c|c|c|c|}
\hline Form of professional development & \multirow{2}{*}{\begin{tabular}{l} 
Respondents who \\
had experienced \\
this form of \\
professional \\
development \\
(N=65) \\
\multicolumn{1}{c}{30}
\end{tabular}} & \multicolumn{2}{|c|}{$\begin{array}{l}\text { Number of } \\
\text { respondents } \\
\text { (N58) who ranked } \\
\text { this as most } \\
\text { valuable at (1) }\end{array}$} \\
\hline $\begin{array}{l}\text { Visits to other classes/schools using } \\
\text { an IWB for lesson observations/ } \\
\text { modelling. }\end{array}$ & & $(n=17)$ & $29 \%$ \\
\hline Collaboration with a colleague & 45 & $(n=15)$ & $26 \%$ \\
\hline $\begin{array}{l}\text { External expert visiting and } \\
\text { demonstrating in your class }\end{array}$ & 30 & $(n=19)$ & $33 \%$ \\
\hline $\begin{array}{l}\text { Participation in a professional } \\
\text { community, school based or } \\
\text { community based }\end{array}$ & 21 & $(n=7)$ & $12 \%$ \\
\hline Reading current research & 17 & 0 & \\
\hline $\begin{array}{l}\text { Other (please state) } \\
\text { - using the internet } \\
\text { - ICT conferences } \\
\text { - Books } \\
\text { - Post graduate study }\end{array}$ & 7 & 0 & \\
\hline
\end{tabular}

The type of activities chosen by the respondents as being most valuable were those that related to their actual classroom lessons: having an external expert visiting and demonstrating in your classroom and observing other teachers to get ideas on how to use the IWB in specific curriculum areas. As Guskey (2002) puts it, "teachers tend to be quite pragmatic. What they hope to gain through professional development are specific, concrete, and practical ideas that directly relate to the day-to-day operation of their classrooms" (p.382). By way of illustration when teachers are being shown how to use the 'hide and reveal' tool on the IWB, they want to know how it could be used, for instance, in their reading programme. 
These preferences, whereby teachers are learning in a collaborative manner with experts and colleagues and building on from what they learn from each other again, clearly demonstrates Vygotsky's (1978) socio-cultural theory, in particular the Zone of proximal development (ZPD) at work. A ZPD is created by a more capable user of an IWB, for example, an external expert or colleague interacting with the teacher learning to use the IWB and leading the teacher to a new level of potential development or in this instance higher skill level of IWB use. This occurs firstly under guidance and once the teacher internalises the new learning it becomes an independent process.

\section{Sustainability of professional development}

The need for sustainability of professional development in the use of an IWB was stated by many of the respondents, including those who had been using one for more than a year. Sustainability has been identified as an effective feature of professional development. For instance, Timperley et al. (2007) found providing for an extended timeframe that emphasised the process of changing teacher practice as iterative rather than linear (57\% respondents said their training was on-going) was a necessary element for effective professional development. In agreement, Garet et al. (2001) state that "professional development is likely to be of a higher quality if it is both sustained over time and involves a substantial number of hours" (p.933).

Respondents, too, recognised the need for on-going professional development. The following comments illustrated this:

- Now that I am familiar with the everyday use of IWB I would be interested in attending a more intensive training seminar with opportunity for 'hands on' experience, observation of skilled practitioners at work with children and some collaboration with classroom practitioners. (R1)

- PD needs to be on going so that as you learn more you will want to do more \& so you need further PD. (R4)

- l'd really appreciate seeing one used by someone further down the track. I want to explore usage, but time is a limiting factor.(R20)

- PD needs to be ongoing and aimed at the right level. Need to have motivated and interested teachers in schools to get IWBs first \& not just one in a school! (R45)Z 
- It's an on-going commitment-keep talking to colleagues, going to workshops, putting ideas into practice, more discussion and trying new things. (R56)

My personal experience certainly echoes the statements above. After my first year of using an IWB in my classroom I had established some 'routine' uses for it in literacy and numeracy. By the end of the second year, however, I felt I was no longer exploring new uses. In my school, the staff with an IWB collaborated informally with each other when we had tried something new on it, but this was not a regular occurrence. While carrying out the case study observations I did reflect on how useful such visits would have been in my second year of IWB use when I was in need of professional development to move up to the next stage.

\section{Principals' response to the professional development}

As with the training to use an IWB, the professional development programme at schools was included in the purchase price and provided by the IWB supplier to eight out of the nine schools. This inclusion obviously impacted on the choice of supplier for one school whose principal said professional development had been negotiated with the suppliers of the IWB and was a major influence on the provider of the boards selected (P6).

Eight principals rated the same forms of professional development that the teachers were asked to. This included visits to other classes/schools using an IWB for lesson observations and modelling; collaboration with a colleague/cluster group; external expert visiting you demonstrating in your class; on-going participation in a professional community; other, please state. I compared the results of this question with the teachers and this is summarised below: 
Table 5: Principals' rating of professional development

\begin{tabular}{|c|c|c|}
\hline $\begin{array}{l}\text { Form of professional } \\
\text { development }\end{array}$ & $\begin{array}{l}\text { Number of } \\
\text { respondents (N58) } \\
\text { who ranked this as } \\
\text { most valuable at (1) }\end{array}$ & $\begin{array}{l}\text { Number of principals } \\
\text { (N8) who ranked this } \\
\text { as most valuable at } \\
\text { (1) }\end{array}$ \\
\hline $\begin{array}{l}\text { External expert visiting and } \\
\text { demonstrating in your class }\end{array}$ & 19 & 0 \\
\hline $\begin{array}{l}\text { Visits to other classes/schools } \\
\text { using an IWB for lesson } \\
\text { observations/ modelling. }\end{array}$ & 17 & 0 \\
\hline Collaboration with a colleague & 15 & $3^{*}$ \\
\hline $\begin{array}{l}\text { Participation in a professional } \\
\text { community, school based or } \\
\text { community based }\end{array}$ & 7 & $6^{*}$ \\
\hline Other & 0 & 0 \\
\hline
\end{tabular}

Interestingly, the principals rated as most valuable on-going participation in a professional community while the teachers thought this the least useful form of professional development. On the other hand, the teachers rated as being most valuable an external expert visiting and visits to other classes/schools but this was not rated highly by the principals. The data showed clear differences between what principals and teachers believed to be the most valuable form of professional development. It is not possible to draw general conclusions from the data in this study as only a small number of principals responded. I did wonder, however, what impact these differences may have on the future provision and effect of professional development. For instance, is it the principal who decides on the form of professional development, or is this restricted by what is available? Timperley et al. (2007) cited active school leadership as an element that contributed to effective professional development. Effective leaders organised opportunities for teachers to learn, have access to expertise and meet in a professional community. LoucksHorsley et al. (1998) argue that leaders, as in a principal or a lead teacher in the professional development programme, "legitimizes changes, provide resources, and create expectations that change will occur" (p.199). In this context leaders are critical to effective professional development. 
To briefly summarise, the information on professional development indicated that the teachers two most preferred forms of professional development were an external expert visiting and demonstrating in their classroom and visits to other classes to observe the IWB being used. The principals, however, preferred participation in a professional community or collaboration with a colleague. The need for sustained professional development was stated by many of the teacher respondents, including those who had used an IWB for more than two years.

\subsection{Chapter summary}

This chapter has presented background information about the survey respondents; their years of teaching experience, the class level taught and time teaching with an IWB. The training experiences to use an IWB were discussed and the findings indicated that the most useful form of training was a mixture of training for colleagues, one-to-one training and observing others. Most respondents wanted 'just in time' training that were relevant to their individual needs instead of 'just in case' training in a group that did not cater to such needs. Principals also supported this preference.

The most preferred form of professional development for the teachers was an external expert visiting and demonstrating in the classroom whilst for principals it was participation in a professional community. As for the training to use an IWB, the professional development was included in the purchase price for eight out of nine schools. It was provided by the supplier of the IWB. Finally, many respondents cited the need for sustained professional development in the use of an IWB.

The following chapter examines the results of the survey that relate to how an IWB is used in the classroom. In particular, I discuss which curriculum areas it is used in, teacher pedagogy with an IWB and the benefits and challenges of using one. 


\section{CHAPTER 5 \\ Survey Results Part 2}

\subsection{Introduction}

Chapter five considers the data from the teacher survey and the principal survey that relates to how an IWB is used in New Zealand classrooms. To understand how and why IWBs came to be in which schools and classrooms, principals' responses to this question are examined. Next, I explored how an IWB is used in a New Zealand classroom in the context of the curriculum area it is used in, teacher pedagogy and the benefits and challenges of using an IWB.

\subsection{How schools came to have IWBs}

Principals were asked why they chose to have IWBs in their schools and what criteria were used for selecting teachers to have one in their classroom. They were also asked to provide the decile ranking of their school to gauge if that impacted on the provision of IWBs for their schools.

\section{Why IWBs are installed in a classroom}

Wood and Ashfield (2008) state that in the UK IWBs were installed in classrooms to help raise the standard of numeracy among students. I was interested in finding out why schools in New Zealand chose to install IWBs so included a question about this in the principals' survey. I asked 'what were the factors that led you to consider purchasing an IWB?' Four principals stated that a local trust donated IWBs to their schools; two noted it was from an involvement in an ICTPL contract, and cluster initiative. Another principal said the school had purchased an IWB due to high interest in e-learning pedagogy and keenness to integrate all ICT tools (P9), while one other stated he had seen it demonstrated at a conference and was heartened by the step up it gave teachers who were into 'talk and chalk teaching practice' (P4). Eight of the principals pointed out that they were able to receive impartial educational advice about IWBs. 


\section{The criteria for selecting teachers to have an IWB}

The survey also asked principals what criteria they used in selecting teachers to have an IWB installed in their classes. This was of interest because Beauchamp (2004) argues that teachers who are already competent in the use of computers are likely to progress more quickly in their use of IWB. In one of the schools all the teachers had IWBs that were supplied by a local trust. For the other seven principals the following criteria used were interest and enthusiasm on the part of the teacher, and a confident user of ICT tools. According to Beauchamp (2004) selecting teachers on the basis of their ICT skill and enthusiasm gives them an advantage starting their journey of IWB use.

\section{Decile rankings of schools}

I was interested in the decile rankings ${ }^{1}$ of the schools to see if this had an impact on the purchase of an IWB. As only eight out of twenty four principals originally asked completed the survey, I used the Ministry of Education website to find their rankings. I found that their rankings and associated funding did not appear to have an effect on the numbers of schools having an IWB. There were for example, four schools with a decile 1 ranking and five schools with a decile 10 ranking. (One of the five decile 10 schools was an independent school.) Forty-six percent taught at schools with a decile 5 ranking or below. Fifty-four percent taught at decile 6 to 10 schools. The highest number of responses came from the respondents who taught at decile 1 schools. Table 5.1 summarises the decile rankings of the respondents' schools.

\footnotetext{
${ }^{1}$ A school's decile ranking is the indicator used to measure the extent to which the school draws its students from low socio-economic communities. The decile rankings are based on data taken from the national census for households. Decile 1 schools are the $10 \%$ of schools with the highest proportion of students from low socio-economic communities, whereas decile 10 schools are the $10 \%$ of schools with the lowest proportion of these students. The Ministry of Education uses decile rankings to allocate funding to state and integrated schools. The lower the decile ranking the more funding a school receives (Ministry of Education, 2008).
} 
Table 5.1 Decile rankings of schools with IWB

\begin{tabular}{cccc}
\hline Decile Ranking & \multicolumn{2}{c}{ Schools at this decile ranking } & Replies from schools \\
\hline $\mathbf{1}$ & $(\mathrm{n}=4)$ & $17 \%$ & $29 \%$ \\
$\mathbf{2}$ & $(\mathrm{n}=3)$ & $13 \%$ & $5 \%$ \\
$\mathbf{3}$ & $(\mathrm{n}=2)$ & $8 \%$ & $1 \%$ \\
$\mathbf{5}$ & $(\mathrm{n}=2)$ & $8 \%$ & $3 \%$ \\
$\mathbf{7}$ & $(\mathrm{n}=2)$ & $8 \%$ & $21 \%$ \\
$\mathbf{8}$ & $(\mathrm{n}=4)$ & $17 \%$ & $16 \%$ \\
$\mathbf{9}$ & $(\mathrm{n}=2)$ & $8 \%$ & $6 \%$ \\
$\mathbf{1 0}$ & $(\mathrm{n}=5)$ & $21 \%$ & $19 \%$ \\
Total & $\mathrm{N} 24$ & $100 \%$ & $100 \%$ \\
\hline
\end{tabular}

Although my study only looked at schools that already had IWBs, this data suggests that the decile ranking does not impede on a school being able to afford one.

\subsection{How are IWBs used in New Zealand classrooms?}

In order to gain a 'snapshot' of how an IWB is used in a New Zealand classroom, teacher respondents were asked to identify the curriculum areas they use an IWB in, and whether it was with the whole class, groups or mixed. I also asked them to comment on the benefits and challenges of using an IWB in their classroom and if its use had changed their teaching pedagogy. Their answers are discussed below.

\section{Curriculum areas IWBs are used in}

In order to identify which curriculum areas teachers used an IWB, I provided a list for them to choose from. Their answers were:

$\begin{array}{ll}\text { Numeracy } & (77 \%) \\ \text { Literacy } & (80 \%) \\ \text { Inquiry } & (25 \%) \\ \text { Physical Education } & (6 \%) \\ \text { Te Reo Maori } & (5 \%)\end{array}$


Numeracy (77\%) and Literacy (80\%) were clearly the curriculum areas where the IWB was used most. These results are similar to the United Kingdom (Beauchamp, 2004; Smith et al., 2005) and Australia (Bennett \& Lockyer, 2008).

Here in New Zealand the Ministry of Education (NZ) National Administration Guidelines (NAGs) 2 states under NAG 1 that each Board, through the principal and staff, is required to:

"(i) develop and implement teaching and learning programmes:

(b) giving priority to student achievement in literacy and numeracy, especially in years $1-4$;

and

(ii) through a range of assessment practices, gather information that is sufficiently comprehensive to enable the progress and achievement of students to be evaluated; giving priority first to:

(a) student achievement in literacy and numeracy, especially in years 1-4;" (Ministry of Education, n.d.)

In light of the above NAG, it is not surprising that the IWB is used by the survey respondents mostly in Numeracy and Literacy. I also found that the case study teachers predominantly used IWBs when teaching Numeracy and Literacy.

\section{Teacher pedagogy}

Higgins et al. (2005) concluded in a two year study that most of the teachers continued to use a whole class model of teaching when using an IWB. Kennewell (2006), Smith et al. (2005) and Bennett and Lockyer (2008) also found that IWBs are being used mainly to support whole class teaching. When respondents were asked how they use the IWB to support their teaching, they responded as follows:

2 The National Administration Guidelines (NAGs) for school administration set out statements of desirable principles of conduct or administration for specified personnel or bodies. Each NAG specifies what each Board, through the principal and staff, is required to do. 
Results

Whole class work

Group work

Mixture of both

Respondents were also asked how often students in their class used the IWB without them. They replied:

Results

Frequently

Sometimes

Seldom

Never

Higgins et al. (2005) concluded that there was "some evidence that IWB lessons may encourage more whole-class teaching at the expense of individual or group work "(p.68). It is interesting to note that my results showed that students frequently use the IWB independently of the teacher.

\subsection{The benefits of using an IWB in the classroom.}

According to Kennewell and Beauchamp (2007), "a number of benefits perceived for teaching are consistently emerging from the results, including efficiency, versatility, multimodal presentation and interactivity" (p.228). These were also cited by the respondents in this survey. Furthermore, when asked what they liked about using an IWB many respondents cited more than one reason. There were recurring themes in the respondents' answers: student motivation and engagement, the distinct feature of IWB technology, efficiency in lesson planning and preparation and the nature of interactions in a class. These themes were all found in the literature reviewed (see, for example, Smith et al., 2005; Haldane, 2007) and are explored below. 


\section{Student motivation and engagement}

Higgins, Beauchamp and Miller (2007) point out that "one of the most widely claimed advantages of IWBs was that they were seen to motivate pupils, with resulting improvement in attention and behaviour "(p.215). Respondents in this study clearly identified with this claim with $40 \%$ citing student motivation, engagement or focus as a reason they like using an IWB in their classroom. By way of illustration:

- Engages children, interactive, can be self monitoring, provides them with new challenges. (R1)

- The children are highly motivated when given the chance to work with the IWB. (R18)

- Maintains children's focus. Even three years in to having the board they want to be picked to use the pen. (R14)

- It grabs the learner! It motivates them into learning. Hugely visual and interactive which today's learners are into. (R47)

- Children motivated. Visual learners, audio learners, kinaesthetic learners-all learning styles can be utilised. (R51)

\section{Distinct features of the IWB}

Smith et al. (2005) and Haldane (2007) assert that the unique features of the IWB, the large screen, interactivity and multimedia capability are highly motivating and engaging for students. The IWB offers distinct technological features:

i. a large screen,

ii. an interactive component that allows users to interact on its large screen,

iii. multi-media availability and

iv. tools such as undo and re-do, record and playback functions.

All the respondents in this survey cited one or more of these as a reason they liked using it. They are discussed in more detail below. 
i. A large screen

Schuck and Kearney (2007) found that both teachers and students liked that everyone could see the IWB at the same time. This was also cited by $38 \%$ of respondents as a benefit to using the IWB. The following statements highlight this:

- Displaying/demonstrating so whole class can see. Engages children. (R15)

- Bigger so all the children can see. Kids hooked in longer. (R22)

- Ability to access online and networked resources in a way that everyone can see \& hear clearly. (R33)

- Everyone can see each others thought process. (R64)

ii. Interactivity

Over a third of respondents mentioned the unique feature of interactivity, with $35 \%$ citing it in their comments. Some examples are as follows:

- Offers more interactive teaching \& access to these resources. Children love it and respond to activities on it. (R9)

- Able to engage student through interactive features it has (R24)

- Interactive practice, ownership of learning, focused learning/engagement, inventiveness, energy and excitement. (R42)

- Focus \& enthusiasm from the kids. They like when they can see \& manipulate things visually. (R64)

iii. Multi-media availability on IWB

Almost half of the respondents, $48 \%$, commented about the instant access or a variety of links to resources such as the internet, You Tube, sound and images as being another feature they liked about using the IWB. For instance:

- Its futuristic-linked to the wider digital world (I use a digital microscope, webcam, digital camera, Skype with other schools, commercial programmes, internet, blogging all available to whole class by 1 PC with multi interactive components built into the IWB to enhance them. (R29) 
- Access to global resources \& the ability to make teaching seamless eg you tube movies, discussion board, photos and writing. (R34)

- It brings a whole new dimension to teaching. You're able to use resources that are usually unavailable or not successful unless you have an IWB. (R 47)

Twelve percent of respondents specified that using the IWB brought the global world into their classroom and allowed for spontaneous 'teachable moments'. Some of their comments were:

- It brings the whole world into the classroom. (R30)

- The world is at everyone's 'finger tips" \& access to information is instant, viewable by all for critique \& understanding of. (R50)

- Gives great access to 'teachable moments'. (R54)

It would appear that the multi-media availability on an IWB is a very good example of how e-learning (learning through ICT) has the potential to support or facilitate learning (Ministry of Education, 2007). The NZC states that elearning may for instance, "assist the making of connections by enabling students to enter and explore new learning environments, overcoming barriers of distance and time" (p.36). It also discusses the potential for shared learning opportunities through communities of learners beyond the classroom and school, providing environments that have resources to cater for learning differences and the opportunities to learn through virtual experiences. The respondents' comments illustrate that this is happening.

\section{iv. Tools specific to IWB}

There are specific tools and functions on an IWB such as 'drag and drop' (anything on the board can be moved around), and 'hide and reveal', that are not available on a computer. Ten percent of respondents mentioned these as illustrated by some of the comments below:

- Able to undo \& then re-do a lesson to reinforce concepts. (R11)

- Being able to show results before \& after, straight away to compare. (R21) 
- Quickly able to flick to internet, curtain to hide work, camera to take photos of sections. (R25)

- Record and playback function-record yourself doing a handwriting lesson \& you can go around watching and prompting children while it plays back. (R53)

It is clear from the above statements that the unique features of an IWB support teachers in many ways.

\section{Efficiency in lesson planning and preparation}

Bennett and Lockyer (2008) established that "overwhelmingly, the teachers felt that the IWB offered efficiencies in terms of planning and lesson preparation...also found transition between lessons to be quicker" (p.296). This factor was identified in some way by $25 \%$ of the respondents in this study. Their comments also appeared to be motivated by the resources available when preparing lessons. For example:

- Lesson prep at home. Prepared lessons/sequences can be saved for future reference. (R20)

- I love the resources you can make \& use with the kids, being able to pull work up from the day/week before. (R26)

- Reduced time spent on resource gathering. Able to preset flipcharts \& links easily. (R29)

- Quickly and easily make appropriate resources to facilitate learning. (R 41)

\section{Nature of interaction}

Twenty-five percent of survey respondents felt the IWB facilitated discussion and/or co-operative learning among students. Their comments illustrate the type of interactions taking place with an IWB.

- Creates great discussion in both whole class/group situations. Promotes co-operative learning between students.(R17)

- Marvellous for facilitating the Key competencies-Thinking (creative, reflective, collaborative etc), Using language signs \& symbols (great enhancer in obvious ways), participating \& contributing (essential), Relating to Others (essential). (R29) 
- Being able to compare \& contrast work as a class \& discuss a piece of writing together \& analyse it in small group. Develop our own matrix for our class. (R32)

- It allows the less capable children to lead discussions/ demonstrations. I do not always have to teach from the front of the room (wireless technologies). (R35)

- Immediate sharing of ideas. New medium for collaboration. (R60)

This result was also found by Bennett and Lockyer (2008) who identified that "in many lessons the IWB became the focus of class discussions rather than teacher-led instruction" (p.298).

\section{Principals' perspective on the benefits of using an IWB}

The principals were also asked to state the benefits of having an IWB in the classroom for students, teachers and the school. They cited the benefits for students were motivation and engagement, and the unique tools of the IWB. These were also identified by Smith et al. (2005) and Haldane (2007). According to the principals the specific benefits for teachers using an IWB were efficiency in planning, access to wide range of resources and up-to date technology. One principal, too, thought it gave teachers a greater choice in finding other ways to get the tuition across (P4). These benefits for teachers are also suggested by Kennewell and Beauchamp (2007).

When commenting on the benefits of an IWB to the school, principals' responses indicated that having one created a positive perception by the community, that their school was progressive and up to date with technology. This is illustrated by the following comments:

- viewed by parents as progressive learning environment; offers teachers opportunity to cater for learning styles. (P3)

- It looks good as a marketing tool so the school has the latest ICT equipment in classes. It gives the teachers the ability to be working at the cutting edge of technology. (P6) 
The literature I reviewed for this study did not include the perspective of school principals on the benefits of having an IWB for students, teachers and the school. However, interestingly, the benefits principals mentioned in their survey responses for students and teachers were the same as those identified by the teachers.

In this section I discussed the benefits of using an IWB in a classroom from the teachers' and principals' perspectives. The recurring themes from the teacher respondents were student motivation and engagement, distinct technological features of the IWB, efficiency in planning and preparation and the nature of the interactions with using one. These themes were also clearly reflected in the comments from the principals. Next I examine the challenges using an IWB in a classroom.

\subsection{Challenges of using an IWB}

There are challenges in using an IWB. Sixty-four respondents identified the following: learning to use the technology, time to explore its capabilities, technical difficulties and classroom management issues. Small numbers of respondents cited different challenges, which I have grouped under 'other issues'. Each of these are explored in more detail below.

\section{Learning to use the technology}

Thirty-six percent of respondents said learning how to use all the software and tools of the IWB was a challenge. Specifically identified were how to use it interactively all the time, continuing to upskill with changes of software and learning to integrate other digital technologies, such as video/digital camera and microscope. These challenges have been previously identified. For example, in a study that focused on the interactions between students, teachers and the IWB, Armstrong et al. concluded that learning to use the interactive technology of the IWB and appropriate software requires training and on-going support, otherwise " the potential affordances of the IWB are often not realised" (2005, cited in Higgins et al., 2007, p. 218). 


\section{Time}

Teacher respondents (33\%) said finding the time to find out what the IWB can do, and just play around with the software was difficult. The time spent creating flipcharts was also cited as a challenging factor. Schuck and Kearney (2007) found that the lack of time to learn how to use the IWB and prepare lessons on it was mentioned most as constraining the use of an IWB. Allowing time to explore how to use an IWB is important. For example, Miller and Glover (2007) recommended that for effective professional development in the use of an IWB teachers "be allowed time for exploration, consolidation and the development of teaching materials as confidence and competence develop" (p.330).

\section{Technical difficulties}

Power cuts or equipment failure, such as computers not working, and internet connection problems were cited by $33 \%$ of the respondents as being challenging. Broadband capability obviously impacts on the use of an IWB in the classroom.

\section{Classroom management issues}

In my study $12 \%$ of respondents talked about challenges related to classroom management. They ranged from behaviour management of children at the IWB while waiting for their turn, to organising a day's work for a relief teacher who did not know how to use an IWB. The following comments illustrate some of the challenges:

- Teaching children how to save files so their learning is not lost. (R44)

- When Plan A using IWB doesn't work, teachers need to be able to have a Plan $B$ ready to go. (R47)

- Show the children how to use it \& be prepared to walk away, leaving them to do the activity independently. (R53)

- Organising a day for a relief teacher who doesn't know how to use the IWB as most of my day is on it. (R5) 
- Behaviour management: at first the chn VERY excited. Teaching new routines, how not to bump the projector, how to use the pens etc. (R22)

Very few studies highlight classroom management issues when using an IWB. Bennett and Lockyer (2008), for instance, cited teachers' concerns about finding a strategy that ensured students had equal access to the IWB. One teacher commented on this stating, make sure all the students get time to use it and enjoy it independently especially when there are 30 in the class. (R7)

\section{Other issues}

Sunlight on the IWB, which made it difficult to see, was viewed as a challenge by $8 \%$ of respondents. This can be a difficult and costly problem to solve and it is one that I have experienced myself. The physical set up of many classrooms, for example, windows on one or two walls of a classroom mean that the places an IWB can be installed are limited. Technical restrictions must also be taken into consideration, such as where the wiring for the internet connection is. Providing some form of screening of the sunlight in a room can be very costly and it appears that it is not an expense taken into account when purchasing and installing an IWB.

The cost of running and maintaining an IWB was only mentioned by one respondent, who commented it was costly to run $-1 \mathrm{yr}$ lamp [was] $\$ 800$ to replace (R24). Interestingly, there was only one principal who talked about the expense stating one of the things we have not budgeted for well enough however is repairs and ongoing maintenance. We will need to address this as the cost is astronomical (P8).

To briefly summarise, the biggest challenge faced by teachers learning to use an IWB is finding out how to use its software and tools and making the time to do this. Technical difficulties, such as power cuts and internet failure, 
classroom management issues and sunlight on the IWB screen were other challenges mentioned.

\subsection{Change in teacher pedagogy by using an IWB}

I asked respondents if using an IWB had changed their teaching at all and, if so, to state how. Fifty-three respondents answered yes, and their changes in teaching pedagogy are broadly in two themes. Firstly, pedagogy had become more collaborative and their role had become that of a facilitator. Secondly, the way in which the curriculum was delivered to the students had changed. I discuss each of these next.

\section{Collaborative/facilitator role}

Most of the literature reviewed (Beauchamp, 2004; Higgins et al., 2005; Smith et al., 2005) concluded that teacher pedagogy when using an IWB did not change and whole class teaching predominated. In my study, however, $28 \%$ of the respondents said that through the use of an IWB they had changed their pedagogy. Collaboration with students about their learning had increased and they had become more of a facilitator. It appears that, from the data on length of time using an IWB, some respondents found a change in their pedagogy occurred relatively quickly. The following comments from the respondents reflect their changing pedagogy (the figures at the end of each quote indicate how long the respondent had been using an IWB and which class level they taught).

- the learning in my class is less teacher directed. More inquiry pedagogically. (R7) 0-6mths Y5/6

- More interesting for children, not all teacher talk. (R8) 1318mths Y4

- The board provides great opportunities for self directed learning. (R14) >2yrs Y4

- Collaborative learning happening more. (R17) 7-12mths Y0/1

- l've learnt a lot from students and looking at how fast they can learn things and it's changed me by accepting that it's OK if they know more than me. (R32) >2yrs $Y 7 / 8$ 
- Hugely ... I have become a facilitator of information. I have become a learner just like my children. Interaction has changed from 'teacher to child' to teacher to child to child. (R34) >2yrs Y0/1

- I have relinquished 'control' of discussions/learning and I lead/facilitate rather than 'pour out' knowledge. (R35) >2yrs Y4/5/6

- More oral language. Starting to put teaching and learning into children's hands. (R37) $0-6 \mathrm{mths}$ Y0/1

- Made more me aware of the ways in which I teach, used to be more presentation \& less interaction. (R45) >2yrs, Y6/7

- I'm more of a facilitator of knowledge in many instances more so than in the past. $\quad(\mathrm{R} 50)>2 \mathrm{yrs} \quad \mathrm{Y} 2$

- More responsibility to students, less talking! (R51) 13-18mths $\mathrm{YO} / 1$

- Children lead the discussions more. I facilitate as they make suggestions. (R56) 13-18mths Y3/4

- Children more involved in instructional sessions. Endless possibilities for presenting ideas to class. (R62)>2yrs Y4

- Catering to the visual learners more. Focus on boys learning with IWB letting children 'have control'. (R 64) 19-24mth Y6

I have included a large number of comments from respondents to demonstrate that their years of IWB use clearly did impact on their pedagogy. By way of illustration, $53 \%$ of these respondents who stated that their role had become more of a facilitator and collaborative with the students had used an IWB for two years or more. They all had teaching experience for at least two years, and most had taught for six years or more. In agreement with Somekh et al. (2007), after two years of using an IWB teachers begin "to facilitate a co-learner style of teaching, where teachers and pupils (we) work together rather than adopting more formal roles as teacher and learner" (p.111). Furthermore, from these comments, it would seem that collaborative learning was taking place not just with the older students of Year 5 and above but also with the younger Year 0/1 students. 


\section{Curriculum Delivery}

Another theme that emerged was how an IWB has changed teacher pedagogy related to the curriculum delivery. Eleven percent of the respondents stated that using an IWB had led to them thinking more about how they teach and delivered the curriculum. This is reflected in the following statements:

- Forces you to think about curriculum delivery. Availability of resources that aren't copyright and can be easily adapted for own use. (R26)

- Integrating ICT into classroom lessons more regularly. More visual cues given to children when modelling. Variety of teaching tools to illustrate a concept. (R28)

- Presentation of work is of a higher standard and can be done in many different ways. (R34)

- More responsive to class moods and needs. Given more freedom to teach in my own style. (R42)

- Makes me think about my activities and cater for diversity far more easily. (R44)

- Made me more aware of the ways in which I teach, used to be more presentation and less interaction. (R 45)

To recap, in this section I looked at how teacher pedagogy had changed since using an IWB. There were two predominant changes identified by the respondents: they collaborated with their students and consequently became more of a facilitator. Secondly the unique features of the IWB had led to teachers thinking more about how they presented and delivered lessons.

\subsection{Chapter summary}

Schools acquisition of IWBs does not appear to be related to their decile ranking. Half of the schools in this study had their IWBs donated by a local trust. When deciding who would have an IWB, the principals chose teachers with advanced ICT skills and enthusiasm.

Teachers mostly used an IWB when teaching Numeracy and Literacy. They used the IWB predominately in a mixture of whole class teaching and group 
teaching and almost half of the respondents stated that their students frequently used the IWB independently.

The benefits of using an IWB were the high level of student engagement and motivation and the distinct technological features of the IWB: the large screen, interactivity, multi-media access and unique tools such as record and playback. Teachers and principals were clearly in agreement about these benefits. There were also challenges identified, which were learning to use the tools of the IWB and its associated software. Teachers felt they did not have the required time to do this. Technical difficulties such as the internet not working or power cuts also presented a challenge. In addition, there were classroom management issues. These were setting up routines for students taking a turn at the IWB and teaching children the necessary technical skills to use it.

Finally, I identified that teacher pedagogy for $28 \%$ of respondents had changed since using an IWB. These teachers had become more of a facilitator of student learning and used the IWB as a mediating tool. In addition, the unique features of an IWB had provided teachers with extra and varied resources at their fingertips to teach with. Consequently, teachers were thinking more about how they would deliver lessons to their students.

In the next chapter I describe how three teachers used an IWB in their classrooms during my observations. I also discuss the results of an interview with each teacher about their professional development experiences and using an IWB. 


\section{CHAPTER 6 \\ Case study teachers' use of an IWB in their classroom programme}

\subsection{Introduction}

This chapter investigates how three teachers use an IWB with authentic examples of how they are used in a classroom programme. The teachers' reflections and an analysis of the benefits of using IWBs are considered. These teachers were selected from the twenty-one who volunteered in the survey to be observed using an IWB in their classroom. As outlined in chapter three, the following criteria were used to select the three participants; proximity to the city I live in, have at least twelve months experience of using an IWB in their classroom, the need to be from three different schools and clusters, currently teaching at the Year One or Two level: (5-6yr old children) and their principal had returned a survey. One teacher met all the criteria whilst two teachers met four points. As very few volunteers were in proximity to the city I live in, I chose one teacher from a city in the South Island, which was first in New Zealand to have IWB in many of its schools. I visited each teacher for one day, from 8.30-4.30pm, between weeks 7-9 of Term 1, 2009 (In New Zealand there are 4 terms of 10 weeks).

\subsection{Lancewood School ${ }^{3}$ visit}

\section{Background information}

Lancewood School is a contributing school (for Year 1 - 6 students, 5-10yrs) with a roll of 105 students and five fulltime teachers. It is a decile 10 school in a rural area. Kathy taught a New Entrant/ Year 1 class of 12 five year old children. She and the Year 5/6 teacher were the only ones in the school to have an IWB in their classroom. The Promethean IWBs had been donated to the school by the local licensing trust.

\footnotetext{
${ }^{3}$ The names of the schools and teachers in the observations have been changed to maintain confidentiality.
} 
I knew from the teacher survey that Kathy had between 26-30 years of teaching practice and had been using an IWB for 12 months. She was given the choice of having an IWB in her classroom, and indicated that she was an initiate user: a teacher beginning to use the IWB to change and enhance their pedagogy. The principal from Kathy's school stated in the survey that the two teachers in the school had been selected to have an IWB in their room due to their enthusiasm.

\section{Kathy's IWB training and professional development}

During the interview Kathy was asked about the type of IWB training she had and her on-going professional development. The IWB supplier included four half day training sessions, one per term, with the purchase price. Kathy had no prior training before the IWB was installed in her room. She said that if she had not asked the technician installing the IWB how to turn it on she would not have been able to do that until the first training session, which was approximately four weeks afterwards. The half day training sessions took place during the school day. The most helpful form of training for Kathy, however, was release time for demonstrations and follow up time to try out the new things she had learnt. At the time of my observation Kathy had attended three training sessions, with one more to do. In addition to the training sessions, Kathy used her own initiative to find out more about using an IWB, in the form of internet searches, books she had purchased about IWB use and research related to a masters paper she had taken on ICT.

\section{Kathy's use of an IWB in her classroom}

On the day of my observation (25.03.09) Kathy's classroom timetable was as follows: 
Table 7: Kathy's classroom timetable

\begin{tabular}{lll}
\hline 9.00 & Roll & \\
9.05 & Fitness & \\
9.15 & News: news groups & \\
9.20 & Storywriting & \\
10.00 & Phonics and handwriting & \\
10.30 & Morning interval & \\
10.50 & Silent reading & \\
11.00 & Shared book & IWB use \\
$\mathbf{1 1 . 1 0}$ & Guided reading & \\
$\mathbf{1 1 . 5 0}$ & MWB use \\
12.30 & Lunch & \\
1.30 & Swimming & \\
2.10 & Te Reo Maori & \\
2.45 & Tidy up & \\
2.50 & Game outside & \\
3.00 & School finishes & \\
\hline
\end{tabular}

I observed the IWB being used on four occasions in the following curriculum areas: writing, reading, mathematics and Te Reo Maori. To follow is a detailed account of how the IWB was utilised. 
Table 8: Observation 1: Story writing

Time Observed: 9.20-9.30am

Subject: Literacy: Story writing

Lesson Objective: To model writing a recount of the class trip to the beach yesterday

Software being used: IWB software and tools, specifically flipcharts

Whole class/group/individual use of the IWB: Whole class

Children using the IWB: Selected students from class

Purpose of IWB use: To show photos of the class trip to the beach the previous day that would provide a stimulus to discussing the trip and then writing about it

\section{What was observed:}

The students were sitting in front of the IWB to look at photos of their trip to the beach the previous day. Kathy had downloaded these photos onto the IWB in the morning to use for this writing lesson with the whole class. The children smiled and laughed as their photo appeared on the IWB screen and clearly loved seeing photos of themselves on it. All eyes were on the IWB as they watched a new page come up with new photos on it. As the photo came up Kathy got each child to describe what he/she was doing in the photo. When each of the photos had been shown Kathy asked the children to think of words they will need for their story and wrote these on the IWB. She prompted the children by asking questions such as "How did we get there? What did we see there? What were you touching?"

Kathy then returned to the little whiteboard to model writing a recount of the visit.

After modelling the writing of a story of the visit, the children were given paper to complete their writing on. The words written on the IWB earlier were still on for all the children to use in their writing. There were three writing groups. One group had to draw a picture about the trip and dictate a sentence about their picture to Kathy who wrote it under their picture. The second group had space for an illustration and lines underneath to write about what they had drawn. The third group had a space for planning their story at the top of the page that included a beginning, middle and end of story.

The children worked on their writing until 10.00am and then went to the mat for some phonics and printing work. 
Using the IWB to show the photos so the whole class could see made good use of the software. This also demonstrated Kathy's competence in using the computer and her level of technical competence with the IWB: Kathy obviously knew how to download photos from a digital camera to a computer, save the photos on to a flipchart on the IWB and then retrieve this file on it later. She had pre-planned and prepared to use the IWB in a specific manner for her writing lesson. According to Beauchamp (2004), this pre planned use of the IWB for specific lessons is an indicator of the initiate stage of IWB use, which is where Kathy rated herself.

The IWB was next used during Reading.

\section{Table 9: Observation 2: Reading}

Time observed: 11.10-11.20am

Subject: Guided Reading

Lesson Objective: For students to familiarise themselves with the tools on Kid Pix

Software being used: Kid Pix ${ }^{4}$

Whole class/group/individual use of the IWB: group

Children using the IWB: Tom and Max

Objective for using the IWB: Make the most of a big screen to create a picture using Kid Pix. By using the IWB the teacher could observe exactly what the students were doing and help if necessary

\section{What was observed}

Kathy had three reading groups. While one group was with Kathy for guided reading, another group was working with puzzles. A third group was working on the IWB. Kid Pix was the programme on the IWB and I observed two students, Tom and Max, using it for 10 minutes. These boys used the mixer and stamp tool to create a

${ }^{4}$ Kid Pix is a software drawing package for young children. It has "all the creative functionality one would expect, from selecting from an array of art mediums (paint, watercolor, airbrush, pencil, crayon, marker, chalk, etc.) to using various finishing techniques (stickers, stamps, typeface, etc.). In addition, the software can add special effects (animate, smudge, smear, warp twist, etc.) for a wacky look, suggest ideas and backgrounds to help get creative juices flowing, and import digital photos to personalize." http://www.broderbund.com/store/broder/en US/DisplayProductDetailsPage/Kid Pixreg Del uxe 4 Home Edition/productID.126904700 
picture of their choice using the whole IWB. They appeared to be very intent on what they were doing. Tom was very quick to help Max when he was unsure of how to use a tool. For example, when Max used the dog stamp on the screen, Tom told him to "make it bigger."

Max replied "How do I do that?"

"Click on that square down there to make it bigger" replied Tom.

"My turn now" said Tom. He drew the outline of a tree beside the dog.

Max said to him, "fill it in".

"OK" said Tom. He clicked on the fill tool and filled the tree so it was brown.

Max went to pick up a pen to draw some leaves on it and Tom said, "you can only use one pen at a time and I still have a pen in my hand."

Tom and Max continued to create their picture, each having a turn using a tool. As illustrated by Tom's comments above he appeared to have more knowledge of how to use the tools on Kid Pix and was happy to provide Max with guidance when Max did not know how to use a tool.

The above observation clearly shows how Tom and Max were working together to create a picture and solve problems with the tools as they arose. Kathy stated in her survey response that collaborative learning was happening more as a result of using the IWB, and this was clearly demonstrated here. Interestingly, Kathy was the only teacher observed to use the IWB to model a software programme for computers. She did this with the objective that the students would then know how to use that programme on the computers independently.

The third observation involved Mathematics. 
Table 10: Observation 3: Mathematics

Time Observed: 11.50am -12.00pm

Subject: Mathematics

Lesson Objective: To practice recalling basic number addition facts to 10

Software/website being used: www.ictgames.com 'Save the whale' game

Whole class/group/individual use of the IWB: Group

Children using the IWB: George, Lucy, Riley, Sam

Objective for using the IWB: So a group of children could easily see the screen and play the game together

\section{What was observed:}

Kathy began the lesson with a whole class warm up game related to number knowledge. Following this she sent a group of four children to the IWB to play a maths game which they had all played before. They lined up facing the IWB and each child had a turn using the IWB pen to move the correct number, which was on another part of the board, to the answer. For example, 1 and _ make 10.

George went first with the IWB pen. While he was thinking about the answer, the other children appeared to be focused on working out the answer. Lucy, for instance, was counting on her fingers to work out the answer while Riley was pointing at what he thought was the answer on the IWB and counting aloud as he did so. The other child, Sam was counting out aloud from the number shown and excitedly stated, "I know, I know 1 and 9, it is 9!

It became apparent that the children had varying levels of skill at using the IWB tools as observed by the comments made to each other. By way of illustration, when it was Sam's turn to move the answer on the IWB he could not get the IWB pen to work. George said to him, "you need the pen straight". When Sam did this the pen worked. After George's turn the children moved down the line for their turn at the IWB.

Playing a game on the IWB gave the children the opportunity to practise the key competencies (Ministry of Education, 2007, p.12) of relating to others, and participating and contributing. Learning to take turns, helping each other (with the tools of the IWB), were all evident in this observation. The children were so excited when they believed they had the answer, as evidenced by 
them jumping and down, and calling it out when, for example, Riley had control of the IWB pen. When the answer was revealed George and Lucy, who had called out the correct answer, were very excited. During this game on the IWB some children were learning how to use the tools of the IWB from more experienced peers and solving the maths problems in collaboration as a group, which clearly demonstrates Vygotsky's (1978) socio-cultural theory.

In the afternoon the first use of the IWB was for a Te Reo Maori lesson.

\section{Table 11: Observation 4: Te Reo Maori}

Time Observed: $2.10-2.25 \mathrm{pm}$

Subject: Te Reo Maori

Lesson Objective: To revise the Maori names for animals

Software being used: IWB software, teacher created flipcharts

Whole class/group/individual use of the IWB: Whole class

Objective for using the IWB: To revise the Maori names for animals in an engaging manner for the students.

\section{What was observed:}

Kathy had prepared a flipchart of pictures of five animals on the IWB with their Maori names placed elsewhere on the IWB. She pointed to each picture of an animal (cat, dog, horse, cow, chicken), asked the students what it was and then how to say the name in Maori. The students repeated the name in Maori. Kathy demonstrated how to use the IWB pen to click on the Maori name and drag it with the IWB pen under its picture. She chose Matt who was sitting up nicely watching the board to come up and find the name for dog in Maori. Every other student on the mat was watching Matt use the IWB pen to drag the Maori name to under the picture of the dog.

I observed three students, Josh, Lucy and Sam moving a finger along in the air, following the path Matt was dragging the Maori name along, to the picture of the dog. After all the Maori names were matched up to the pictures, Kathy gave the students a follow-up activity to re-enforce what they had been doing on the IWB. The students were given a page with the pictures of the animals that were on the IWB and their Maori names. The students needed to cut out the pictures and names 
of each animal and match them up.

These students were clearly engaged with the activity even though they were not up at the IWB by physically moving the answer to the correct place in the air. Kennewell and Beauchamp (2007) also observed that when one student used the IWB to carry out some action on it there continued to be a high level of engagement of the other students indicating "that all or most of students were thinking along with the selected student about what the best action would be" (p. 234).

This lesson appeared to be a good example of how useful the drag and drop tool on IWBs software is. Kathy could have used paper and a type of adhesive to replicate this activity but it would have taken a lot longer to prepare and the children would not have all been able to see the pictures in the same way. Furthermore, allowing the children to be physically interacting with the IWB is an important feature of the initiate stage of IWB use and one that "is planned by the teachers and is an integral part of the learning process" for children using an IWB (Beauchamp, 2004, p. 339).

\section{Interview with Kathy}

For each of the interviews I asked the teachers to discuss a specific IWB lesson that occurred, what they liked about using the IWB and what its benefits were. Kathy chose to focus on the Te Reo Maori lesson. When asked why she had planned to use the IWB for this lesson, Kathy said:

Mainly because it was revision and with all the interruptions over the last two or three weeks I wanted to do it in a really fun way that would catch the kids. I knew the whiteboard does that. It was quick and it was easy and really got them to think about what they are doing. It was actually bringing in a whole pile more skills than just Te Reo because they were using their letter sound skills, visual graphic skills - you could see them trying to work it through (25.03.09).

Kathy clearly identified the motivational and engagement factor for students using an IWB found by Bowman and Tait, (2005) and Higgins et al. (2007). 
This was also cited by $40 \%$ of survey respondents as a reason they like using an IWB in their classroom.

We discussed changes she could have made to this particular lesson. Kathy said that she knew there was a recording tool on the IWB; however she did not know how to use it but would like to. She went on to make an interesting point that one might get carried away with its capabilities.

Make sure I knew how to use the microphone so we could actually tape noises and add them. The kids would have had an absolute ball. Trouble is you have got to decide if they are going to get carried away with making the sounds and how much it actually adds to the lesson. I could have got them to record some of the Ata marie Kuri sounds and made the next set of flipcharts and had the two animals talking to each other and had the children recording it. It would have been fun. Then they could refer back to it later (25.03.09).

Kathy's comment also reflected how she would use the tools specific to an IWB such as the record function, save and return, do and re-do function. Her flipchart was a resource she had specifically made to facilitate the students' learning and one that could be saved for future reference and practice. This was an example of efficiency in lesson planning and preparation. Furthermore, Kathy's enthusiasm for what she could have done was very obvious and it was apparent that she was continually reflecting on and evaluating her use of the IWB.

\section{Benefits of using an IWB}

In her survey response Kathy pointed out what she liked most about using an IWB; the engagement of the students, that high interest lessons could be developed easily and it allowed access to a wide range of resources right in the classroom so everyone could share in the learning. During the interview I asked her again what affordances she particularly liked about IWBs. Kathy's reply was similar to what she had written in the survey:

Have to be the engagement of the kids, the way the kids are motivated by it. It really hooks them in and they are really enthusiastic about anything we do on the board. Anything that keeps the kids hooked in is great (25.03.09). 
Further, Kathy was one of the $48 \%$ of survey respondents who specifically mentioned the instant access to the internet as a benefit to using an IWB. During the interview she stated:

Being able to access the internet and sharing it with the class. I think that's a big one because suddenly you've got a whole world of resources that you can use so much more easily and tap into (25.03.09).

To briefly summarise, during the year that Kathy had been using the IWB the only professional development received was three half day training sessions, spread out over three terms. Kathy found the demonstrations valuable but thought they would be more useful if she had more time to practice what she saw and then plan how to use it in her programme. In addition to using the IWB to motivate and engage her students having instant access to the internet were, in Kathy's opinion, benefits to using an IWB.

\subsection{Akeake School}

\section{Background information}

Akeake School is a full primary school (for students Year 1-8, 5-12yr) with a roll of 321 students and fifteen fulltime teachers. It is a decile 5 school in an urban area in the North Island. Wendy taught a Year 2 class of 20 six to seven year old children. All the teachers in the school had Interwrite IWBs in their classroom. She had five years of teaching practice and had been using an IWB for three years. Wendy rated herself at the blackboard stage of use: the teacher predominately uses the IWB to write and draw, as she would on her standard whiteboard. She was given the choice of having an IWB in her classroom and was consulted where it would be located. The principal stated that he had seen IWBs being used at a conference six years ago and was so impressed with what he saw decided to invest in IWBs for each classroom at Akeake School (Pers.Comm 02.04.09).

\section{Wendy's IWB training and professional development}

When I asked Wendy about her IWB training and professional development she replied that the IWB supplier trained her to use one. This was over two 
sessions: one before it was installed in her classroom and the other on the day of installation. Both sessions occurred after school and were one and a half hours long. The most helpful form of training Wendy found was from other teachers and just trying things out herself. Wendy had professional development in the form of collaboration with a colleague, participation in an ICT school cluster programme and IWB conferences.

\section{Wendy's use of an IWB in her classroom}

On the day of my observation (02.04.09) the classroom timetable was as follows:

Table 12: Wendy's classroom timetable

\begin{tabular}{rll}
\hline $\mathbf{9 . 0 0}$ & Roll, Rules, Calendar & IWB use \\
$\mathbf{9 . 2 0}$ & Handwriting & IWB use \\
9.35 & Blend Cards & \\
$\mathbf{9 . 4 5}$ & Storywriting & IWB use \\
10.30 & Morning interval & \\
10.50 & Browsing boxes & \\
$\mathbf{1 1 . 0 0}$ & Shared book & IWB use \\
$\mathbf{1 1 . 1 0}$ & Reading Games & IWB use \\
11.30 & Guided reading & \\
12.30 & Lunch & \\
1.30 & Story & \\
1.40 & Mathematics & \\
2.25 & Centre time & \\
3.00 & School finishes & \\
\hline
\end{tabular}

The following observations detail how the IWB was used in Wendy's classroom. It was used first at the beginning of the school day. 
Table 13: Observation 5: Roll and handwriting

Time observed: 9.00-9.35am

Subject: Class rules, calendar, handwriting

Lesson Objective: To re-enforce class rules and learn days of the week, months of the year. To practise the correct formation of the letter ' $u$ '

Software being used: IWB software, teacher created flipcharts

Whole class/group/individual use of the IWB: Whole class

Objective for using the IWB: To engage students when going over the class rules by having their photos up on the big screen, using a pre-recorded function for handwriting

\section{What was observed:}

After the roll was called Wendy asked the children to face the IWB. They were sitting in four vertical lines with five students in each one. The lines corresponded to their group seating arrangements at their tables. This was the class routine for sitting on the mat and in front of the IWB. On the IWB was a flipchart that had the title "Class Rules". On it was a whole screen of cartoon animals. Wendy asked Hamish to get the IWB pen and choose an animal to click on. He clicked on the elephant and a photo appeared of the some of the students showing the class rule: "we always use our quiet voices inside the class". Hamish clicked on the "undo" icon at the side of the IWB and the elephant re-appeared in front of the rule. Hamish chose Casey, who was "sitting nicely" to come and click on another character. This routine continued with four more children clicking on a rule until all the six class rules had been revealed.

Wendy then brought up a flipchart of a calendar she had created on the IWB. Jack was chosen to use the fill in tool to colour the box with the day in it. Next Leo used the dragging tool to move the date beside the day and finally Justine used the highlighting tool to show which graphic indicated the weather for the day.

The students then moved to their tables for printing. Wendy brought up a flipchart that had pre-recorded handwriting on it, which she done before school started that morning. (As Wendy wrote the letter ' $u$ ' on the IWB it recorded exactly where she started and how she formed it. When Wendy had finished writing she simply saved it for the lesson. On playing the lesson back all you could see was the letter ' $u$ ' being 
formed from start to finish, without a hand or pen showing at all. Known as the record and playback function, it was like magic!) Wendy instructed the students to "watch how the little $u$ is made" and when the first line of ' $u$ ' was complete on the IWB she paused the pre-recording and asked the children to write a line of ' $u$.' The students watched each line of printing on the IWB and Wendy would pause the recording as the students copied that line in their book until completed.

Wendy's use of the IWB to go over the class rules was, clearly from the above observation, very engaging for the children. They all sat watching the screen as the selected child chose which character to click on. The children appeared to enjoy seeing photos of themselves on screen and listening to what they said. It was a fun way to reiterate the class rules on a daily basis. Whilst one would be able to, with a great amount of work, replicate photos under a picture of a cartoon character on a whiteboard or large piece of paper that could be flipped over or up, I do not know how you would replicate the sound that went with each photo without an IWB.

The pre-recorded flipchart of printing could not be replicated without an IWB as the recording facility appears to be a unique feature of the IWB. This flipchart and the rules flipchart were a reflection of how skilled Wendy was in using the IWB software to create a lesson specifically to cater to the children's needs. Knowing how to record a sound file on top of a photo and embed it so that it appears on a clickable graphic requires proficient computer skills and knowledge of the IWB software. Consequently, I would place Wendy at the advanced stage of IWB use (Beauchamp, 2004) in the mechanical skills category.

The next observation of the IWB was during story writing. 
Table 14: Observation 6: Story Writing

Time observed: 9.45-10.20am

Subject: Literacy: story writing

Lesson Objective: To model writing a story and how to edit writing

Software being used: IWB software, teacher created flipcharts

Whole class/group/individual use of the IWB: Whole class

Objective for using the IWB: To model writing a story so that the whole class could see and be involved in the editing process using particular stamps to edit the work

What happened:

The students were seated in front of the IWB and Wendy brought up a flipchart of lines on the IWB to write on. She asked, "who has got a story for me today?" Hazel put her hand up and when asked to speak by Wendy replied, "I'm getting a new fish today."

Wendy wrote on the IWB "A now fish is arnvin at hazels hse toda." She asked the students to remind her how they edit writing on the IWB.

Jimmy replied, "we put a moon over the words that are right".

Tess said, "we use a different coloured pen above the words that are wrong."

Wendy said she would choose someone who was sitting up nicely to put a moon, using the stamp tool, over each correctly spelt word. The whole class immediately sat up very straight, which indicated that they were all very eager to be chosen for the stamping task on the IWB. Tim was chosen to do this and the other students all watched what he was doing very intently, obviously engaged in the task.

Wendy sounded out the incorrect words left and asked the children what the correct sounds/spelling would be. She asked Maisy to choose a colour for her to write the corrections in and made any needed above the incorrect word. The students returned to their desk to write a story about a topic of their choice. They worked on this until 10.20am when Wendy shared some of their stories with the rest of the class.

Wendy used the IWB to model story writing just as one might use a whiteboard or pen and paper. The difference is that with an IWB the whole class can see the board easily and the children seem to be so focused on the task at hand, whether it is underlining or using a stamp. In this observation Wendy chose the tools to use and the children just had to select the colour. 
Allowing students to use the IWB in this manner is the first step in the teacher adapting to becoming a "coach, observer and facilitator as teachers transfer greater responsibility for their own learning to their pupils" (Beauchamp, 2004, p. 355) and is an indicator of an IWB user at the apprentice level.

The third observation occurred during a Reading lesson.

\section{Table 15: Observation 7: Reading}

\section{Time: $11.00-11.20 \mathrm{am}$}

Subject: Literacy: shared reading and reading games

Lesson Objective: Shared reading of a book and modelling how to play a new game that focused on using a full stop correctly

Software being used: Internet website: www.roythezebra.com, IWB software games

Whole class/group/individual use of the IWB: Whole class for shared reading and group for reading games

Objective for using the IWB: Using a big screen for all the students to see the big book and to show the students how to play a new game that was going to be the day's computer activity

\section{What happened}

\section{Shared reading}

Wendy had a story called "Roy the Zebra" up on the IWB, from an English website. She gave the pointer to Jay to turn the pages by tapping on the page on the IWB. As the story is read all children appear to be following the words on the IWB and listening intently.

Roy the Zebra Game

Next Wendy showed the students how to play a game related to the story they had just read. A sentence was read out on the IWB and the students had to decide where to put a full stop in. Wendy chose Gemma to write a full stop with the IWB pen in the correct place. Wendy had the game ready to play on the six computers in the room for each reading group when it was their turn on the computers. One reading group was sent to use the computers; one to the class library, one to Wendy 
for guided reading and one group was left to use the IWB reading games.

IWB reading games

The four students left at the IWB had a choice of five activities: rhyming pairs, handwriting practice over basic sight words, such as 'for', finding the initial consonant, writing in the medial vowel of a word and putting the days of the week in the correct order on a train. Each activity required the student in control to select and use the basic tools on the IWB such as the writing tool, drag and drop, highlighting tool, and the 'undo' tool. Hilary chose the days of the week game to play and started to drag the days of the week into the correct order on a little train. Brayden was telling her which day to drag on next and then May and Amy joined in too and it was soon complete. Even though Hilary had 'control' of the IWB pen all the students were participating in the task and watching her move the days about. Hilary did not appear to mind being told what to do.

Brayden was the next to choose a game. He had trouble choosing the correct icon on the IWB to move forwards and backwards on the games menu but was scaffolded by Amy who knew. Brayden chose the rhyming game but soon after wanted to play a different game. The rest of the group reminded him of the rule that he needed to finish one game before going on to another and pressured him to give the IWB pen to the May, which he did. May was having trouble finding the forward icon when suddenly the screen went blank. The software had crashed. Wendy came over to fix it but couldn't get it back up so selected the Roy the Zebra game from the website that was on the computers in the room for this group to play.

Using the IWB for a shared reading of a book worked well on the big screen as it meant all the children could see and hear the words at the same time. Showing the students how to play a new game using the IWB was an efficient use of Wendy and the students' time as all could see the screen. The students appeared to be all clearly engaged in what was happening on the IWB even though someone else had control of the IWB pen. These students using the IWB games had to select the tools from the software menu that they needed to use, for example, the writing tool or undo tool and were thus extending their skill in using the IWB independently. Students' 
developing their skills in this way is one indicator of the initiate stage of IWB use.

During this observation one of the challenges that $33 \%$ of respondents cited in the survey occurred: technical difficulty. In this case the IWB software crashed and the students were left with a blank screen and no idea of how to fix it. Wendy had to leave the guided reading group she was working with to come over and fix the problem. As she was unable to fix it, the students had to use a different programme.

After lunch the IWB was used for Mathematics.

\section{Table 16: Observation 8: Mathematics}

Time Observed: $1.40-2.25 \mathrm{pm}$

Subject: Mathematics

Lesson Objective: To practice addition and subtraction facts to ten

Software being used: IWB software games

Whole class/group/individual use of the IWB: Whole class

Objective for using the IWB: To provide practice of addition and subtraction facts to ten in a fun and engaging manner.

\section{What happened:}

The lesson began with a 'warm-up' dice game. On the IWB screen two dice appeared being rolled. When the dice stopped rolling the students had to add the two numbers showing together and put their hand up with the answer. After the correct answer was given the Wendy tapped on the screen with an IWB pen to roll the dice again. This game was played for five minutes.

Wendy then divided the students into two teams to play the next game called 'Bowling'. On screen was an image of a ten pin bowling alley with two sets of ten pins. The object of the game was to be the first team to knock the ten pins down. To send a bowl down the student having a turn tapped on the screen with the IWB pen and a bowling ball raced down to knock the pins over. The team had to work out how many bowls had been knocked over and how many were left. The student 
bowling had to say, for example, 10 bowled out 2 , leaves 8 .

The children were very excited playing this game as evidenced by the way they all watched the screen and laughed and clapped when the bowling pins were knocked over. The class played this game for ten minutes. Wendy then turned off the IWB and replicated the game with counters on the mat space in front of the children.

The use of the IWB for a maths game was an example of a novelty use. Both games could have been played on the floor with equipment, however, the IWB does appear to engage the students, which appeared to work well in getting the students warmed up for maths, as noted by Wendy below. The children found the bowling activity difficult to replicate.

\section{Interview with Wendy}

Wendy chose to discuss the mathematics lesson. She often used the SIMS (Interwrite Simulation games that are part of a particular brand of IWB software package) in mathematics because:

The kids love them. They do maths and add and subtract and they don't even realise they're doing maths. I've had them say to me at the end of a lesson, when are we going to do maths? The children were quite engaged for the whole time. It moves and makes noises and things like that and I can't make anything like that. I'd like to be able to make something like that but I can't at this point so it solves the problem. It's a little bit more than just rolling a dice and a dice rolling across the floor. It was quick and easy and kept their attention. (02.04.09)

Wendy stated that the students loved playing the bowling game on the IWB and she was amazed at the mathematical learning occurring.So it was very interesting to hear Wendy talk about the problems the students had when she replicated the bowling game with counters on the mat. Wendy explained:

After you left I used the counters and said I have this many counters and l'd bowled away this many how many have I left? They couldn't tell me how many I had bowled away even though they could tell me on the board. Strange, very peculiar! (02.04.09)

It is difficult to say why the students were unable to replicate the bowling game using the counters but I did wonder if writing down the equation at the 
side of the IWB as the ten pin bowls were knocked may have helped the students learn how to record in number form the bowls being knocked over. I agree with Wood and Ashfield's (2008) observation that with a huge number of ready made teaching resources available for the IWB, "it is possible that a teacher may be controlled by the design of the software rather than the reverse... and take on the role of software operator: acting as a human conduit between class and software" (p.95).

\section{Benefits of using an IWB}

During the interview Wendy explained what she liked most about using an IWB in her class:

Honestly I have to say that it would be the fact that it's all whizzy bang and its bright colours. It's quite a lot of fun to use. I like the technology myself. I think it makes a difference for the children too. It seems to be more fun than just getting out a piece of paper and a vivid. The kids just don't even really know they're learning half the time (02.02.09).

Whilst Smith et al, (2005) and Haldane, (2007) emphasise that students find IWB use highly engaging and motivating, Wendy's comment suggests that teachers do as well. The teacher survey responses further supports this, with one teacher stating love the resources you can make and use with the kids (R26).

In summary, Wendy experienced in her three years of IWB use many forms of professional development. She felt she had completed all the professional development and training available from other teachers and just trying things herself had been the most helpful experience. Wendy was clearly very advanced in using the tools of the IWB, enjoyed using the technology, and thought it was fun for the students too. 


\subsection{Nikau Grove School}

Nikau Grove School is a contributing primary school (for students Year 1-6, $5-10 \mathrm{yr}$ students) with a roll of 283 students and twelve fulltime teachers. It is a decile 10 school in a semi-rural area in the South Island. Liz taught a Year 1 class of 20 five to six year old children. I knew from the teacher survey that Liz had 16-20 years of teaching practice. She was not given the choice of having an IWB in her classroom but wanted one anyway. There was only one place an IWB could go in her room so placement was not an issue. Liz had been using an IWB for 13-18 months and on the survey rated she herself as an advanced user: the teacher involves the students in using the IWB and shows a high level of skill in using the software. All the IWBs at Nikau Grover School were Promethean and had been donated by the local licensing trust.

\section{Liz's IWB training and professional development}

Liz was away the first term that the IWB was in her room so missed out on the initial training other teachers received from the supplier as soon as they were installed. Upon her return she did receive similar training about a month later from the IWB advisor. (The local licensing trust employed a full time IWB advisor, from the IWB supplier, to provide training and professional development in the area). This person was on call to any teacher who needed support or help with a problem when using the IWB. The training was on-going and took place during school assembly so that the teacher wanting training could be released from his/her class. Liz said that the most helpful form of training she had was being shown what the board is capable of doing and having the support available to help if she was having problems trying to do something on it. She had other professional development in the form of visits to other classes/schools, collaboration with a colleague, an external expert demonstrating in her class, participation in a professional community, reading current research and visiting a Promethean (a brand of IWB) website. 


\section{Liz's use of an IWB in her classroom}

On the day of my observation (06.04.09) Liz's classroom timetable was as follows:

Table 17: Liz's classroom timetable

\begin{tabular}{rll}
\hline 8.50 & Roll/Adminstration & \\
9.00 & Newsboard & IWB use \\
$\mathbf{9 . 1 0}$ & Maths & IWB use \\
10.00 & Interval & \\
10.20 & Browsing boxes & \\
10.30 & Reading & \\
11.30 & Brain break/Fitness & \\
$\mathbf{1 1 . 4 0}$ & Written language & \\
12.15 & Oral language & \\
12.30 & Lunch & \\
1.30 & Printing & \\
$\mathbf{1 . 4 5}$ & Inquiry & \\
2.45 & Tidy up & \\
2.50 & Game outside & \\
3.00 & School finishes & \\
\hline
\end{tabular}

Liz used the IWB for whole class lessons and incorporated flipcharts that she had created herself. Each of these IWB sessions is outlined below. 
Table 18: Observation 9: Roll/News board

Time: 9.00-9.10am

Subject: Roll/Newsboard

Lesson Objective: To call the roll and discuss the forthcoming Easter holiday.

Software/website being used: Teacher made flipchart

Whole class/group/individual use of the IWB: Whole class

Objective for using the IWB: Tools were used 'hide' the students' photos

What was observed:

Liz discussed with the class the exciting news that it was Easter at the end of the week and asked will Easter Bunny be bringing some eggs? She then flipped on to a chart on the IWB that had a class photo. An Easter egg had been superimposed over their bodies, which the students found very funny. They were all glued to the IWB screen as Liz tapped each photo to call the roll. After the roll was called the students told their personal news.

This lesson clearly illustrated how proficient Liz was in using the tools of the IWB. Furthermore, her flipcharts addressed the interests of her young students, who are at an age where they love seeing themselves on the big screen and hearing themselves speak. This activity could have been replicated on a piece of paper but it would have taken a long time to prepare this. Downloading a photo of each child, importing a graphic over the photo and then making it a clickable graphic is evidence of a technically proficient IWB user at the advanced stage (Beauchamp, 2004).

Next the IWB was used during a Mathematics lesson. 
Table 19: Observation 10: Mathematics

Time: 9.15-9.30am

Subject: Mathematics

Software/website being used: IWB tools: the pens, their colours and widths Whole class/group/individual use of the IWB: Class and then group

Objective of lesson: Identify the family of facts for numbers to 10 , practice forming numbers to 100

How the IWB was being used: As a whiteboard that everyone could see

\section{What was observed:}

The class was sitting in front of the IWB and Liz asked what the family of facts are for 6 ? She recorded the student answers on the IWB: $5+1=6 \quad 1+5=6$ until all the facts were on the board. Liz then sent one maths groups off to work on independent maths activities one group was left at the IWB and Liz worked with the remaining group. The group of four children at the IWB practised writing numbers 1 to 100 on the IWB. They had turns at the IWB in pairs. One child would call out the number and another wrote it on the IWB. I noticed one student Jamie, spent a lot of time choosing which colour to use and what width. He wrote number 37 and said "it's a bit too light". He chose a dark green and said "no, l'll rub it out because it's too thin. Jamie chose a thicker width and another colour blue and was happy with that. This group moved to another activity when they had all had a turn.

In this observation Liz used the IWB as a substitute for a whiteboard. The family of facts exercise was a warm up for the maths that was to follow. The group activity could also have been carried out on a whiteboard or with pen and paper and possibly even completed sooner. Jamie seemed to take a long time to decide which colour pen to use on the IWB. Interestingly, the other three children in his group all continued to watch him trying out different colour and widths of the pen. From my personal experience it seems that many five year old children love experimenting with different colours on the IWB and like to see specific colours used rather than just choosing one form the menu. Allowing the children to use the IWB independently provides the opportunity for them to develop their skills and confidence in using one and is a feature of an IWB user at the initiate stage of use (Beauchamp, 2004). 
The next incident when the IWB was used occurred during Literacy.

Table 20: Observation 11: Literacy

Time: $11.20-11.35 \mathrm{am}$

Subject: Literacy: letter of the week/spelling/word of the week

Lesson Objective: Recognise the letter ' $v$ ' and the sound it makes

Software/website being used: Teacher prepared flipchart

Whole class/group/individual use of the IWB: Class

Objective of using IWB: As a big screen that everyone could see

\section{What was observed:}

The class was sitting in front of the IWB and Liz asked what the letter of the week was.

Liz changed the flipchart on the IWB to show a template which included the letter of the week: $v$, a picture of a vase and a poem with lots of ' $v$ ' words in it. Amy was asked to go up and tap the vase with the IWB pointer. When she did this a prerecorded sound for ' $v$ ' was heard. The students then read the poem together. Liz brought up on the screen a link to a video clip of a volcano erupting which had the students exclaiming in wonder.

\section{Spelling}

Liz changed to another flipchart, which had four rows of three numbers in each row. There was a basic sight word hidden behind each number. Rosa was called up to click on a number. When she clicked on three the box disappeared and was replaced by the word 'went'. Rosa recognised this word, said it and spelt it out. Rosa chose another student who was sitting 'nicely' to pick another number on the IWB. This game continued until all the numbers had been chosen.

\section{Word of the week}

After the spelling game Liz changed to the next flipchart entitled 'Our word of the week is 'are'. Below that were are, one, are, ane, are, ar, are. Jonty was chosen to come up and circle in red the words that spell 'are' and cross out the words that were wrong. As Jonty did this the rest of the students were all watching the board carefully. 
The letter of the week lesson was another example of Liz's advanced technical skills with the IWB: inserting a link to a website to show a volcano erupting, for the letter ' $v$ ' is further evidence that she is an advanced user of the IWB. Seeing a volcano erupt by virtual reality was seamlessly integrated in the children's learning. It is also an example of how the 'real world' can be brought in to the classroom through the multimedia capabilities of an IWB. According to Beauchamp (2004), using the IWB to illustrate specific points is also a feature of the advanced stage of use. The spelling and word of the week charts were created by Liz specifically to meet her students' needs. These charts could have been replicated on a whiteboard or paper but once used could not have been used again. This illustrates how creating flipcharts on an IWB can save teacher time in preparation as they can be used, undone and saved for future use.

The final use of the IWB before lunchtime was for story writing.

Table 21: Observation 12: Story writing

Time: 11.40-11.50am

Subject: Literacy: Writing

Lesson Objective: To model writing and editing a story

Software/website being used: Teacher prepared flipchart

Whole class/group/individual use of the IWB: Class

Objective of using IWB: So the whole class could observe the modelling of writing on a big screen.

\section{What was observed:}

Liz used the IWB to model writing a story about Easter and began by asking the children "what do I need to be a great writer?" Samantha replied "write on the lines" and Danielle said "use a finger space." As Liz wrote she sounded out the spelling of the words she used. After writing four sentences Liz finished the story and asked again "what makes a good writer?"

"Finger space after each word," responded David. Liz used the highlighter tool on the IWB to highlight the space between each word in the story. She then asked what 
comes at the end of each sentence. "A full stop" replied Felix. Liz asked Felix to go up to the IWB and highlight each full stop. Felix chose the colour of highlighter he wanted to use by tapping on the colour menu and activating the green one.

Liz talked about trying the words you didn't know how to spell and how these words need to be underlined. She used a green highlighter from the IWB menu to underline words the children thought weren't spelt correctly in the first sentence. Liz then asked Paddy to underline words he wasn't sure of in the second sentence using the green highlighter pen.

Paddy quickly used the IWB pen to activate the green highlighter from the colour menu and underline any words he wasn't sure of in the second sentence. Paddy chose Jasmine to underline words in the third sentence using the green highlighter and Simon completed the task in the third sentence. Liz then sent the children to their desks to write a story about Easter.

Like Wendy, Liz used the IWB to model story writing just as one might use a whiteboard or pen and paper. Again the difference was that the whole class can see the IWB easily and the children appeared to be completely focused on what was happening on it. They knew they had to be sitting still, watching the work going on to be the next person chosen to use the IWB highlighter pen. This outcome appeared to be highly motivating for the children as they seemed to enjoy using the IWB tools. Allowing students to use the IWB is an indicator of an IWB user at the apprentice level (Beauchamp, 2004).

The final use of the IWB for the day was for a goal setting exercise. 
Table 22: Observation 13: Goal setting

Time: $1.45-2.10$

Subject: Goal Setting

Lesson Objective: Students to verbalise their learning goal for the following term. Also to give the students practice at speaking into a microphone by recording each student saying what their personal learning goal would be and why.

Software/website being used: Teacher prepared flipchart

Whole class/group/individual use of the IWB: Class

Objective of using IWB: There was a flipchart with a class photo of all the students. The recording of each student talking was linked to their photo so that when their photo was tapped, you heard the student saying their goal. Liz planned to have this class photo on the IWB on the parent conferencing night so they could hear their child say what their goal was going to be. Liz said she thought this would be a novel way of the child sharing the goal with the parent rather than have the child write it down and the parents would enjoy hearing their child talk.

\section{What was observed:}

Liz had the flipchart of the class photo up on the IWB and she called each child up to the computer that was attached to the IWB. Amy was the first child to go up and record her goal which was "to remember to bring my book bag in each morning to my group basket so that I do not have to go out and get my book bag when reading starts." Liz played back the recording for Amy to hear and to check that was her goal. Liz then attached this sound file to Amy's photo and asked Amy to click on her photo. Amy smiled widely and laughed when she heard her voice. The rest of the class had been given a choosing time and they all stopped what they were doing to listen to Amy. Liz proceeded to record each child's goal on the same manner and each time the whole class would stop, watch the child click on his/her photo and listen to that child's goal.

This observation was another example of Liz's technical expertise in using the computer and IWB to record a sound file and create a clickable graphic. It also showed how Liz was happy to spend time creating something special for her students. I do not know how this task could have been replicated without 
an IWB. It was further evidence that Liz was at the advanced stage of IWB use.

\section{Interview with Liz}

Liz did not wish to discuss any particular lesson that used the IWB, stating I don't use it as a lesson, it's through my day (06.04.09).

In her survey response, she noted what she liked most about using an IWB was that it was fun to use and everyone could see it. During the interview she re-iterated this point and spoke about how engaging she personally found it to use: I probably like the creativity of it too for me, when I'm preparing lessons I like being creative...there are lots and lots of pluses (06.04.09).

Liz, like Kathy, also talked about having access to the internet as another benefit:
I think having the access to the internet through the whiteboard too is very good for showing children things, when the site is working. I think that's quite a good thing because if you're finding out information you can go very quickly to get it and the whole class can see (06.40.09).

Liz's flipchart about the letter ' $v$ ' was certainly evidence that she makes use of the internet with its link to the volcano erupting.

To briefly summarise, Liz had experienced a range of professional development experiences, with some training on-going. Liz's use of the IWB showed she had advanced technical skills, which she frequently used when creating lessons to support her students' learning needs. What Liz liked most the IWB was that it was fun to use, everyone could see it and there was instant access to the internet. 


\subsection{Chapter summary}

This chapter examined how three junior class ( $\mathrm{Y} 1 / 2)$ teachers used an IWB in their programme. They used the IWB throughout the day with a mixture of the whole class and groups, and predominately in Literacy and Numeracy. Wendy and Liz were very skilled in using the tools of the IWB. Although their experience in using an IWB ranged from Kathy's one year to Wendy's three years, they all stated similar benefits for using one. They found IWBs highly motivating and engaging for their students, and fun to use. The affordance of instant assess to the internet was another benefit highlighted. All teachers commented that they preferred teaching with one.

In the next chapter the professional development experiences of these three teachers, how they use an IWB and the contextual factors that enhanced or constrained their use of one are evaluated. 


\section{CHAPTER 7}

Factors that support and hinder teachers learning to use an IWB

\subsection{Introduction}

In this chapter I examine the case study teachers' professional development and how they use an IWB. This included the curriculum areas they used the IWB in, specific resources used for planning and teaching with one, and what they thought was an effective use of IWBs. Finally, I consider the factors that enhanced and hindered the teachers' use of it.

\subsection{Professional development experiences}

As one of my research questions relates to IWB professional development and how it impacts on IWB use in the classroom, it was interesting to compare each of the three teachers' experiences and thoughts on the professional development they had, which were discussed in the follow-up interview. The three teachers were at different stages of professional development, as summarised in Table 23.

Table 23: Summary of the 3 teachers' professional development

\begin{tabular}{|c|c|c|c|c|c|c|}
\hline Teacher & $\begin{array}{l}\text { Class } \\
\text { level }\end{array}$ & $\begin{array}{c}\text { Years of } \\
\text { teaching } \\
\text { experience }\end{array}$ & $\begin{array}{c}\text { Time } \\
\text { using } \\
\text { an IWB }\end{array}$ & $\begin{array}{l}\text { Stage of } \\
\text { IWB use }\end{array}$ & $\begin{array}{l}\text { Stage of } \\
\text { training } \\
\text { and PD }\end{array}$ & $\begin{array}{c}\text { How they rated forms } \\
\text { of PD }\end{array}$ \\
\hline Kathy & Y1 & $26-30$ yrs & $1 \mathrm{yr}$ & initiate & $\begin{array}{l}\text { one } \\
\text { session } \\
\text { to go }\end{array}$ & $\begin{array}{l}\text { 1. Participation in a } \\
\text { professional } \\
\text { community } \\
\text { 2. Collaboration with a } \\
\text { colleague } \\
\text { 3. External expert } \\
\text { visiting }\end{array}$ \\
\hline
\end{tabular}




\begin{tabular}{|c|c|c|c|c|c|c|}
\hline Wendy & Y2 & 5 yrs & $3 \mathrm{yr}$ & blackboard $^{5}$ & completed & $\begin{array}{l}\text { 1. Collaboration with a } \\
\text { colleague } \\
\text { 2. Participation in a } \\
\text { professional } \\
\text { community } \\
\text { 3. Conferences }\end{array}$ \\
\hline Liz & $\mathrm{Y} 1$ & 16-20yrs & $2 y r$ & advanced & on-going & $\begin{array}{l}\text { 1. External expert } \\
\text { demonstrating in her } \\
\text { class } \\
\text { 2. Collaboration with a } \\
\text { colleague } \\
\text { 3. Visits to other } \\
\text { classes/schools }\end{array}$ \\
\hline
\end{tabular}

Interestingly, Kathy's number one choice of professional development was only ranked first by $12 \%$ of the survey respondents, compared to $33 \%$ who valued an external expert visiting as being most valuable. Wendy's ratings, however, differed to the many of the survey respondents, with 33\% ranking an external expert visiting as the most valued form of professional development, which she did not rank. Liz was one of the $33 \%$ of survey respondents who rated an external expert visiting as the most valuable.

Kathy, Wendy and Liz were all at different stages of professional development, with Liz being the only one with on-going and sustained PD. This seemed to encourage Liz to try different things on the IWB as she knew that help was only a phone call or e-mail away. Wendy appeared to feel that she had completed her professional development and felt that now her use of it would expand as she became a more experienced teacher. Kathy, on the other hand, had the least training and professional development but even at that early stage she was eager to use the IWB to support learning rather than learning to use the board (25.03.09). 'Just in time' training is what Kathy

\footnotetext{
${ }^{5}$ Wendy rated her IWB use as being at the blackboard stage but my classroom observation showed that this was clearly not the case. The classroom observation showed she was the advanced user stage: the teacher involves the students in using the IWB and shows a high level of skill in using the software.
} 
wanted more of rather than the 'just in case' training she had had to date (Hixon \& Buckenmeyer, 2009).

\subsection{IWB use}

Another research question asked which curriculum area teachers use the IWB in and whether it was predominately with the whole class, groups or a mixture. The following table provides a comparison of these areas.

Table 24: summary of IWB use

\begin{tabular}{|c|c|c|c|c|}
\hline \multirow[t]{2}{*}{ Teacher } & \multicolumn{2}{|c|}{ Survey response } & \multirow[t]{2}{*}{ Observation } & \multirow{2}{*}{$\begin{array}{l}\text { Whole } \\
\text { class/group/ } \\
\text { mixture of } \\
\text { both }\end{array}$} \\
\hline & $\begin{array}{l}\text { Curriculum Area } \\
\text { used in }\end{array}$ & $\begin{array}{l}\text { Mostly } \\
\text { used in }\end{array}$ & & \\
\hline Kathy & $\begin{array}{l}\text { Handwriting/Printing, } \\
\text { Music, morning roll call, } \\
\text { Mathematics, Reading, } \\
\text { Science, Social Studies, } \\
\text { Writing, working with } \\
\text { Special Needs students. }\end{array}$ & $\begin{array}{l}\text { Literacy } \\
\text { Numeracy }\end{array}$ & $\begin{array}{l}\text { Literacy } \\
\text { Numeracy } \\
\text { Te Reo Maori }\end{array}$ & Mixture \\
\hline Wendy & $\begin{array}{l}\text { Handwriting, } \\
\text { Mathematics, Reading, } \\
\text { Social Studies and } \\
\text { Writing }\end{array}$ & $\begin{array}{l}\text { Literacy } \\
\text { Numeracy }\end{array}$ & $\begin{array}{l}\text { Handwriting, } \\
\text { Mathematics, } \\
\text { Reading, } \\
\text { Writing }\end{array}$ & Mixture \\
\hline Liz & $\begin{array}{l}\text { Dance, Printing, } \\
\text { Languages, Music, } \\
\text { Newsboard, } \\
\text { Mathematics/Numeracy, } \\
\text { Reading Inquiry, Te Reo } \\
\text { Maori and Writing. }\end{array}$ & $\begin{array}{l}\text { Literacy } \\
\text { Numeracy }\end{array}$ & & Mixture \\
\hline
\end{tabular}

To summarise, Kathy, Wendy and Liz used the IWB mostly in Literacy and Numeracy. This was also the case with the majority of the survey respondents. Liz, for instance, stated this was because that was where the 
need is and I can design flipcharts to engage children in my room. Also there are lots of on-line resources in Literacy and Numeracy (06.04.09).

All three teachers used the IWB in a similar manner with writing lessons, whereby the children used IWB tools such as the highlighter, different coloured pens, and the stamp to edit writing that the teacher had modelled on the IWB. As with $66 \%$ of survey respondents Kathy, Wendy and Liz used the IWB for a mixture of whole class teaching and for small groups to work on it independently.

\section{Specific resources used for planning and teaching with the IWB}

As it was not included in the teacher survey, one of the interview questions was about the planning and teaching resources teachers used with the IWB. Kathy used games found on the internet to support student learning such as the whale bond game her students used in maths, simply because it is time good for me. It's quick, it's easy (25.03.09.) A series of books: Learning Journeys with ICT: Interactive Whiteboards by Angie Simons had provided Kathy with really good ideas on how to use the IWB in a classroom programme. Kathy had been sent by e-mail, collections of flipcharts for specific topics such as dinosaurs, by her trainer. She said the supplier's website has many collections that can be easily downloaded but it is a matter of having the time to browse through and do this.

Wendy stated that the teachers at her school did not plan specifically to use the IWB, rather if there was an activity that goes with what was planned then they would use it. This is in line with Bennett and Lockyer (2008) finding that "it was clear that the lesson content and learning objectives determined the use of the IWB rather than the teachers looking for opportunities to exploit the IWBs potential" (p.298). In her discussion about a specific lesson, maths, Wendy said she often used a software package of maths games that came with the IWB. In regard to planning Wendy did add at the end of the interview that we don't have a set way of using the IWB in terms of how to plan, which now I think about it, could be quite useful (02.04.09). 
Liz, on the other hand, made use of the IWBs brand website and the internet when planning and teaching with the IWB. She innovated on ideas from a variety of sources as shown by the following comment:

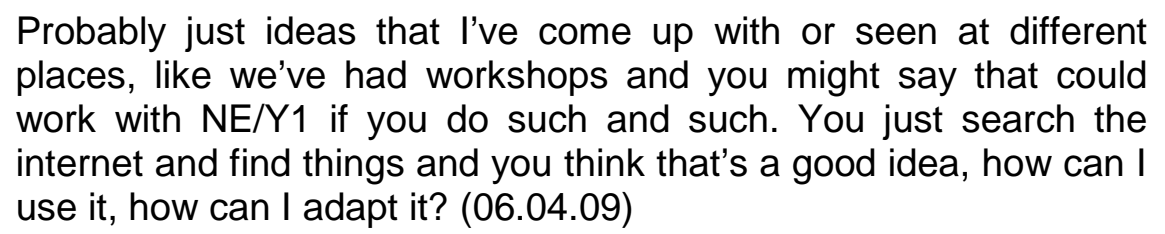

This points to how Liz uses a social constructivist process of building up her knowledge of IWB use. This process, as Warwick and Kershner (2008) state, "takes the form of reciprocal interaction as people move between different activities and contexts, bringing knowledge gained elsewhere, participating in knowledge-building activities and, in turn, taking the transformed thinking forward to new activities" (p.281).

Games from websites were popular with all three teachers. Kathy and Liz created flipcharts and used games from websites to specifically cater for their students' needs whilst Wendy used commercially made games. Both Kathy and Liz acknowledged the large amount of time you could spend making flipcharts on the IWB but still created flipcharts for specific lessons. Wendy's attitude appeared to differ as making the resources doesn't seem to me to be the most useful way to use my time (02.04.09).

\section{An effective use of the IWB}

During the interviews I was interested to hear the teachers' thoughts on what they felt was the most effective use of an IWB. Kathy, for instance, thought that modelling is probably one of the best things to do on the IWB. Although she did not use it that day for writing Kathy said the students love editing writing on the IWB, changing the pen colours to do so. She felt that modelling a software programme such as Kid Pix on the IWB rather than the computer was a very effective way for the students to learn how to use a programme. Furthermore, Kathy found that when the students were using the Kid Pix on the IWB independently, the large screen allowed her to see exactly how they 
are using it, what stage they are at in learning and what the next step was for her to teach them to use the tools of Kid Pix. It appears that from such observations Kathy made informal assessments of the students' needs and subsequently identified her next teaching step with Kid Pix:

I need to do a lot more modelling with it now to get them past just playing with the pictures and things and start actually create stories. I think it's got that potential that I can do that so well and if I can model it up there then they can use the computers more independently as a result (25.03.09).

Kathy stated how she can also correct things for them while they were using the IWB, which was a lot easier than when they were on the computer.

For Wendy, however, the most effective use of the IWB was the record and playback function which she had learn from another teacher in the previous year and felt it had made such a huge difference. Wendy was clearly very excited about this function:

I love the record and playback function, it's got so many uses. The kids love the handwriting with the recorded playback and I love it as I get to walk around and see what they're doing and they can play it back another time if they want to and look at it. There's no way that I could do that anywhere else. I can record something earlier and say this is how you play this game or this is how you do this activity or this is how you make this letter. And even if I'm doing something else around the room they can play it back themselves and have me teaching there as opposed coming up to me and interrupting me or having to feel bad because they've asked for the fifth time how to do something. So that's a function that just can't be compared (02.04.09).

Liz, in contrast, thought there were many effective uses of the IWB, however she did specify how she used it for an Inquiry topic that worked very well as a pre and post assessment:

We did metals so in the context of metals if you thought something was a metal or something wasn't, agree or disagree, the children were able to move their photo into the agree or disagree boxes. And then at the end of the inquiry we had the same things and could compare who had changed their mind on that question. I thought that was quite effective. They liked moving their little pictures to where they thought. And then someone might say l've changed my mind because "..." and move it out and in to the other box. So that was quite good as an inquiry thing (06.04.09). 
I thought it significant that all three teachers spoke about a different aspect of the IWB as being most effective. This may reflect their stage of IWB use. For example, Kathy may not have known about the record and playback function. This could also reflect the type of professional development they had experienced and what they had seen carried out on the IWB.

\subsection{Factors that enhance the use of an IWB}

One of the reasons for carrying out this research was to examine the factors that enhance the use of an IWB. During the interviews I asked the three teachers what they believed these factors were. Kathy said there were two factors that helped her to use an IWB effectively in her teaching. Firstly, a knowledge of the IWB software and how you can use it. Secondly, time to plan how to use the IWB. These factors were also mentioned by $36 \%$ and $33 \%$ respectively, of survey respondents as challenges to using the IWB.

Wendy, like Kathy, cited knowledge of the IWB software and how you can use it as the main factor that helped her to use an IWB. As Wendy put it:

The more you use it the more confident you become with it and even little problems, like the board suddenly turning off don't become such a big deal. I think it's a lot harder to use it when you don't know how to use it yourself and it's a lot harder to feel confident about it. Also knowing what it can do means you can be doing something and it allows for the teachable moment a lot more. The board is actually really good for the teachable moment (02.04.09).

Liz, however, stated three main factors that enhanced her use of IWB. Firstly, the software programme on her IWB (Active Primary) was very user friendly and as a result it had not been difficult to use the IWB. It was interesting to hear Liz talk about the software programme being easy to use as $36 \%$ of survey respondents identified learning to use the IWB software as a challenge. Kathy and Liz had also identified knowing how to use all the software as a factor that enhanced their use of the IWB. Secondly, Liz said having on-going professional development was very beneficial. She had ready access to help if she had problems doing something on the IWB. To 
cite it as an enhancing factor in her use of the IWB, Liz's professional development experience appears to have been very effective. Perhaps this is because her on-going professional development allows for 'just in time' training (Hixon \& Buckenmeyer, 2009) that is specific to her individual needs. This was in contrast to Kathy's 'just in case' training. A third factor for Liz was being able to take a laptop home to work on planning and create flipcharts to be used on the IWB.

The one factor that all three teachers said enhanced their use of the IWB was knowing the software on the IWB and how to use it. This factor impacted on how each teacher used the IWB and is related to their professional development. For example, Kathy who had participated in only three training sessions to date said that she was aware of many different tools available on the IWB software but it was knowing what I can do with it and then having the time to plan to use it in a lesson (25.03.09). Wendy echoed similar thoughts as cited on the previous page.

Learning about the software on the IWB and how to use it is clearly a factor that needs to be re-examined by those providing professional development for teachers learning to use an IWB. It appears to hinder teachers moving on to the next stage of IWB use.

\subsection{Factors that hinder the use of an IWB}

I was interested too, to know what factors hindered the teachers' use of an IWB. During the interviews I asked each of the case study teachers this question. Not having enough time to get to know the tools of the board was a factor Kathy felt hindered her use of the IWB as it meant she could not yet use it as quickly and easily as she wanted to. Learning to use the technology of the IWB was a factor also cited by $36 \%$ of survey respondents as a challenge.

For Wendy, it was the amount of time needed to make resources and her lack of teaching experience. She stated this quite succinctly: 
Time and again experience, making the resources doesn't seem to me to be the most useful way to use my time. I'm still new to teaching myself, this is my fifth year now, so I think the better teacher I become the easier it will be to use the board (02.04.09).

This was a salient comment as no one in either the teacher or the principal survey stated teaching experience as a factor hindering their use of IWBs. Mouza (2006) argues that teaching experience is an important factor in using an IWB and Wendy's comment suggests this as well. She believed that having an IWB did not make her a better teacher rather it is her years of teaching experience that will improve her pedagogy.

Liz identified sunlight, access to the internet and time as factors that hindered her use of the IWB. The sunlight and amount of lightness in her classroom meant that at times the IWB could not be seen because of this. Eight percent of survey respondents mentioned the sunlight on the IWB as being problematic. When preparing work at home Liz often created links to websites but then had problems accessing these the next day at school because the internet was down. This was also a problem for $33 \%$ of survey respondents.

Just as Kathy and Wendy did, Liz also said time was a factor that hindered her use of the IWB. Liz said creating resources to use on the IWB for a lesson was quite time consuming: I scan books quite often and put them on and again it's a matter of do I have time to do that? (06.04.09). Time spent learning to use the IWB or creating flipcharts for lessons was stated by $33 \%$ of respondents as a hindrance. It was pertinent that Liz, who has on-going professional development, still cited time as a hindering factor. I believe this is a reflection of her being an advanced user who knows the software tools and enjoys the "excitement of discovering their impact on teaching and learning" (Beauchamp, 2004, p.340). Professional development with IWB needs to allow teachers time to learn and embed the content of sessions before moving on to something new. Both these factors are cited as characteristics of effective professional development by Timperley et al, (2007). 


\title{
7.6 The impact of professional development on the teachers' IWB use
}

The purpose of the classroom observations were to observe each teacher using the IWB and relate it where possible back to the professional development they had experienced. This was to ascertain what impact the professional development had on their IWB use, which was the main question of my study. In the context of the three teachers, the answer to this question will now be explored.

\section{Kathy}

Kathy made it clear that she enjoyed using an IWB and her current form of professional development was challenging:

\begin{abstract}
I wouldn't give it away now, I love using it. As far as PD goes you have to have time. You might have an hour's tutoring and then you need the rest of the day to play with what you've learnt and that's what's not happening. You get two and half hours flat out with a tutor and then you go away with your head stuffed full of ideas that you haven't really taken on board. I know I have been shown so many cool things like making the letters transparent and fading things in and out that I would love to be doing but I haven't just simply done it on my own. I have done it in my PD session but it's having time to come back and do it (25.03.09).
\end{abstract}

It appears that what is learnt in these training sessions was not retained. At the time of this interview there was no more professional development planned for Kathy after the supplied training sessions. From Kathy's comment above one may place her level of technical competence with the IWB software at the apprentice level. However, I believe that she had within a year of using an IWB moved to the next stage of use: the initiate stage. "The key development in this stage is an awareness of the potential of the IWB to change and enhance practice" (Beauchamp, 2004, p.338, author's italics). Kathy indicated this in her final comments in the interview:

My challenge now is to integrate the board into daily practice and to develop more complex flipcharts to support lessons and to teach the children how to use skills more specific to the IWB than the computers. More using the IWB to support learning rather than learning to use the board (25.03.09). 
She seems to be well aware of what stage she is at in the use of the IWB and where she is aiming to be in terms of her pedagogy.

\section{Wendy}

Wendy stated that she had finished her professional development with the IWB so it is difficult to say what impact her initial training had on the skills she has developed in using it over the last three years. In terms of her technical knowledge Wendy was clearly very skilled in using the tools of the IWB and programme variables such as sound files and hyperlinks to the websites. According to Beauchamp (2004), these skills are at the level of an advanced user, one level away from the final stage in the transition framework. However, in terms of Wendy's pedagogy I thought she was not beyond the initiate stage of IWB use as the way in which her students used the IWB was always teacher initiated and planned. Her students predominately used the IWB to play games from the internet or the IWB's software. Wendy did not appear to create flipcharts specifically for her students needs when there are so many already available. When asked if there was any additional or further comments she would like to make, Wendy made pertinent comments about the professional development available for teachers using IWB and her hope for future users:

l've had quite a lot of professional development. I think l've mentioned before that I'm a generation of computers. I've grew up with computers so it wasn't too hard for me. I think there is a certain level of professional development available for teachers who are coming in new but I think that there needs to be a lot more. That's part of my job is to provide that and make sure there are opportunities for that. I also think, teachers as a whole, we would benefit from being a lot more co-operative and a lot more sharing with our resources and our ideas and things like that so that we're not all continually making the same resources for the same thing. Hopefully we will get to that point as more and more teachers become familiar with the boards (02.04.09).

I found it significant that Wendy began by acknowledging that there are stages a teacher goes through in using an IWB:

Even though l've had it for that many years l've used it for various things over that time and there's a process you go through. When I first used it I used it like a whiteboard for handwriting and story writing. Over the years l've just become more 'au fait' with it. 
I'm still at the stage of working out what resources fit in with it. (02.04.09)

I believe that many teachers beginning to use an IWB would be heartened to hear from an experienced IWB user that this is the case. Wendy's comment also suggests the need for sustained professional development to further expertise in the use of the IWB, and in terms of the transition framework move to the final stage of being a synergistic user. It should be noted that Beauchamp (2004) found only one teacher who was approaching this stage of use by "focusing on the opportunities offered by the IWB to create new learning scenarios (rather than reinterpreting existing strategies) where teacher and pupils work together to achieve learning objectives" (p.343).

\section{Liz}

Of the teachers observed I thought that Liz was very close to being in the final stage of Beauchamp's framework: the synergistic user, even with her young five year old students. She was the only teacher to have sustained professional development and this seemed to encourage her to try lots of new activities and tasks with the IWB as she knew if she struck a problem help was available.

Liz also spoke about the impact using an IWB has on some children's confidence:

I think that for children who actually don't contribute a lot in the classroom orally and they're not very confident I think that the whiteboard gives them a lot of confidence and it's just because we encourage the children to do things and to try it out and if you make a mistake then that's fine (06.04.09).

This was similar to an observation made by Beauchamp (2004) about lower ability children using the IWB:

They seem to be more prepared to have a go if they think they can come out and have a go on the board; they're not bothered whether they get it wrong or not because they're coming out and they're using the pen, they just have a try, they love it (p.339).

None of the survey respondents mentioned the IWB as being helpful in building up children's confidence. The interview perhaps gave Liz more time 
to reflect on different aspects of the IWB and respond with comments she had not thought of at the time of the survey. Liz finished the interview with the following reflections, which succinctly summed up what her view on the need for sustained professional development and how using an IWB has changed her pedagogy:

We are really grateful that we have got the ILT funding for this and the PD as a follow up because some teachers would be lost without it. I look at it and think I have been teaching for so long and yet it is amazing what this can do. It's really opened up my teaching because I used to take the newsprint home and do the news board on the newsprint and it was so boring. Now I look at it and I think it has just opened up the world, as far as being creative, the colour on it, all those things, the size of the pens are good, and it gives children some choice about what they want to do. I would just hate to go teaching without a whiteboard now (06.04.09).

\subsection{Chapter summary}

Each of the teachers experienced different forms of professional development. Liz was the only teacher who had on-going and sustained professional development and was the most advanced user of the IWB. All three teachers felt that knowing the software on the IWB and how to use it enhanced its affordances. Conversely, having the time to learn to use the software and to create specific flipcharts to meet the learning needs of the children in their class was the factor that most hindered their IWB use.

In the next chapter I will discuss the key findings of my study. 


\section{CHAPTER 8 \\ Discussion of results and conclusion}

\subsection{Introduction}

This chapter critically examines the results of the teacher and principal surveys, the classroom observations, teacher interviews and documentation. It addresses the research questions. Recommendations are made regarding the type of professional development for teachers using an IWB that appears to effectively impact on their use in the classroom. Finally, the limitations of this thesis and possibilities for future research on professional development for teachers learning to use an IWB and children using one are discussed.

When analysing the data problems with the IWB training and professional development were identified. Teacher pedagogy when using an IWB was also investigated. This data provide the answers to the key question of my research: how does professional development impact on teachers' use of an interactive whiteboard (IWB) in a New Zealand Primary classroom?

The following sub questions were also asked.

(i) What form of professional development did the teachers have before and after the installation of the IWB?

(ii) What contextual factors enhance the introduction of an IWB for a teacher learning to use it in their class programme?

(iii) What contextual factors constrain the introduction of an IWB for a teacher learning to use it in their class programme?

(iv) How is an IWB used in the classroom programme?

The answers to these questions are critically examined below. 


\subsection{How does professional development impact on teachers' use of an interactive whiteboard (IWB) in a New Zealand Primary school?}

The type of professional development that appears to have the most impact on teachers' learning to use an IWB in the classroom is external experts demonstrating in classrooms, visiting colleagues in the same or other schools to observe an IWB being used and on-going professional development. Timperley et al. (2007) assert that sustained professional development is a characteristic of effective professional development. The participants in my study certainly supported the need for that. Furthermore, these forms of professional development all demonstrate Vygotsky's (1978) socio-cultural theory. An external expert scaffolded the teacher's learning to use the IWB, and an observation in another class provides the opportunity for both teachers to interact and learn from each other. In addition, on-going professional development allows for collective scaffolding among groups of teachers.

I also identified another possible factor impacting on how teachers use the IWB in the classroom, which is years of teaching experience. This was particularly evident from these teachers. Kathy had taught over 26 years, Liz had taught between 16-20 years and Wendy was in her fifth year of teaching. All three used IWB games from the internet. However, it was noticeable that Kathy and Liz used the IWB to meet the specific needs of their students. Whilst Wendy felt it was a not a good use of her time to make flipcharts for her students when there were so many available on the internet, Kathy and Liz were happy to create these to meet and enhance the learning objectives of their lessons. Wendy did, however, acknowledge that further teaching experience would enhance her use of the IWB. 


\subsection{What form of professional development did the teachers have before and after the installation of the IWB?}

The majority of survey respondents (92\%) received professional development. This was predominately training sessions to learn to use the basic tools of the IWB. Many tools, common to all brands of IWBs, include pens that come in a range of colours, thickness, and transparency levels for writing, highlighting or drawing, shapes, stamps, tools to drop and drag, layer, magnify or spotlight, camera, screen shade and a tool with a recording function. The survey respondents participating in these training sessions were also shown how to make flipcharts. ${ }^{6}$ Seventy-two percent underwent training before or as soon as an IWB was installed in their room. Another $22 \%$ received training from a week to a month or more after it had been installed, while $6 \%$ received no training at all. Eighty percent of this training was carried out in the teachers' own time, either in their lunch hour or after school.

The number of training sessions ranged from one session of twenty minutes to what was more common: two sessions of one to two hours long. Of interest, the training for $92 \%$ of respondents was provided by the IWB supplier in group sessions of six to eight teachers. When the training sessions were completed further professional development was left to schools to fund and arrange. The survey responses indicated that colleagues were the main source of professional development and it was largely up to teachers to make time to learn how to use the IWB in their programmes. After initial training, the form of professional development most commonly experienced was collaboration with a colleague and then visits to other classes or schools using an IWB for lesson observations and an external expert visiting and demonstrating in your classroom.

\footnotetext{
${ }^{6}$ The IWB screen is used to write on like a page in a book. Each IWB manufacturer has a different terminology for this page as described by Betcher and Lee (2009) "dedicated IWB software is generally based on a series of screens that can be flipped as individual pages (On a SMART Board these screens are referred to as a'notebook', Interwrite call theirs a 'workbook', Easiteach uses the term 'easibook' and Promenthan refer to theirs as a 'flipchart')" (p.81).
} 


\subsection{What contextual factors enhance the introduction of an IWB for a teacher learning to use it in their class programme?}

From the data emerged five factors that appear to enhance teachers learning to use an IWB in their classroom. These were time, type of professional development, sustained professional development, years of teaching experience and level of computer skills. Each one is examined separately below.

\section{Time}

Being provided with time to learn how to use the software on the IWB and then develop teaching materials with it was cited by many teachers (33\%) as a factor that enhanced their use of the IWB. Teachers said they knew what the software was capable of but felt they did not have the time to play around and learn to use it. Some teachers (11\%) suggested having classroom release time that focused entirely on using the tools of the IWB would be very beneficial. Providing teachers with such opportunities to try out different practices with new technology and reflect on it is effective professional development for integrating new technology into a classroom programme (Mouza, 2006; Miller \& Glover, 2007).

\section{Type of professional development}

The type of professional development that teachers found to be most helpful was an external expert visiting and demonstrating on the IWB in the classroom, and secondly visits to other classes and schools to observe one being used. The teachers were able to observe lessons in an authentic classroom context and then take back what they saw to adapt and use in their own classroom. As Timperley et al. (2007) assert, the content of the professional development is critical and both types of visits provided teachers with content to further develop their use of an IWB in classroom programmes. 


\section{Sustained professional development}

Survey respondents from two areas, Hastings and Invercargill, had sustained professional development from an IWB mentor or advisor. In Hastings a mentor was provided by a cluster of schools pooling resources together to pay for a teacher to fulfil this role on a part time basis. Invercargill, on the other hand, was fortunate to have their local licensing trust pay for a full time IWB advisor who was freely available to all schools with an IWB in the region. Some idea of the impact of this sustained professional development may be gained by looking at what stage of IWB use the teachers from these two areas placed themselves at. Forty-five percent of respondents came from Hastings (28\%) and Invercargill (17\%). The other fifty-five percent of respondents had either no or unspecified sustained professional development. The table below identifies at what stage of IWB use respondents with sustained professional development placed themselves.

Table 25: Stage of IWB users with sustained professional development

\begin{tabular}{lcccc}
\hline Stage of IWB use & $\begin{array}{c}\text { Survey } \\
\text { respondents } \\
\text { at this level }\end{array}$ & $\begin{array}{c}\text { Respondents } \\
\text { with } \\
\text { sustained PD }\end{array}$ & Invercargill & Hastings \\
\hline $\begin{array}{l}\text { Black/whiteboard } \\
\text { substitute }\end{array}$ & 2 & & & \\
Apprentice & 9 & 1 & 6 & 1 \\
Initiate & 19 & 9 & 4 & 3 \\
\hline Advanced & 25 & 14 & 1 & 4 \\
\hline Synergistic & 9 & 5 & 10 \\
\hline
\end{tabular}

Respondents with sustained professional development represented over half of all respondents at the two highest stages of IWB use: advanced and synergistic. Sustained professional development appears to have a positive impact on how teachers use an IWB in their classroom and assists them to move on to the final stages of IWB use. 
Fifty-eight percent of survey respondents made additional comments in relation to professional development and learning to use an IWB. Twenty-six percent of those comments identified the need for sustained professional development. Interestingly, $50 \%$ of those comments were made from respondents who had used an IWB for over two years, yet still clearly felt the need for sustained professional development. According to Beauchamp (2004), without providing sustained professional development teachers are unlikely to progress further along the stages of IWB use and change their pedagogy. Liz, one of the case study teachers, provided further evidence of the benefits of sustained professional development. She had ready access to help when she was trying to use it in a new way or encountered a problem with the IWB. As a result, Liz was always thinking of new ways to use the IWB in her programme to meet the needs of her students. Furthermore, sustained professional development enhances the development of professional communities among teachers and "strong professional communities empower teachers and provide a context for sustained learning" (McLaughlin \& Talbert, 1993, as cited in Mouza, 2006, p.408). However, finding a way to sustain professional development in the use of an IWB is a challenge for schools.

\section{Years of teaching experience}

My findings suggest that the years of teaching experience may lead to a change in teacher pedagogy with an IWB. Eighty-two percent of the survey respondents felt that using an IWB had changed their pedagogy. Twentyeight percent of respondents said their role had become more of a facilitator and collaborative. Eighty percent had taught for over six years and, of those, $60 \%$ had more than 11 years of teaching experience. Even when looking at the seven teachers who had used an IWB from 0-24 months, six had taught for over 11 years. The change in teacher pedagogy may have been due to their teaching experience, which provided them with increasing curriculum knowledge and stages of student learning. This appeared to prescribe how the teachers used the IWB more to support their students' specific learning 
needs and facilitate collaborative learning with them. It seems, then, that the more experienced teachers are the sooner they will change their pedagogy. This suggests that teaching experience may be a critical factor when selecting which teachers should an IWB installed in their room.

\section{Level of computer skills}

All three case study teachers were computer literate, and obviously knew how to download photos, save files, link to the internet, and send e-mails. According to Beauchamp (2004), the more skilled people are in using computers the faster they will learn to use the tools of an IWB and move through the stages of IWB use. Some survey respondents also mentioned it would be difficult to use an IWB if you were not computer literate. Betcher and Lee (2009) suggest "the more intimately you know your software, the more confident, competent and creative you will feel about the whole IWB experience. This leads to more interesting lessons and a general feeling that the IWB is truly a tool for better learning and teaching" (p. 65). Liz and Wendy, two of the case study teachers, certainly reflected the creativity that comes with knowing how to use the software on the IWB.

\subsection{What contextual factors constrain the introduction of an IWB for a teacher learning to use it in their class programme?}

Several problems concerning professional development and IWB use were identified in the study. These were: training to use the IWB, the professional development available, learning to use the software and tools of the IWB, and the time that this takes, and, finally, technical difficulties. These are discussed below.

\section{Training}

The timing, intensity and type of training experienced were problematic for teachers learning to use an IWB. Many teachers (82\%) had to undergo training in their own time, either in their lunch hour or after school. Furthermore, the predominant intensity of the training, one per term was not 
regular enough and it did not allow for the needs and stage of each teacher. The biggest problem seemed to be the type of training provided; 'just in case,' whereby a group of people were put together for a training session, regardless of their present skills, and shown how to use the software, just in case they may need it one day.

Teacher survey respondents also indicated that too much was provided in one session and, consequently, much of it was forgotten, or not used. This type of training was part of a set purchase package of four sessions, one per term over a year, and is an example of how the time spent in professional development is not always successful. Timperley et al. (2007) found "successful use of time was measured by the extent to which the activities in which teachers engaged during that time deepened their understanding and extended their skills" (p.194). Whilst some training is needed to learn to use the tools of the IWB, there also needs to be professional development that focuses on integrating the use of the IWB into classroom programmes. As Mishra and Koehler (2006) argue "merely knowing how to use technology is not the same as knowing how to teach with it" (p.1033). This may explain why thirty-five percent of survey respondents stated that colleagues provided the most useful form of training. They showed how to use the tools of the IWB and whilst doing so provided examples of how to teach with these. In this manner colleagues were further developing their knowledge of pedagogy with an IWB.

\section{Professional development available}

The predominant form of professional development experienced by $70 \%$ of respondents was collaboration with a colleague. The most valued forms however, were an external expert visiting and demonstrating in the respondents' class and then visits to other classes/schools.

In addition, the professional development preferences show that teachers are enthusiastic about learning how to integrate the use of an IWB into their teaching pedagogy, rather than just learning about the technical aspects. For 
this reason they "need extended opportunities to think through new ideas and to try out new practices, ideally in a context where they get feedback from a more expert practitioner and continue to refine their practice in collaboration with colleagues" (Warwick \& Kershner 2008, p.281). Sustained professional development to continue their learning is essential. Providing professional development that does not cater for this is a constraining factor on how teachers learn to use an IWB.

\section{Learning to use the software and time to do this}

Learning to use the software of the IWB was a factor cited by $36 \%$ of the survey respondents as a constraint on how they one. Survey respondents specifically mentioned learning to use the IWB interactively all the time, keeping up with software changes and learning to integrate other digital technologies such as digital cameras, microscopes, video/DVD as further challenges. Kathy, one of the case study teachers, explained that because she did not have enough time to get to know the tools of the IWB she felt it hindered her use of the IWB. She could not use it as quickly and easily as she wanted to.

\section{Technical difficulties}

Thirty-three percent of survey respondents indicated that they experienced technical difficulties when using an IWB, such as power cuts, faulty equipment and internet connection problems. The situation of a computer suddenly not working or having no internet connection obviously impacted on teachers' use of the IWB. This resulted in not being able to access preplanned lessons, work from a previous day or a particular website or game that was planned for use in a lesson. Some respondents mentioned the need for a 'back up' plan for when such technical difficulties occurred.

\subsection{How is an IWB used in a New Zealand classroom programme?}

In order to answer this question, different aspects of the classroom programme were explored in terms of how the IWB was used. These were 
the curriculum areas it was used in, the teacher pedagogy, and the nature of the interaction between teachers, students and the IWB and, finally, how planning and preparation for using the IWB impacted on teachers' use of the IWB. An explanation of these factors follows.

\section{Curriculum areas for IWB use}

Most survey respondents and all three case study teachers used the IWB mostly in the curriculum areas of Numeracy $(77 \%)$ and Literacy $(80 \%)$. This was predominately because these two subjects are the focus of learning for many schools. This is in line with The New Zealand Ministry of Education citing Numeracy and Literacy as being the required focus for Years 1-4 in National Administration Guidelines (NAGs). Furthermore, respondents talked about the number of on line resources readily available in these two subjects specifically for use on an IWB.

\section{Teacher pedagogy}

Many survey respondents (66\%) used the IWB for whole class work and group work and this was also observed during the three classroom visits. Forty percent of respondents cited the reason they liked using an IWB was because it was highly motivating and engaging for their students. Twenty-five percent of respondents commented on how the IWB facilitated discussion in both whole class teaching and group teaching situations, and co-operative learning among students. In each of my classroom observations there were many examples of how the children were working and collaborating together to solve a problem on the IWB. Sometimes the problems were of a technical nature and the more highly skilled student would scaffold their less skilled peer. The IWB became a new medium for collaboration among the students. In addition, teachers felt they had changed the way they taught and had become more of a facilitator of learning since using the IWB. Many felt this was due to the multi-media availability on the IWB $(48 \%$ commented on how beneficial this was). This feature of the IWB enabled teachers to diversify the resources they used in their lessons and discussions, and instantly bring the

global world into their classroom. This instant access to the 'world at your 
fingertips' provided for spontaneous teaching moments in a way that could not be done without an IWB and was clearly a feature used by many respondents.

\section{Lesson planning and preparation for IWB lessons}

Twenty-five percent of survey respondents mentioned how efficient planning and preparation was for lessons on the IWB. They found that being able to do all of this on a laptop which is transferred to the IWB or simply plugged into it decreased the amount of time spent on such tasks. One of the case study teachers, Liz, felt that being able to plan her IWB lessons at home on her laptop had made a huge difference to her planning. It was far quicker and convenient being able to plan and prepare her daily programme in this way. This efficiency in planning and preparation was considered by many respondents to be a factor that enhanced their use of an IWB.

\section{Summary of findings}

To briefly summarise the findings of my study, the most common form of professional development experienced by the teacher respondents was four group training sessions from the IWB supplier. The most valued professional development was an external expert demonstrating in a classroom and then visits to other schools and colleagues. Sustained professional development was a clearly identified need by many teacher respondents and had the most impact on how teachers used an IWB.

Five factors were found to enhance the introduction of an IWB in a New Zealand classroom and four reflect the features of effective professional development from the literature reviewed in chapter two. These are: time to learn to use the tools on the IWB, on-going and sustained professional development in using an IWB, external experts or mentors visiting a teacher's class to demonstrate using the IWB and lastly being competent with computer skills before learning to use an IWB. The fifth factor was years of teaching experience. 
The factors that were considered to be constraining were 'just in case' training sessions that focused on learning about the tools of the IWB without any connection to a classroom programme, unsustained professional development, the time it took to learn to use the software of an IWB and finally technical difficulties.

\subsection{Recommendations}

Based on the findings of my study I make the following recommendations which are a school implementation plan for IWBs, the type of training given, sustained professional development and a professional community of IWB users, criteria for teacher selection to have an IWB, and pre-teacher training. These are discussed below.

\section{Implementation plan}

It appears that schools do not budget for professional development for IWBs beyond its introduction. Although it may be tempting for schools to purchase the 'cheapest option' it is critical that schools look at the total package being offered. The commonly used tools and features of an IWB are becoming increasingly standardised across all brands (Betcher \& Mal, 2009). The point of difference, then, is the support that is offered with an IWB. Ask the supplier: what type of technical back-up, training, professional development and on-going support is offered and if these factors are not included in the purchase price, how much do they cost? One way to potentially increase the value of an IWB purchase package may be to create a cluster of schools interested in purchasing IWBs to gain 'buying power', as one cluster of schools reported they did in the teacher survey.

It appears that many schools do not realise the continued need for professional development by teachers after putting IWBs into classrooms and as one supplier recently stated, "a core challenge is the lack of buy-in from senior management on the time and support required," (Rolleston as cited in Suckling, 2010, p.20). Schools therefore, need to ensure that there is an 
implementation plan for IWB use in a school that includes budgeting for ongoing and sustained professional development for teachers. This plan would be part of a school's strategic plan focusing on improving student learning outcomes. How IWBs as a teaching tool might support these outcomes needs to be included.

\section{Training to use an IWB}

Respondents found group training sessions to be overwhelming with so much information that a lot of it was often forgotten. It seems that providers need to be more flexible in their planning of professional development so that they are not providing 'just in case' training for groups of people that cannot possibly target individual needs. There needs to be more flexibility in the type and timing of their training sessions for teachers learning to use an IWB. For example, four sessions in two terms may be more useful to IWB users then four sessions spread over four terms. For the suppliers to offer such flexibility may be uneconomical for them but I recommend that with the marketplace becoming more competitive, schools had to become proactive in selecting the IWB provider. Schools need to specify exactly the type of training that is going to suit them best of all. 'Just in time' training is the most effective along with professional development that "focuses on curriculum as the central component, not technology" (Betcher \& Lee, 2009, p.146). For this reason, schools should request that their trainers be primary teachers with teaching experience and knowledge of the curriculum. Terrini (2009) also made this point in relation to professional development for early childhood teachers who were IWB users.

\section{A professional community of IWB users and sustained professional development}

The teachers in this study obviously valued professional development that focused on the teaching and learning rather than just technical aspects. Teachers, too, were enthusiastic about learning how to integrate the use of an IWB into their teaching pedagogy. The second most preference of professional development was visits to other classes/schools. To 
accommodate this form of professional development I recommend the creation of a professional community of IWB users that includes as many schools as possible, in each city or region (as the Ministry of Education does not keep a register of IWB users through the country, I envisage that regional registers could be set up through the principals' association). Within a professional community teachers could then visit other schools to observe teachers integrating the IWB in to their teaching pedagogy and meet on a regular basis to share how they are using one in their classroom programmes. This would lead to a process of knowledge building where teachers interact together and build on and from each others' knowledge (Warwick \& Kershner, 2008). Participating in a professional community of IWB users would be one way to sustain professional development that is affordable to all schools, which at present appears to be a challenge for schools. An alternative way to provide sustained professional development would be for schools in the same area or region to pool resources to fund a mentor teacher, as schools in Hastings have done.

\section{Criteria for selecting teachers to have an IWB}

It appears that teaching experience may be a critical factor in the way teachers use an IWB. The more knowledge teachers have of the curriculum and how children learn may impact on how they use an IWB to meet the needs of their students. Consequently, I recommend that schools consider years of teaching experience as one criterion for selecting who should be given an IWB in their classroom. Another criterion would appear to be computer literacy which is being able to use a computer and its software competently. In agreement with Beauchamp (2004), when one is learning to use an IWB being computer literate is a factor that will determine how fast teachers move through the stages of IWB use. In my study, survey respondents felt that being computer literate was a pre-requisite to having an IWB in the classroom. 


\section{Pre-teacher training}

Finally, with the increase of IWBs in New Zealand schools it would seem appropriate that all teacher training organisations provide IWB for student teachers. This should be part of their core studies.

\subsection{Limitations of this study}

It is important to recognise that my study was small: a national survey carried out with 65 respondents and only three case studies of one day observations at the same class level. Unfortunately, the Auckland area was under represented with only one school participating in the survey. Therefore, the study results cannot be generalised to schools in New Zealand and can make no claims to being typical in the use of an IWB in New Zealand Y1/2 classrooms. Further, as the focus was on Year 1/2 classes, I cannot generalise the use of an IWB to older levels who undoubtedly use it differently according to their skill level, both academically and technically. The findings about the professional development undertaken and its impact on IWB in New Zealand classrooms cannot therefore be generalised (Yin, 2003).

\subsection{Future research}

The use of IWB is becoming more widespread in primary schools and whilst this study provided some insights into the available professional development at the time, there are areas that require future research. However, prior to any future research in New Zealand, the formation of a national register of IWB users by the Ministry of Education would be very useful. Researchers would not have to rely on one or two agencies that may or may not respond, to know which schools have an IWB.

My findings point to the need to develop a sustained professional development programme for IWB use in a classroom. This should be based on the best evidence synthesis of professional development (Timperley et al., 2007). A professional community of IWB users that includes an advisor and 
mentoring could be set up and through a case study the effects of sustained professional development within such a community could be carried out.

A longitudinal study that compares years of teaching experience with IWB experience will help to identify if it is indeed a critical factor in changing pedagogy.

A fourth area for future research relates to collaborative learning by students. Although this was not the focus of my study, the observations have shown that students using an IWB do work together in a collaborative manner. Student collaboration embodies the five key competencies identified in the NZC which are "thinking, using language, symbols and texts, managing self, relating to others and participating and contributing...and are the key to learning in every learning area" (Ministry of Education, 2007, p.12). It is, therefore, timely that a research project explores exactly how the use of an IWB further encourages and establishes collaborative learning among students.

To conclude, the findings of this study point to the need for effective on-going professional development and describe its features for teachers learning to use an IWB. It should, however, be remembered that an IWB is just another tool in the classroom. Teacher pedagogy with an IWB is the critical factor that determines its use: in the hands of a teacher with sound pedagogical practices and sustained effective professional development, it appears to be an exciting tool with potential for new ways of teaching and learning. 


\section{References}

Beauchamp, G. (2004). Teacher use of the interactive whiteboard in primary schools: towards an effective transition framework. Technology, Pedagogy and Education, 13(3), 327-348.

Bell, J. (2005). Doing your research project ( $4^{\text {th }}$ ed.). Berkshire: Open University Press.

Bennett, S., \& Lockyer, L. (2008). A study of teachers' integration of interactive whiteboards into four Australian primary school classrooms. Learning, Media \& Technology, 33(4), 289300.

Berg, B. (2004). Qualitative research methods for the social sciences $\left(5^{\text {th }}\right.$ ed.). Boston: Allyn and Bacon.

Betcher, C., \& Lee, M. (2009). The interactive whiteboard revolution: Teaching with IWBs. Victoria: ACER Press.

Bowman, D., \& Tait, C. (2005). Young children's on-task behaviour with interactive whiteboards. Computers in New Zealand Schools, 17(3), 39-42.

British Educational Communications and Technology Agency. (2005). What research says about interactive whiteboards. Retrieved 21 July, 2007, from www.becta.org.uk/research

Burton, D. (Ed.). (2000). Research training for social scientists. London: Sage.

Clarke, D., \& Hollingsworth, H. (2002). Elaborating a model of teacher professional growth. Teaching and Teacher Education, 18, 947-967.

Cowie, B., Jones, A., \& Harlow, A. (2008). TELA: Laptops for teachers evaluation final report Years $7 \& 8$. Wellington: Ministry of Education.

Denscombe, M. (2007). The good research guide. ( $3^{\text {rd }}$ ed.). Berkshire: Open University Press.

Denzin, N., \& Lincoln, Y. (Eds.). (2008). Introduction: The discipline and practice of qualitative research. In N.Denzin, \& Y. Lincoln (Eds.), The landscape of qualitative research ( $3^{\text {rd }}$ ed.) (pp.1-43). California: Sage. 
Desimone, L. (2009). Improving Impact studies of teachers' professional development: Towards better conceptualizations and measures. Educational Researcher, 38(3), 181-199.

Education Review Office, (2009). Managing professional learning and development in primary schools. Ministry of Education: Wellington.

Eun, B. (2008). Making connections: Grounding professional development in the developmental theories of Vygotsky. The Teacher Educator, 43(2), 134-155.

Fullan, M. (2007). The new meaning of educational change $\left(3^{\text {rd }}\right.$ ed). New York: Teachers College Press.

Garet, M., Porter, A., Desimone, L., Birman, B., \& Yoon, K. (2001). What makes professional development effective? Results from a national sample of teachers. American Educational Research Journal, 38(4), 915-945.

Gillen, J., Staarman, J., Littleton, K., Mercer, N., \& Twiner, A. (2007). A learning revolution? Investigating pedagogic practice around interactive whiteboards in British primary classrooms. Learning, Media \& Technology, 32(3), 243-256.

Glover, D., \& Miller, D. (2003). Players in the management of change: Introducing interactive whiteboards into schools. Management in Education, 17(1), 20-23.

Guskey, T. (2000). Evaluating professional development. California: Corwin.

Guskey, T. (2002). Professional development and teacher change. Teachers and teaching: Theory and practice, 8(3/4), 381-391.

Haldane, M. (2007). Interactivity and the digital whiteboard: Weaving the fabric of learning. Learning, Media \& Technology, 32(3), 257-270.

Hawley, W., \& Valli, L. (2007). Design principles for learner-centered professional development. In W.Hawley \& D.Rollie (Eds.), The keys to effective schools: Educational reform as continuous improvement $\left(2^{\text {nd }}\right.$ ed.), (p.117-137). California: Corwin Press. 
Higgins, S., Falzon, C., Hall, I., Moseley, D., Smith, H., \& Wall, K. (2005). Embedding ICT in the literacy and numeracy strategies: final report. Newcastle: University of Newcastle. Retrieved 19 July, 2007, from http://partners.becta.org.uk/page documents/research/univ newcastle evaluation whiteboards.pdf

Higgins, S., Beauchamp, G., \& Miller, D. (2007). Reviewing the literature on interactive whiteboards. Learning, Media \& Technology, 32(3), 213225.

Hixon, E., \& Buckenmeyer, J. (2009). Revisiting technology integration in schools: Implications for professional development. Computers in the Schools, 26(2), 130-146.

Hooper, S., \& Rieber, L. (1995). Teaching with technology. In A. C. Ornstein (Ed.), Teaching: Theory into practice (pp. 154-170). MA: Allyn and Bacon. Retrieved 5 September 2008, from http://www.nowhereroad.com

Keller, J., Bonk, C., \& Hew, K. (2005). The tickit to teacher learning: Designing professional development according to situative principles. Journal of Educational Computing Research, 32(4), 329-340.

Kennedy, H., \& Anderson, J. (2005). Interactive whiteboards and student motivation in oral literacies. Computers in New Zealand Schools, 17(3), 36-38.

Kennedy, M. (1998). Form and substance in inservice teacher education. Research Monograph No.13. National Institute for Science Education, University of Wisconsin-Madison.

Kennewell, S., \& Beauchamp, G., The features of interactive whiteboards and their influence on learning. Learning, Media \& Technology, 32(3), 227-241.

Kennewell, S. (2006). Reflections on the interactive whiteboard phenomenon: A synthesis of research from the UK. Retrieved 26 July, 2007, from http://www.aare.edu.au/06pap/ken06138.pdf 
Knight, P., Pennant, J., \& Piggott, J. (2004). What does it mean to use the interactive whiteboard in the daily mathematics lesson? Micromath, 20(2), 14-16.

Loucks-Horsley, S., Hawson, P., Love, N., \& Stiles, K. (1998). Designing professional development for teachers of science and mathematics. Thousand Oaks, CA: Corwin Press.

McDowell, A., \& Murray, M. (2005). Interactive whiteboard technology and its role in peer tutoring, using written and visual language. Computers in New Zealand Schools, 17(3), 25-27.

Marzano, R., \& Haystead, M.,(2009). Evaluation study of the effects of promethean ACtivclassroom on student achievement. Marzano Research Laboratory. Retrieved 3 April, 2010, from

http://www.prometheanworld.com/upload/pdf/Final Report on ActivCl assroom \%282\%29.pdf

Merriam, S. (1998). Qualitative research and case study applications in education. ( $2^{\text {nd }}$ ed.) California: Jossey-Bass.

Miller, D., \& Glover, D. (2007). Into the unknown:The professional development induction experience of secondary teachers using interactive whiteboard technology. Learning, Media \& Technology, 32(3), 319-331.

Ministry of Education (N.Z.). (2006). Enabling the 21st century learner. Wellington: Learning Media.

Ministry of Education (N.Z.). (2007). The New Zealand curriculum. Wellington: Learning Media.

Ministry of Education (N.Z.). (2008). What are deciles. Retrieved 28 September, 2009, from

http://www.minedu.govt.nz/NZEducation/EducationPolicies/Schools/Sc hoolOperations//OperationalFunding/Deciles/FrequentlyAskedQuestio nsAboutDeciles/What are deciles.aspx

Ministry of Education,(NZ.) (2009) The National Administration Guidelines (NAGS) Retrieved 1 October, 2009, from 
http://www.minedu.govt.nz/NZEducation/EducationPolicies/Schools/P olicyAndStrategy/PlanningReportingRelevantLegislationNEGSAndNA GS/TheNationalAdministrationGuidelinesNAGs.aspx

Mishra, P., \& Koehler, M., (2006). Technological pedagogical content knowledge: A framework for teacher knowledge. Teachers College Record, 108 (6), 1017-1054.

Mouza, C. (2009). Does research-based professional development make a difference? A longitudinal investigation of teacher learning in technology integration. Teachers College Record, 111(5), 1195-1241.

Mouza, C. (2006). Linking professional development to teacher learning and practice: A multi-case study analysis of urban teachers. Journal of Educational Computing Research, 34(4), 405-440.

Patton, M. (2002). Qualitative research and evaluation methods. ( $3^{\text {rd }}$ ed.).California: Sage.

Penuel, W., Fishman, B., Yamagauchi, R., \& Gallagher, L. (2007) What makes professional development effective? Strategies that foster curriculum implementation. American Educational Research Journal, 44(4), 921-958.

Ruane, J. (2005). Essentials of research methods: A guide to social science research. Maldane: Blackwell.

Ryan, B., \& Cowie, B., (2009). Exploring the use of an interactive whiteboard in a primary science classroom. Set, (1), 43-48.

Schuck, S., \& Kearney, M. (2007). Exploring pedagogy with interactive whiteboards. Sydney: University of Technology. Retrieved 21 July 2007 from

www.eddev.uts.edu.au/teachered/research/iwbproject/pdfs/iwbreportw eb.pdf

Smith, A. (1998). Understanding children's development. A New Zealand perspective. $\left(4^{\text {th }}\right.$ ed.) Wellington: Bridget Williams. 
Smith, F., Hardman, F., \& Higgins, S. (2006). The impact of interactive whiteboards on teacher-pupil interaction in the national literacy and numeracy strategies. British Educational Research, 32(3), 443-457.

Smith, H., Higgins, S., Wall, K., \& Miller, J. (2005). Interactive whiteboards: Boon or bandwagon? A critical review of the literature. Journal of Computer Assisted Learning, 21, 91-101.

Somekh, B., Haldane, M., Jones, K., Lewin, C., Steadman, S., Scrimshaw,P., Sing, S., Bird,K., Cummings, J., Downing, B., Stuart, T., Jarvis, J., Mavers, D., \& Woodrow, D. (2007). Evaluation of the primary schools whiteboard expansion project. University of Manchester: BECTA.

Stake, R. (2005). Qualitative case studies. In N.Denzin \& Y. Lincoln, (Eds.) The handbook of qualitative research. ( $3^{\text {rd }}$ ed.) (pp.463-464). California: Sage.

Suckling, L., (2010, May). Drawing on technology for new and improved teaching. Interface 23, 19-22.

Sweeney, T. (2008). Transforming learning with interactive whiteboards: Towards a developmental framework. Australian Educational Computing, 23(2) 24-31.

Terrini, L. (2009). A case study: How young children and teachers use an interactive whiteboard in a New Zealand kindergarten setting for visual art learning experiences. (Master's Thesis, Victoria University of Wellington, Wellington.)

Tharp, R., \& Gallimore, R. (1988). Rousing minds to life: Teaching, learning, and schooling in social context. Cambridge, England: Cambridge University Press.

Timperley, H., Wilson, A., Barrar, H., \& Fung, I. (2007). Teacher professional learning and development: Best evidence synthesis iteration (BES). Wellington: Ministry of Education.

Vygotsky, L. (1978). Mind in society: The development of higher psychological processes. Massachusetts: Harvard University Press. 
Warwick, P., \& Kershner, R. (2008). Primary teachers' understanding of the interactive whiteboards as a tool for children's collaborative learning and knowledge-building. Learning, Media \& Technology, 33(4), 269287.

Wayne, A., Yoon, K., Zhu, P., Cronen, S., \& Garet, M. (2008). Experimenting with teacher professional development: Motives and methods. Educational Researcher, 37(8), 469-479.

Wink, J., \& Putney, L. (2002). A vision of Vygotsky. Boston: Allyn \& Bacon.

Wood, R., \& Ashfield, J. (2008) The use of the interactive whiteboard for creative teaching and learning in literacy and mathematics: A case study. British Journal of Educational Technology, 39(1), 84-96.

Woods, B., Stevens, L., Mes, F., \& Reid, S. (2005). Investing in IWBs: A tool for collaborative inquiry. Computers in New Zealand Schools, 17(3), $51-54$.

Yin, R. (2003). Case study research: Design and methods ( $3^{\text {rd }}$ ed.). California: Sage. 


\section{APPENDICES}

\section{APPENDIX A:}

TE WHARE WĀNANGA O TE ŪPOKO O TE IKA A MĀUI

59

COLLEGE OF EDUCATION

\section{Research Project: How does professional development impact on teachers' use of an interactive whiteboard in New Zealand primary classrooms?}

\section{INFORMATION SHEET FOR PRINCIPALS AND BOARD OF TRUSTEES}

My name is Robyn Grover and I am a M.Ed student at Victoria of University of Wellington College of Education. This is my final year and I am conducting research on how professional development impacts on teachers' use of an interactive whiteboard (IWB) in New Zealand primary schools. I am writing to request your consent for teachers at your school to participate in this research.

I am a primary teacher currently on study leave. Personal experience of using an IWB in my Year One classroom programme two years ago has motivated this study. IWBs are relatively new to New Zealand education and to date there has been little research on IWB use in our schools. The purpose of this research is to find out how professional development impacts on the way teachers use an IWB in a New Zealand classroom. The research is supervised by Dr Mary Jane Shuker 04463 9659, MaryJane.Shuker@vuw.ac.nz.

There will be two phases to this research. The first phase involves a survey in the form of a national postal questionnaire to principals of primary schools with an IWB and their teachers currently using an IWB in their classroom. Information on which schools have IWBs has come from ICT advisors throughout New Zealand and Core.net in Christchurch who are responsible 
for the ICT PD clusters. The names of the principals and teachers have not been supplied. I anticipate that the survey will take 10 to 15 minutes to fill in. In order to gain a broad picture of the impact professional development has on teacher use of an IWB in New Zealand classrooms it will be important to get a good response rate to this survey. All information provided will be treated as confidential and names of individuals and schools will not be used in reporting responses.

Phase two will involve 3 in depth case studies of teachers using an IWB. Three teachers, from different schools, will be selected from the responses of the survey. The case study will involve

1. Each teacher keeping a log in the form of a checklist of the curriculum areas the IWB is used in over a two week period.

2. Document analysis of teacher's timetable, school ICT policy and school professional development policy.

3. Observation of the teacher using the IWB over two consecutive days.

4. An interview with the teacher at the end of the observation.

It is envisaged that I will spend two days in each of the three schools selected for data collection for phase two. All data gathered for this research will be confidential and neither the school, teacher or Principal will be identified in the research report. Access to the data will be restricted to the supervisors and myself. All research data will be securely stored for two years and then destroyed. The teachers participating in the case study will have the right to check the transcript of the interview to ensure what they said has been correctly written down. Participants will be given the opportunity to request a summary of the research findings.

Victoria University of Wellington College of Education Human Ethics policy requires approval to be sought from all participants before the research is carried out.

What do I need from you?

- Your permission to send a survey to teachers at your school who have an IWB in their classroom. 
If a teacher at your school is selected to participate in a case study, I will need

- Permission from the Board of Trustees and yourself for a teacher at your school to participate in a case study.

- Permission to take a copy of the teacher's classroom timetable.

- A copy of the school's ICT policy and professional development policy.

- To act as liaison between the chairperson of the BOT, staff and myself.

AS THE PRINCIPAL, YOU HAVE THE RIGHT:

a. To decline to participate in the research;

b. To withdraw your school from this research at anytime;

c. To ask any questions about the study at any time during the participation;

d. To know that the names of your school and the teacher participant will not be used;

e. To be given access to a summary of the findings when the research is completed.

If you have any questions concerning this Information Sheet or the research project, please feel free to contact myself or my supervisor for further information.

Yours sincerely

Robyn Grover

(04 476 9340)

rigrover@xtra.co.nz 


\section{APPENDIX B:}

TE WHARE WÁNANGa O TE ŪPOKO O TE IKA A MĀUI

Research Project. How does professional development impact on teachers' use of an interactive whiteboard in New Zealand primary classrooms?

\section{INFORMATION SHEET FOR PRIMARY SCHOOL TEACHERS}

My name is Robyn Grover and I am a M.Ed student at Victoria of University of Wellington College of Education. This is my final year and I am conducting research on how professional development impacts on teachers' use of an interactive whiteboard (IWB) in New Zealand primary schools. I am writing to request your consent for to participate in this research.

Personal experience of using an IWB in my Year One classroom programme two years ago has motivated this study. IWBs are relatively new to New Zealand education and to date there has been little research on IWB use in our schools. The purpose of this research is to find out how professional development impacts on the way teachers use an IWB in a New Zealand classroom. The research is supervised by Dr Mary Jane Shuker 04463 9659, Mary-Jane.Shuker@vuw.ac.nz

There will be two phases to this research. The first phase involves a survey in the form of a national postal questionnaire to principals of primary schools with an IWB and their teachers currently using an IWB in their classroom. Information on which schools have IWBs has come from ICT advisors throughout New Zealand and Core.net in Christchurch who are responsible for the ICT PD clusters. The names of the principals and teachers have not been supplied. I anticipate that the survey will take 10 to 15 minutes to fill in. In order to gain a broad picture of the impact professional development has 
on teacher use of an IWB in New Zealand classrooms it will be important to get a good response rate to this survey. All information provided will be treated as confidential and names of individuals and schools will not be used in reporting responses.

Phase two will involve 3 in depth case studies of teachers using an IWB. At the end of the questionnaire, teachers will asked if they are interested in being a participant in a case study. Of those interested, three teachers, from different schools, will be selected for a case study. There is an information sheet attached outlining what would be involved in a case study.

If you have any questions concerning this Information Sheet or the research project, please feel free to contact myself or my supervisor for further information.

Yours sincerely

Robyn Grover

(04 476 9340)

rigrover@xtra.co.nz 


\section{APPENDIX C:}

TE WHARE WĀNANGA O TE ŪPOKO O TE IKA A MĀUI

Research Project. How does professional development impact on teachers' use of an interactive whiteboard in New Zealand primary classrooms?

\section{INFORMATION SHEET FOR CASE STUDY PARTICIPANTS}

Three teachers, from different schools, will be selected from the responses of the survey. The case study will involve

5. Each teacher keeping a log in the form of a simple checklist, of the curriculum areas the IWB is used in over a one week period.

6. Document analysis of teacher's timetable, school ICT policy and school professional development policy.

7. Observation of the teacher using the IWB over one to two days.

8. An interview with the teacher at the end of the observation.

It is envisaged that I will spend one to two days in each of the three schools selected for data collection for phase two. All data gathered for this research will be confidential and neither the school, teacher or Principal will be identified in the research report. Access to the data will be restricted to the supervisors and myself. All research data will be securely stored for two years and then destroyed. Participants will be given the opportunity to request a summary of the research findings.

Victoria University of Wellington College of Education Human Ethics policy requires approval to be sought from all participants before the research is carried out.

What do I need from you?

- Your permission, if selected, to participate in a case study.

If selected to participate in a case study I will need:

- A copy of your classroom timetable. 
- You to keep a log in the form of a checklist of the curriculum areas the IWB is used in over a two week period.

- To be informed of any changes which may take place during the scheduled observation times.

- You to give out to all parents an information sheet about the case study and a parental and student consent form. These forms will be provided by me.

- Your permission to observe and interview you with regards to how you use the IWB in your classroom.

- Your permission to tape record the interview and then transcribe it.

AS A CLASSROOM TEACHER, YOU HAVE THE RIGHT:

f. To decline to participate in the research.

g. To withdraw from this research at anytime.

h. To ask any questions about the study at any time during the participation.

i. To know that your name and your school's will not be used.

j. To check the transcript of the interview.

k. To be given access to a summary of the findings when the research is completed.

If you have any questions concerning this Information Sheet or the research project, please feel free to contact myself or my supervisors for further information.

Yours sincerely

Robyn Grover

(04 476 9340)

rigrover@xtra.co.nz 


\section{APPENDIX D:}

How does professional development impact on teachers' use of an interactive whiteboard in New Zealand classrooms?

\section{A questionnaire for principals}

School:

Principal:

\section{Demographic data}

1. School roll

2. Decile ranking of school:

3. Type of school:

State
Integrated
Independent
Primary
Full primary

City

Urban

Rural

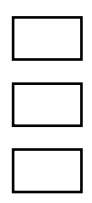

\section{School ICT Policy}

4. Do you have a school developed policy for use of ICT in your school? Yes $\square$ No

a. If so, how was this policy developed? 
b. Describe the process of implementing this policy into the classroom.

If possible please attach a copy of this policy. Please remove school identification to retain confidentiality.

Interactive Whiteboards

5. What were the factors that led you to consider purchasing an IWB?

6. Who was involved in making the decision to purchase an IWB?

7. Were you able to receive impartial, educational advice about IWBS?

Yes $\square \quad$ No

If so, where did you go for this?

8. Were you able to access research material about IWBs to inform you before making a decision? 
9. What criteria did you use to select the teacher/ teachers to have an IWB installed in their classroom?

10.Does the school have a goal for IWB use in the classrooms?

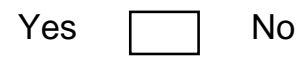

If yes, how is this goal monitored?

\section{Training to use an IWB}

Training is defined here as learning to use the tools of the IWB.

11. Has the school a training programme for teachers to learn how to use an IWB?

$$
\text { Yes } \square \text { No }
$$

If yes, who provided the training?

\begin{tabular}{ll}
\hline & IWB supplier \\
$\square$ & School ICT co-ordinator \\
$\square$ & Colleague/s \\
$\square$ & On-line training \\
$\square \quad$ Conference/audio call \\
$\square \quad$ Outside agency
\end{tabular}

Please state

which

agency: 
12. What factors influenced your choice of training for teachers?

Cost

Availability of trainers

Recommendation

Cluster group choice

Was included in purchase price by IWB supplier

Other factors, please state

\section{Professional Development}

Professional development is defined here as learning how to use the IWB in the curriculum.

13. Do you have a policy for professional development in your school? Yes $\square$ No

b. If so, how was this policy developed?

14. Has the school a professional development programme for teachers to learn to use in IWB in their programme?

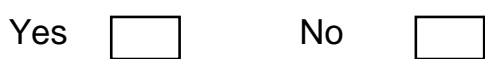

15. What factors influenced the school's choice of professional development for teachers to learn to use an IWB in their programme?

$\square \quad$ Cost

Availability of facilitators

Recommendation

Cluster group choice

Was included in purchase price by IWB supplier 
16. What do you see as being the most valuable form of professional development? Please number in order as 1 being the most valuable.

$\square$ Visits to other classes/schools using an IWB for lesson observations and modelling

Collaboration with a colleague/cluster group

External expert visiting you demonstrating in your class

(Please state, who this expert was eg ICT advisor,)

On-going participation in a professional community

$\square$ Other,

please

state

\section{Evaluation}

17. If you were introducing IWB into your school again, is there anything you would change in relation to

a. The training programme

Yes

No

If yes, please explain

c. The professional development programme Yes

No

If yes, please explain

18. What benefits do you see an IWB in a classroom providing to 
a. Students

b. Teachers

c. School

19. Any further comment about training, professional development and use of an IWB in your school?

Thank you for taking the time to complete this questionnaire.

Please return in self addressed envelope supplied by

6 March 2009 


\section{APPENDIX E:}

How does professional development impact on teachers' use of an interactive whiteboard in New Zealand primary classrooms?

\section{A questionnaire for teachers}

As there are currently so few IWBs in schools I would appreciate your feedback.

\section{Demographic Information}

1. Years of teaching practice

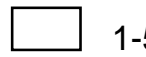

$1-5$

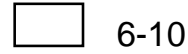

$\square$ 11-15

$16-20$
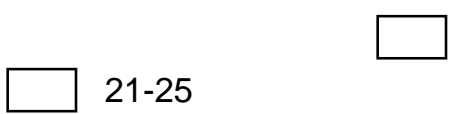

$21-25$

26-30

$>31$

2. Class level currently teaching

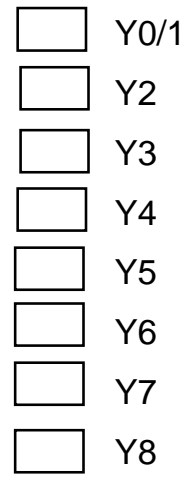

2a.Years teaching at this level

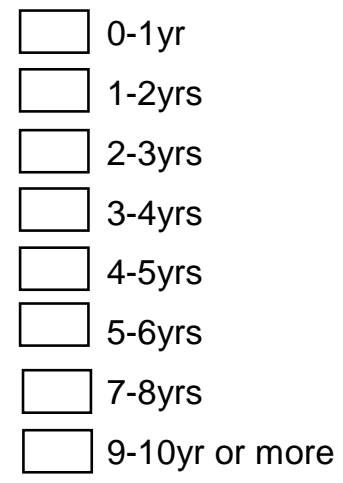

3. How long have you been teaching with an IWB?
$\square$ 0-6 month
7-12months
$13-18 m$ ths
19-24 months
$\square>2$ years

4. Was there an IWB in your classroom when you moved into it? Yes

No 
5. Were you given the choice to have an IWB in your classroom? Yes $\square$ No

6. Was there more than one place the IWB could have been installed in your room?

Yes $\square$ No $\square$

If so, were you consulted as to where you would like it placed? Yes

No

\section{Computer skills}

7. Please tick the approximate level you think you are at in terms of how you use the IWB

\section{$\square$}

black/whiteboard substitute

apprentice user: the teacher is using a wider range of computer skills

initiate user: teachers begin to use the IWB to change and enhance their pedagogy

advanced user: the teacher involves the students in using the IWB and shows a high level of skill in using the software

synergistic user: the teacher and pupils are interacting together using the IWB to achieve

learning objectives.

\section{Training to use the IWB.}

Training is defined here as learning to use the tools of the IWB.

8. Who trained you to use the IWB?

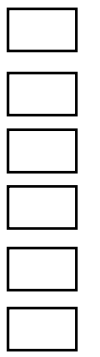

IWB supplier

School ICT co-ordinator

Colleague/s

On-line training

Conference/audio call

Outside

agency.

Please

state

which

agency:

9. When did you begin training to use the IWB?

Before it was installed in my classroom

As soon as it was installed in my classroom

A week to a month after it had been installed in my classroom

A month or more after it had been installed

Did not receive any training

Other time, please state

10. How long was your training? Please tick box and indicate length of each session.

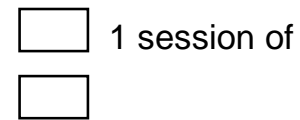


2 sessions of

3 sessions of

$\square 4$ sessions of

1 day

Is on-going

Other, please state

11. Were you released from the classroom for training? Yes

No

12. Was training carried out

During your lunch hour/interval/ after school?

During the school day?

13. What was the most helpful form of training you received?

\section{Technical Help}

14. If you have a technical problem with the IWB is there always technical help available if you need it?

$\square$ Straight away
$\square$ Same day
$\square$ Next day
$\square$ Later in the week
$\square$ Next week
$\square$ Varied
$\square$ Other:

15. If you have had a technical problem how has it impacted on your use of the IWB in your programme? 


\section{Professional Development}

Professional development is defined here as learning how to use the IWB in the curriculum.

16. What type of professional development have you had to help you learn how to use the IWB in your classroom programme?

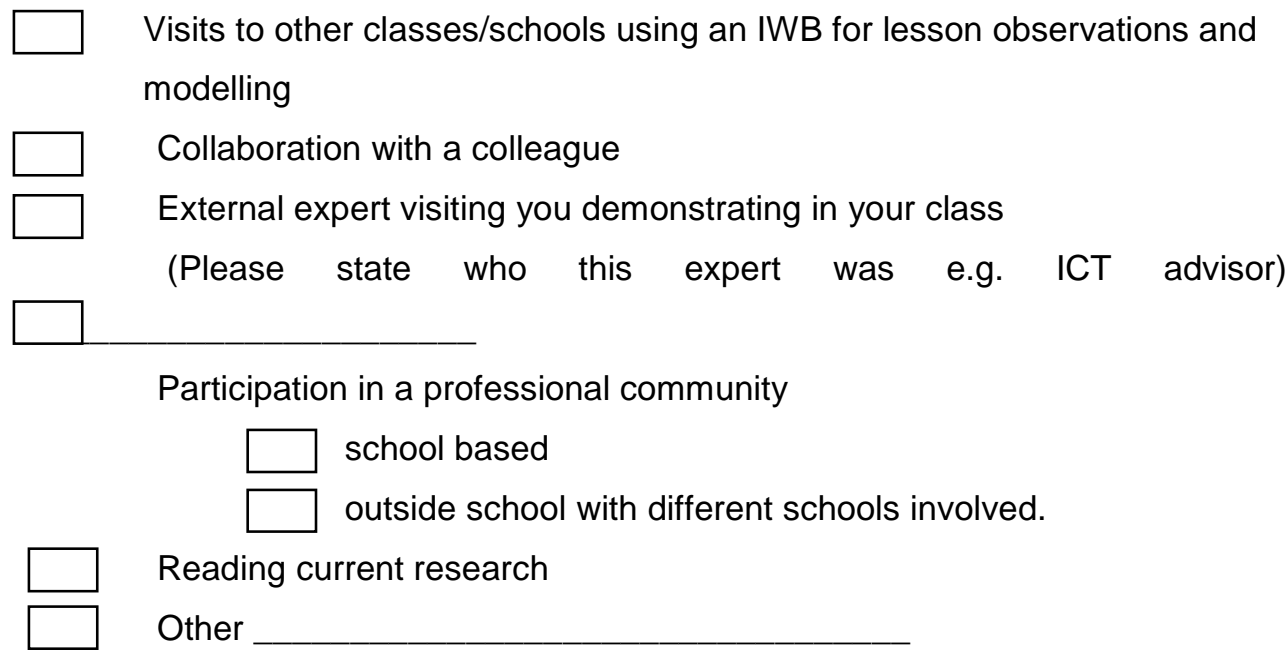

17. What do you see as being the most valuable form of professional development? Please number in order as 1 being the most valuable.

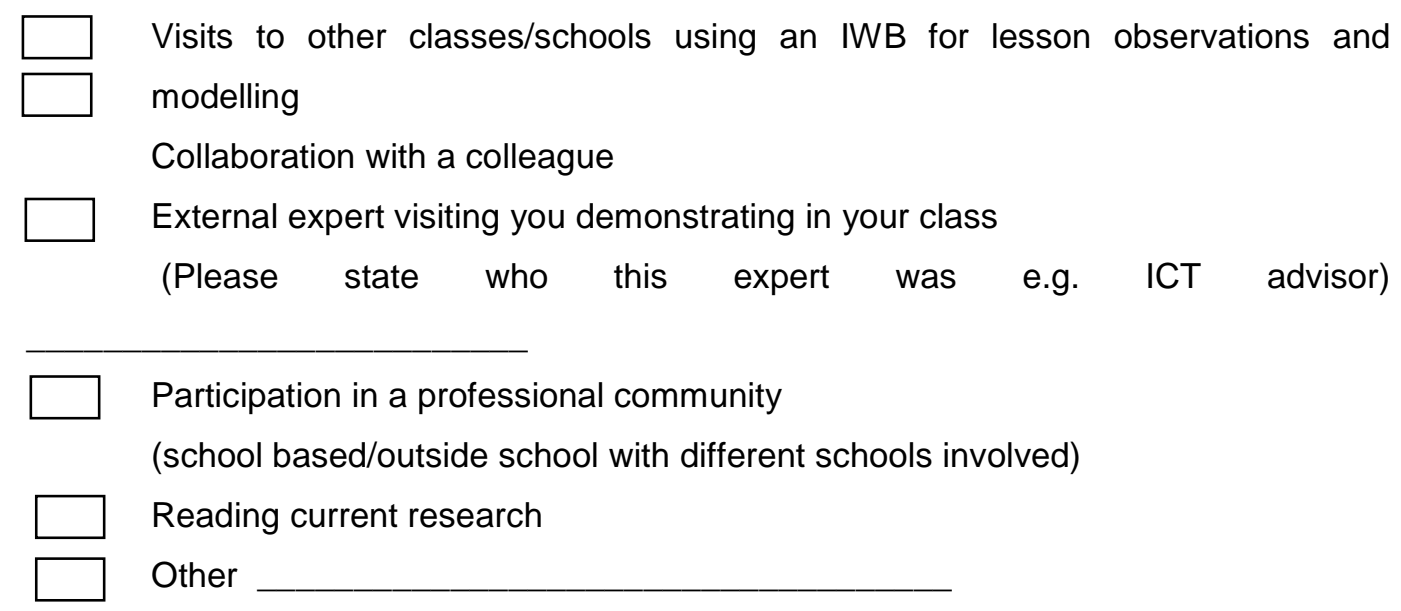

18. Did you have a professional learning goal linked to your use of an IWB? Yes No a. If so, what was the goal? 
b. Was there some form of monitoring to check that the goal was met? Yes $\square$ No $\square$

c. What was the monitoring?

\section{School Culture}

19. Is there an expectation that staff would use the IWB in their teaching?<smiles>O[Nb]1CC2CCC21</smiles>

20. Are staff supportive of IWB use?

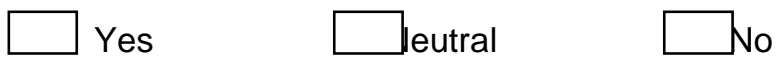

21. Is the principal enthusiastic about the use of IWB in the classes?

Dalways $\square$ Sometimes $\square$ Usually $\quad$ arely

22. Does the principal show a keen interest in how the IWB is being used?

$\square$ Always $\square$ Sometimes $\square$ sually $\square$ arely

23. Are students interested in using the IWB?
Always
Sometimes
$\square$ sually
prely

\section{Curriculum Use}

24. Please tick all the curriculum areas you use the IWB in

\begin{tabular}{l}
$\square$ Current events \\
$\square$ Dance \\
Drama \\
$\square$ Handwriting/printing \\
\hline Health \\
$\square$ Languages \\
$\square$ Music \\
Mathematics \\
\hline Other:
\end{tabular}

\begin{tabular}{l}
$\square$ Physical Education \\
$\square$ Reading \\
\hline Science \\
$\square$ Social Studies \\
$\square$ Te Reo Māori \\
$\square$ Technology \\
$\square$ Visual Arts \\
$\square$ riting
\end{tabular}

25. Which areas of the curriculum would you use the IWB most in? 
26. Why do you think you use the IWB most in these areas?

27. Would you use the IWB predominately in

$\square$ Whole Class work

$\square$ Group work

$\square$ Mixture of both

28. Do the students in your class use the IWB independently of the teacher?

$\square$ Frequently

$\square$ Sometimes

$\square$ Beldom

$\square$ ever

29. What do you like most about using an IWB in your class?

30. What do you think your students like most about using an IWB?

31. What are the benefits of using an IWB in your classroom teaching? 
32. What are the challenges for teachers using an IWB?

33. Has using an IWB changed your teaching at all?

a. If so, in what ways?

34. Any further comment in relation to professional development and learning to use a IWB?

\section{CASE STUDY}

Please indicate if you are interested in being a participant in a case study.

$\square$ I have read the information sheet about the case study.

$\square$ I am interested in being a participant in a case study. 
Name:

Contact e-mail:

Thank you for taking the time to complete this questionnaire.

Please return in self addressed envelope supplied by

6 March 2009 


\section{APPENDIX F:}

TE WHARE WĀNANGA O TE ŪPOKO O TE IKA A MĀUI

Consent Form for Primary School Principals

\section{Research project: How does professional development impact on teachers' use of an interactive whiteboard in New Zealand primary classrooms?}

I have read the information sheet about the research project.

I have had the purpose of the research explained to me.

I understand that participants' responses will be treated as confidential.

I understand that the research data will be securely stored and destroyed two years after the completion of the research.

I give consent for a teacher to be a participant in a case study which will include a classroom observation over one day, followed by an interview.

Name of primary school:

Name of person responding:

Signature:

Date:

Please indicate if you would like to receive a summary of the findings from the research project.

Yes

] No 
If yes, please indicate where it should be sent. If possible please provide an e-mail address, otherwise a postal address to which a hard copy can be sent. 


\section{APPENDIX G:}

TE WHARE WĀNANGa o TE ŪPOKo O TE IKA A MĀUI

Consent Form for Primary School Teachers

Research project: How does professional development impact on teachers' use of an interactive whiteboard in New Zealand primary classrooms?

I have read the information sheet about the research project.

I have had the purpose of the research explained to me.

I understand that my responses will be treated as confidential.

I understand that the research data will be securely stored and destroyed two years after the completion of the research project.

I am willing to be a participant in the case study.

I give my consent to participate in this research under the conditions stated on the information sheet.

Name of primary school:

Name of person responding:

Signature:

Date:

Please indicate if you would like to receive a summary of the findings from the research project.

Yes

$\square$ No 
If yes, please indicate where it should be sent. If possible please provide an e-mail address, otherwise a postal address to which a hard copy can be sent. 
Research Project. How does professional development impact on teachers' use of an interactive whiteboard in New Zealand primary classrooms?

INFORMATION SHEET FOR PARENTS AND STUDENTS IN THE CASE STUDY

My name is Robyn Grover and I am a M.Ed student at Victoria of University of Wellington College of Education. I am conducting research on how professional development impacts on teachers' use of an interactive whiteboard (IWB) in New Zealand primary schools. Personal experience of using an IWB in my Year One classroom programme two years ago has motivated this study. There is no commercial involvement with any IWB suppliers. The research is supervised by Dr Mary Jane Shuker 044639659 , Mary-Jane.Shuker@vuw.ac.nz

On Thursday 2 April 2009 I will be observing how your child's teacher is using the IWB in the usual classroom programme. In the course of this observation there may be occasions when your child will be using the IWB. This would mean I would be observing how they are using the IWB and their use would become part of the data I collect for the research. I am therefore writing to request your permission for your son/daughter to participate in the research. The students will not be missing out on any work in the class programme.

As a participant in this research your son /daughter will have the right to

- Decline to participate 
- Decline to answer any particular question

- Withdraw from the study at any time prior to data analysis

- Ask any questions about the study at any time during participation

- Provide information on the understanding that his/her name will not be used, and

- Be given access to a summary of the project finding when it is concluded.

Would you please discuss this proposed research with your son/daughter, whose consent to participate is needed, fill in the consent slips attached and return to your child's teacher.

I am happy to answer any questions you have about this study and can be contacted by e-mail: rigrover@xtra.co.nz or telephone: 04 476-9340.

Kind regards

Robyn Grover 


\section{APPENDIX I:}

Research Project. How does professional development impact on teachers' use of an interactive whiteboard in New Zealand primary classrooms?

PARENT CONSENT FOR STUDENT TO PARTICIPATE IN RESEARCH

I have read the information sheet regarding this research project and discussed it with my son / daughter.

My son/ daughter is willing to participate in the research.

My son/daughter is not willing to participate in the research.

I give my permission for my son/ daughter to participate in the research.

I do not give my permission for my son/ daughter to participate in the research.

Student's name:

School:

Student's teacher: 
Parent's name:

Parent signature:

Date: 


\section{APPENDIX J:}

TE WHARE WÁNANGa O TE ŪPOKO O TE IKA A MĀUI

Research Project. How does professional development impact on teachers' use of an interactive whiteboard in New Zealand primary classrooms?

\section{STUDENT CONSENT FORM}

I have read the information sheet and have had the details of the research project explained to me. My questions have been answered to my satisfaction and I know that I may ask further questions at any time. I understand that I may withdraw from participating in the research project at any stage before the classroom observation begins.

I am willing to participate in the research.

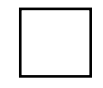

I am not willing to participate in the research.

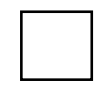

Student's name:

Signature:

School:

Date: 


\section{APPENDIX K:}

TE WHARE WĀNANGA O TE ŪPOKO O TE IKA A MĀUI

Research Project. How does professional development impact on teachers' use of an interactive whiteboard in New Zealand primary classrooms?

Teacher Log for IWB use.

At the end of each day please tick the curriculum areas you have used the IWB in.

Week:

\begin{tabular}{|l|l|l|l|l|l|}
\hline Curriculum area & Monday & Tuesday & Wednesday & Thursday & Friday \\
\hline $\begin{array}{l}\text { Current events } \\
\text { Newsboard }\end{array}$ & & & & & \\
\hline Dance & & & & & \\
\hline Drama & & & & & \\
\hline Handwriting/Printing & & & & & \\
\hline Health & & & & & \\
\hline ICT & & & & & \\
\hline Languages & & & & & \\
\hline Music & & & & & \\
\hline Mathematics & & & & & \\
\hline Physical Education & & & & & \\
\hline Reading & & & & & \\
\hline Religious Education & & & & & \\
\hline Science & & & & & \\
\hline Social Studies & & & & & \\
\hline Te Reo Maori & & & & & \\
\hline Technology & & & & & \\
\hline Visual Art & & & & & \\
\hline Writing & & & & & \\
\hline Other: & & & & & \\
\hline
\end{tabular}




\section{APPENDIX L:}

TE WHARE WĀNANGA O TE ŪPOKO O TE IKA A MĀUI

How does professional development impact on teachers' use of an interactive whiteboard in New Zealand classrooms?

\section{Teacher Interview Schedule}

\section{School:}

Teacher:

1. How long have you had an IWB in your classroom?

2. What do you like most about using an IWB?

3. Could you comment on one or two IWB lessons that you felt were very effective and/or innovative. 
4. Are there any specific resources you use for planning and teaching with the IWB?

5. Overall, what do you think are the main things that help you to use an IWB effectively in your teaching?

b. Is there anything hindering you from using the IWB more effectively? If so, what is it and what support do you need to address this?

\section{The Observed Lesson}

6. Why did you choose to use the IWB for this lesson? 
7. How did you plan for the students to use the IWB in this lesson?

8. What changes would you make, if any, if you gave this lesson again?

9. Are there any particular experiences of using the IWB that you would like to recount?

10. Any comments you would like to add? 